OAK RIDGE

NATIONAL

LABORATORY

\title{
MAPPING FLOW LOCALIZATION PROCESSES IN DEFORMATION OF IRRADIATED REACTOR STRUCTURAL ALLOYS
}

\author{
K. Farrell, T. S. Byun, and N. Hashimoto
}

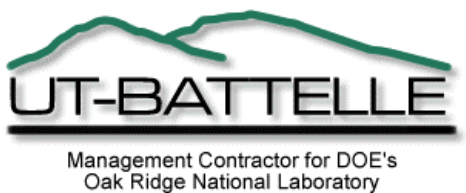




\title{
MAPPING FLOW LOCALIZATION PROCESSES IN DEFORMATION OF IRRADIATED REACTOR STRUCTURAL ALLOYS
}

\author{
NUCLEAR ENERGY RESEARCH INITIATIVE PROGRAM No. MSF99-OO72 \\ TECHNICAL PROGRESS REPORT FOR YEAR 2 OF PROJECT \\ PERIOD: AUGUST 2000 THROUGH SEPTEMBER 2001.
}

K. Farrell, T. S. Byun, and N. Hashimoto

Date Published: July 2002

\author{
Prepared for the \\ U. S. Department of Energy \\ Office of Nuclear Energy, Science and Technology
}

Prepared by the

OAK RIDGE NATIONAL LABORATORY

Oak Ridge, Tennessee 37831

Managed by UT-BATTELLE

For the

U. S. DEPARTMENT OF ENERGY

Under contract DE-AC05-00OR22725 


\section{MAPPING FLOW LOCALIZATION PROCESSES IN DEFORMATION OF IRRADIATED REACTOR STRUCTURAL ALLOYS}

\section{Contents}

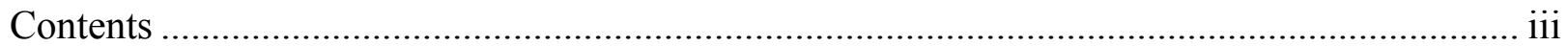

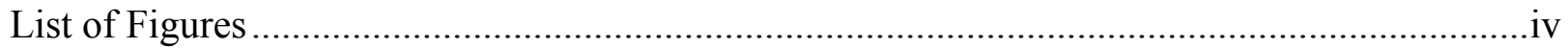

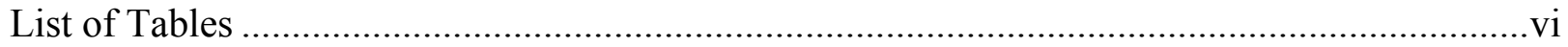

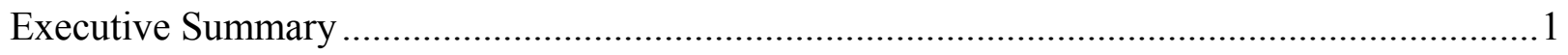

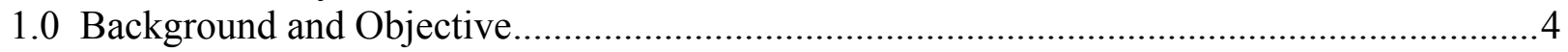

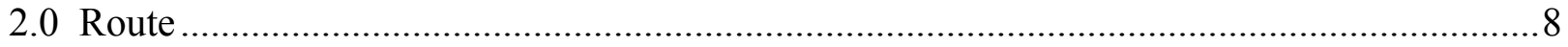

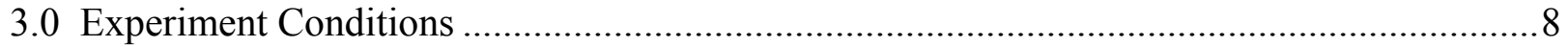

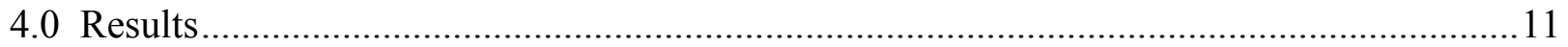

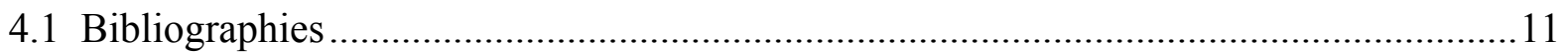

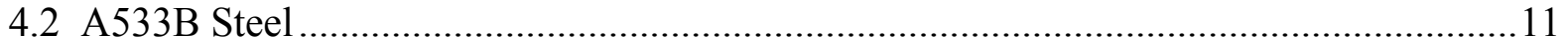

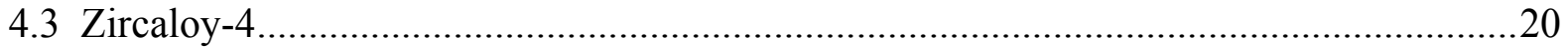

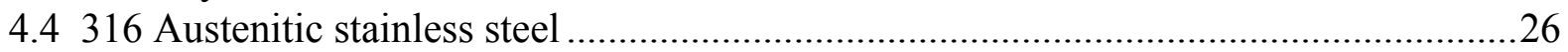

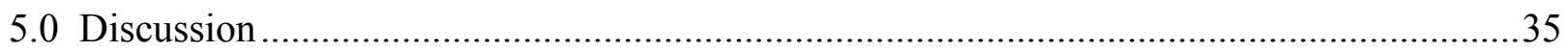

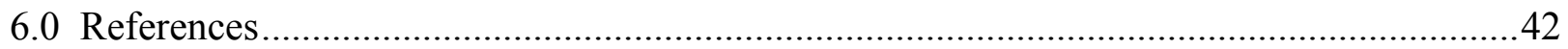

Appendix A: Details of Experiment conditions...............................................................44

A1. Sources and compositions (Wt.\%) of the three alloys, and heat treatments for the tensile

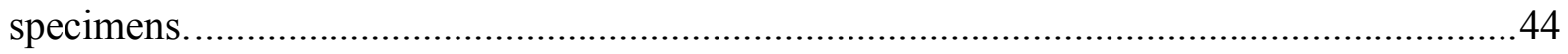

A2. Specimen size and handling ........................................................................... 47

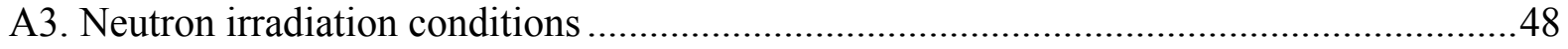

A4. TEM preparations and observation conditions ..................................................5 50

Appendix B: Bibliography of localized plastic flow in irradiated iron and ferritic steels..........51

Appendix C: Bibliography of localized plastic flow in irradiated austenitic stainless steels .....52

Appendix D: Bibliography of localized plastic flow in irradiated $\mathrm{Zr}$ alloys ...........................55

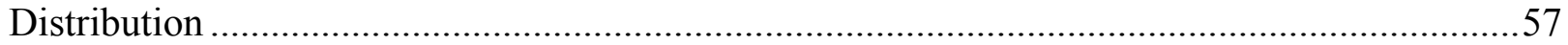


ORNL/TM-2002/66

\title{
MAPPING FLOW LOCALIZATION PROCESSES IN DEFORMATION OF IRRADIATED REACTOR STRUCTURAL ALLOYS
}

\author{
List of Figures
}

Fig. 1. Schematic tensile curve showing salient features employed in this work.

Fig. 2. Deformation mode-fluence maps for nickel and gold irradiated and tensile strained at $300 K[9]$.

Fig. 3. The tensile specimen...................................................................................... 9

Fig. 4. Microstructure of unirradiated $A 533 B$ steel at $6 \%$ strain. ....................................... 12

Fig. 5. Black spot irradiation damage structure in A533B steel irradiated to 0.89 dpa........... 12

Fig. 6. Size distribution of black spot RDS in A533B steel after irradiation to $0.89 \mathrm{dpa}$...........13

Fig. 7. Representative tensile test curves for A533B steel after different neutron exposures.... 13

Fig. 8. Dose dependence of tensile properties of A533B steel. .............................................. 15

Fig. 9. Deformation structure of unirradiated A533B steel and low dose specimens: (a) at 0.001 dpa after 5\% strain, (b) at 0.01 dpa after 10\% strain.

Fig. 10. Deformation mode map for A533B steel neutron-irradiated at $65-100^{\circ} \mathrm{C}$ and tested at

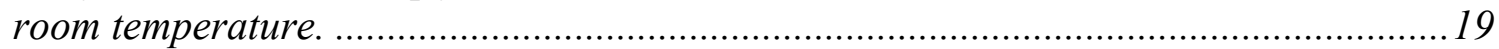

Fig. 11. Size distribution of black spot RDS in Zircaloy-4 irradiated to 0.8 dpa.....................20

Fig. 12. Tensile test curves for Zircaloy-4......................................................................21

Fig. 13. Dose dependence of tensile properties of neutron irradiated Zircaloy-4....................22

Fig. 14. Typical dislocation structure in unirradiated, deformed Zircaloy-4; at 3\% strain......23

Fig. 15. Dislocation arrays in channels in Zircaloy-4 irradiated to 0.009 dpa and strained 4.8\%;

(b) is slightly tilted from (a) to reveal the channels................................................24

Fig. 16. Dislocation channels in Zircaloy-4 irradiated to 0.8 dpa and strained $6.3 \%$............25

Fig. 17. Deformation mode map for Zircaloy-4 neutron-irradiated at $65-100^{\circ} \mathrm{C}$ and tested at

room temperature. ..................................................................................... 25

Fig. 18. Size distributions of black spot RDS in 316 stainless steel after irradiation to (a) 0.001,

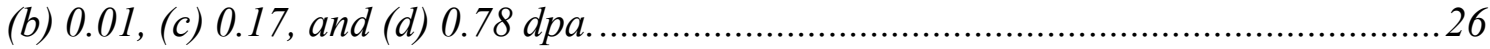

Fig. 19. Representative tensile curves for 316 stainless steel. ............................................28

Fig. 20. Fluence dependence of the tensile properties of annealed 316 stainless steel............30

Fig. 21. Planar deformation in unirradiated stainless steel strained 1.5\% at room temperature.

Fig. 22. Deformation twins in unirradiated 316 stainless steel strained $54 \%$ at room

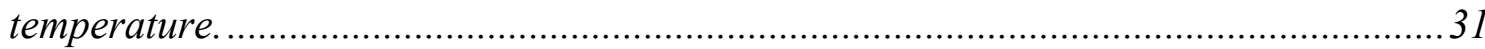

Fig. 23. Dislocation channels in 316 stainless steel irradiated to $0.15 \mathrm{dpa}$ and strained $6 \%$....32

Fig. 24. Blocky arrangement of dislocation channels in 316 stainless steel irradiated to $0.78 \mathrm{dpa}$

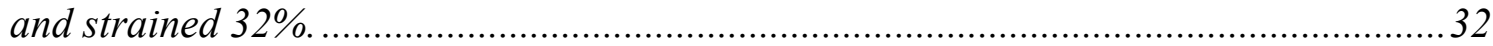

Fig. 25. Fragmented channels within the blocks in 316 stainless steel irradiated to $0.78 \mathrm{dpa}$ and strained $32 \%$. 


\section{List of Figures (continued)}

Fig. 26. Deformation mode map for 316 austenitic stainless steel neutron-irradiated at 65$100^{\circ} \mathrm{C}$ and tested at room temperature.

Fig. 27. Engineering tensile curves for the deformation mode maps in Fig. 2 [9]......................39

Fig. 28. Determination of radiation hardening exponents for the three alloys...........................41

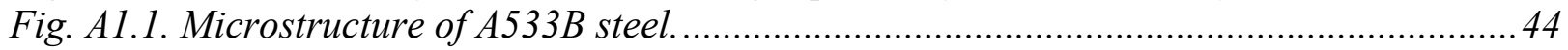

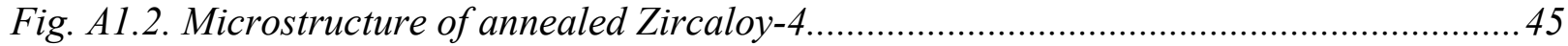

Fig. A1.3. Microstructure of annealed 316 stainless steel. ....................................................46

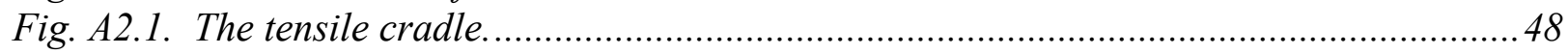


ORNL/TM-2002/66

\title{
MAPPING FLOW LOCALIZATION PROCESSES IN DEFORMATION OF IRRADIATED REACTOR STRUCTURAL ALLOYS
}

\author{
List of Tables
}

Table 1. Project tasks, Phases 1-3. 9

Table 2. NERI deformation mode studies, Years 1 and 2. Matrix of tensile tests for each alloy at room temperature and a strain rate of $10^{-3} \mathrm{~s}^{-1}$

Table 3. Average work hardening rates (MPa, engineering units) in the plastic strain range 0 to $5 \%$ elongation. Values of work hardening exponent, $n$, are shown in square brackets.... 15

Table 4. Channel widths and spacings in irradiated stainless steel.......................................33

Table A1. 1. The chemical composition of A533B steel............................................................ 44

Table A1. 2. The chemical composition of Zircaloy-4 ........................................................ 45

Table A1. 3. The chemical composition of 316 stainless steel.............................................46

Table A3. Irradiation exposure conditions. Neutron fluences are in units of $n . m^{-2}$.................49 
ORNL/TM-2002/66

\title{
MAPPING FLOW LOCALIZATION PROCESSES IN DEFORMATION OF IRRADIATED REACTOR STRUCTURAL ALLOYS
}

\author{
NUCLEAR ENERGY RESEARCH INITIATIVE PROGRAM No. MSF99-OO72 \\ TECHNICAL PROGRESS REPORT FOR YEAR 2 OF PROJECT \\ PERIOD: AUGUST 2000 THROUGH SEPTEMBER 2001.
}

\author{
K. Farrell, T. S. Byun, and N. Hashimoto
}

\begin{abstract}
Executive Summary
Metals that can sustain plastic deformation homogeneously throughout their bulk tend to be tough and malleable. Often, however, if a metal has been hardened it will no longer deform uniformly. Instead, the deformation occurs in narrow bands on a microscopic scale wherein stresses and strains become concentrated in localized zones. This strain localization degrades the mechanical properties of the metal by causing premature plastic instability failure or by inducing the formation of cracks. Irradiation with neutrons hardens a metal and makes it more prone to deformation by strain localization. Although this has been known since the earliest days of radiation damage studies, a full measure of the connection between neutron irradiation hardening and strain localization is wanting, particularly in commercial alloys used in the construction of nuclear reactors. Therefore, the goal of this project is to systematically map the extent of involvement of strain localization processes in plastic deformation of three reactor alloys that have been neutron irradiated. The deformation processes are to be identified and related to changes in the tensile properties of the alloys as functions of neutron fluence (dose) and degree of plastic strain. The intent is to define the role of strain localization in radiation embrittlement phenomena. The three test materials are a tempered bainitic A533B steel, representing reactor pressure vessel steel, an annealed 316 stainless steel and annealed Zircaloy-4 representing reactor internal components.
\end{abstract}

Tensile specimens of the three alloys were irradiated in the hydraulic tube facility of the High Flux Isotope Reactor at Oak Ridge National Laboratory to fast neutron fluences of $6 \times 10^{20}, 6 \mathrm{x}$ $10^{21}, 6 \times 10^{22}, 6 \times 10^{23}$, and $5.3 \times 10^{24} \mathrm{n}^{-\mathrm{m}^{-2}}, \mathrm{E}>1 \mathrm{MeV}$, corresponding to doses of $0.0001,0.001$, 0.01, 0.1, and 0.8-0.9 displacements per atom (dpa). The irradiation temperature was $65-100^{\circ} \mathrm{C}$. Post-irradiation tensile properties were measured at room temperature at a strain rate of $10^{-3} \mathrm{~s}^{-1}$. All three materials underwent progressive irradiation hardening and loss of ductility with increasing dose. Flow stresses were increased, yield point drops were developed, work hardening rates were reduced, elongations were severely reduced, and early onset of failure occurred by plastic instability. The modes of plastic deformation involved in the tensile behaviors were determined by curtailing tensile tests at prescribed levels of strain then sectioning the specimens for examination by transmission electron microscopy. Four modes of deformation were identified, namely three-dimensional dislocation cell formation, planar dislocation activity, dislocation channel deformation (DCD) in which radiation damage structure has been swept away, and fine-scale twinning. These modes varied with material, dose, and strain level. 
In the body-centered cubic A533B steel, deformation in the unirradiated specimens was homogeneous and occurred by interaction and tangling of dislocations to form dislocation cells. In those specimens of A533B steel irradiated to the two lowest doses, no radiation damage structure (RDS) was detected and there was only minor radiation hardening; the deformation behavior was similar to the unirradiated material. At the middle dose of $0.01 \mathrm{dpa}$, no RDS was seen but there was considerable radiation strengthening and the work hardening rate was reduced almost to zero. For this dose, the arrangement of strain dislocations was more linear, consistent with the decreased work hardening rate, but there was still some dislocation cell structure. At the highest dose, black spot radiation damage with a mean defect size of $1.3 \mathrm{~nm}$ and concentration of about $6.5 \times 10^{22} \mathrm{~m}^{-3}$ was evident. In the two highest dose specimens prompt plastic instability failures occurred at the yield stress. Some DCD was observed but the strain in the tensile specimens was too highly localized to allow retrieval of truly representative TEM specimens from the deformed regions. The channels were about $40 \mathrm{~nm}$ wide.

The fluence dependence of the tensile properties of the close-packed hexagonal Zircaloy-4 alloy was found to be of similar form as for the A533B steel except that the degree of radiation hardening was higher at the lower doses and lower at the higher doses. No RDS was visible at the lowest dose of $0.0001 \mathrm{dpa}$. At $0.001,0.01,0.1$, and $0.8 \mathrm{dpa}$ there was fine black spot damage, reaching a size of $1.4 \mathrm{~nm}$ and a concentration of $6.1 \times 10^{22} \mathrm{~m}^{-3}$ at $0.8 \mathrm{dpa}$. For a dose of 0.001 $\mathrm{dpa}$, and in the unirradiated Zircaloy, plastic deformation during tension testing occurred by coarsely dispersed planar slip primarily on the slip system $\{0001\}<11 \overline{2} 0>$, and to a lesser extent on $\{10 \overline{1} 1\}<11 \overline{2} 0>$. At $0.01 \mathrm{dpa}$, the deformation mode was still planar slip but with stronger participation of $\{10 \overline{1} 1\}<11 \overline{2} 0>$. At the two highest doses, where plastic instability failure was entered at the yield stress, the deformation mode was DCD on the same slip systems. Channel widths were of order $50 \mathrm{~nm}$.

The austenitic 316 stainless steel, which has a face-centered cubic lattice and low stacking fault energy, behaved quite differently from the other two alloys. It displayed a similar degree of radiation hardening as the A533B steel yet it retained substantial work hardening and uniform elongation at all doses. In its unirradiated condition, and at the two lowest fluences, where no RDS was visible, it deformed by planar slip on its $\{111\}<110>$ slip systems. As the level of strain was increased, the slip bands became more pronounced and tangled dislocations appeared in the matrix between the bands. Streaks from fine twins appeared in electron diffraction patterns. Dark field microscopy revealed that the twins were located within the deformation bands. At an irradiation dose of 0.01 dpa some black spot RDS was found, but the deformation mode was not altered. For the two highest doses, where black spot-type RDS was strong, dislocation channels primarily on the easy slip systems were cleared through the RDS. In specimens irradiated to $0.1 \mathrm{dpa}$, most of the channels were superimposed on the dislocation bands; there were also some very narrow channels containing neither dislocations nor twins. At the highest dose, where the black spot concentration was $4 \times 10^{23} \mathrm{~m}^{-3}$ with a mean size of $1.8 \mathrm{~nm}$, the dislocation bands and microtwins and channels were superimposed in the deformation bands and were very pronounced. Channel widths were about $20 \mathrm{~nm}$. With increasing strain, the blocks of material between the heavy channel bands became subdivided into smaller blocks by development of new channel bands. 
These observations are used to construct the first strain-neutron fluence-deformation mode maps for A533B pressure vessel steel, Zircaloy-4, and 316 austenitic steel. Analyses of the data show that correlations between deformation mode and tensile properties are more complex than expected. Although there is a clear connection between the presence of DCD and yield point drops, reduced work hardening and severe ductility loss at high irradiation doses, the interactions are more subtle at lower doses and the changes in the tensile curve are more difficult to interpret. Most notably, irradiation encourages planar deformation which is seen as a precursor to channeling and which contributes to changes in the tensile curve. The pattern of change in deformation mode with increasing irradiation dose seems to be: Normal unirradiated mode $\longrightarrow$ planar banding $\longrightarrow$ DCD.

The deformation behavior of austenitic stainless steel is different from the other two alloys. Even in its unirradiated condition it deforms in a planar manner yet has high work hardening rate. After irradiation, when channels form they are not devoid of dislocations as in the other two alloys. They contain extended dislocations and microtwins. Significant work hardening is retained. Of the three alloys investigated here, the stainless steel has the narrowest channels at a given dose and it is the most resistant to necking. It is suggested that the presence of microtwins in the channels moderates the behavior of glide dislocations in the channels and helps retain some work hardening in the channels, thereby reducing the concentrations of stress and strain in the channels and delaying necking.

Analyses of the fluence $(\phi t)$ dependencies of the increases in tensile yield strengths $(\Delta Y S)$ for all three alloys were made in terms of the relationship $\Delta Y S \propto(\phi t)^{m}$. Values of the radiation hardening exponent, $m$, were in the range $0.36-0.38$ for fluences up to $6 \times 10^{23} \mathrm{n} \cdot \mathrm{m}^{-2}(0.1 \mathrm{dpa})$. Saturation in hardening was noted at higher fluences and was concurrent with acceleration of gross strain localization. 
ORNL/TM-2002/66

\title{
MAPPING FLOW LOCALIZATION PROCESSES IN DEFORMATION OF IRRADIATED REACTOR STRUCTURAL ALLOYS
}

\author{
NUCLEAR ENERGY RESEARCH INITIATIVE PROGRAM No. MSF99-0072 \\ TECHNICAL PROGRESS REPORT FOR YEAR 2 OF PROJECT \\ PERIOD: AUGUST 2000 THROUGH SEPTEMBER 2001.
}

\author{
K. Farrell, T. S. Byun, and N. Hashimoto
}

\subsection{Background and Objective}

Under applied loads, a plastically deformable metal can undergo considerable strain and tolerate much permanent change in shape without breaking. Such deformation takes place by the generation and movement of dislocations on multiple slip planes within the metal. Interaction and tangling of dislocations on intersecting planes causes resistance to further dislocation movement and requires a higher stress to continue the deformation. Such strain hardening, or work hardening as it is commonly known, is necessary to continue and extend the deformation in a uniform manner. Metals that deform in this manner are strained homogeneously throughout their bulk and they tend to be tough and malleable. On the other hand, if the metal does not deform homogeneously but instead the strain is restricted to a localized region, its mechanical properties are impaired and it fails prematurely. These contrasting features of uniform and nonuniform plastic deformation can be seen in the graphical record of a tension test. Fig. 1 is a schematic representation of a tensile test curve illustrating the characteristics of both uniform strain and strain localization by necking and showing the salient features for reading the tensile properties. Hereafter the word 'strain' is used synonymously with 'elongation', in both cases meaning the fractional increase in length of the gauge section.

In the tensile curve, plastic deformation is seen as the retained elongation, either uniform elongation (up to the ultimate tensile stress, or UTS) or as total elongation. Work hardening is registered as the increase in stress needed to continue increasing the elongation and to maintain uniform deformation. This engineering stress reaches a maximum at the UTS, which is the point where in true stress units the work hardening rate falls below the true stress level. As a consequence, uniform strain ceases and deformation continues locally by the formation of a neck. Residual flaws such as inclusions or other natural weaknesses in the metal can prompt the onset of necking. At the UTS, any weak spot is more susceptible to plastic flow and will stretch a little more than in the rest of the specimen. This further raises the local stress in the weak spot, which accelerates the degree of local elongation and so on, concentrating the stresses in the weak region and causing a pinched-in neck and failure there. Since this necking occurs in a narrow region, less applied load is required to maintain or raise the necking stress, hence necking continues under a falling applied bulk stress; the work hardening slope is negative. (Actually, the slope is negative only in terms of engineering stress-strain units. In true stress-true strain units, where the reduced cross-section in the neck is taken into consideration, the work hardening in the neck has a positive value.) Such necking failure is the best-known type of strain localization. 
It is a gross phenomenon and is the normal fate of a ductile metal that has been strained too much.

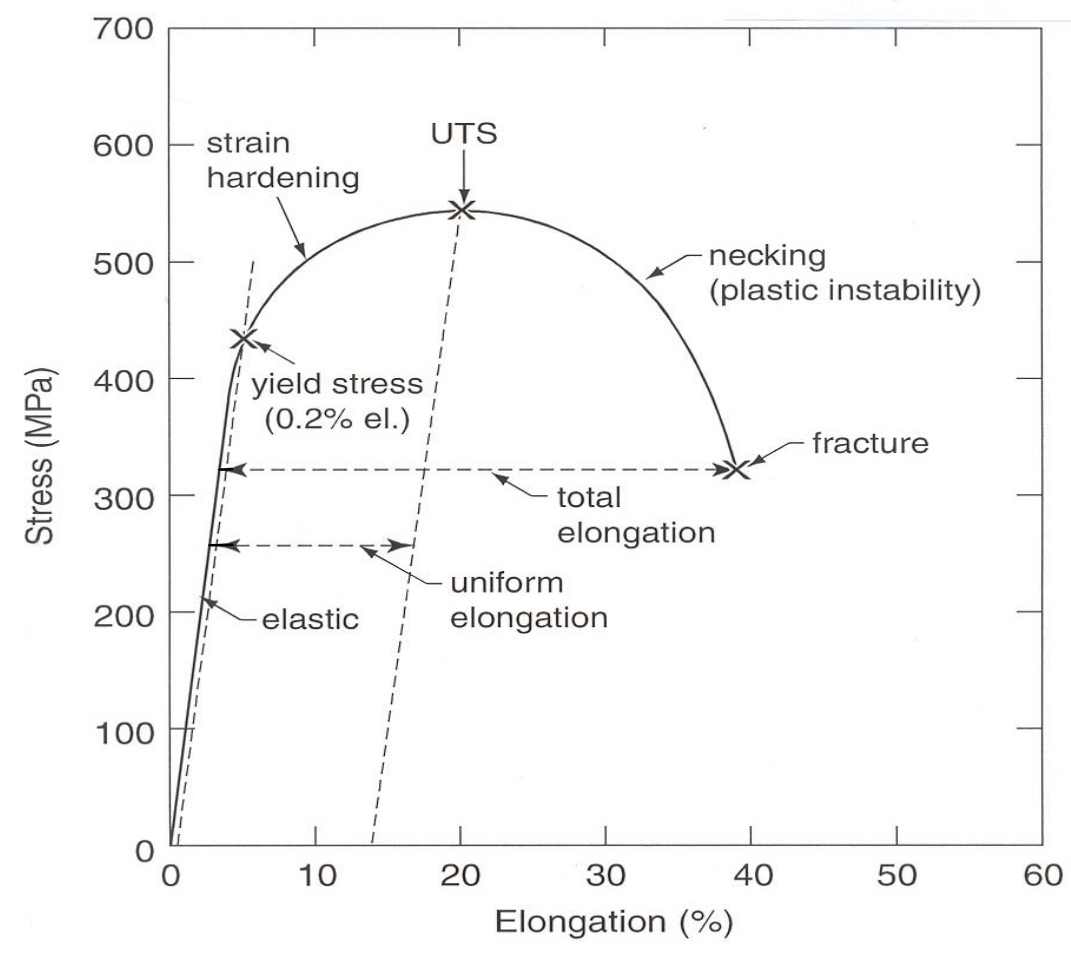

Fig. 1. Schematic tensile curve showing salient features employed in this work.

There are more insidious types of strain localization that occur in prehardened metals on a microscopic scale without the aid of built-in flaws and which can severely degrade the mechanical properties of the metal by causing premature plastic instability failure or by inducing the formation of cracks. One of these microscopic strain localization processes is dislocation channel deformation [1-3], hereafter referred to as DCD. DCD is a process of heterogeneous plastic deformation that entails only a few dislocation sources operating on widely separated slip planes. Dislocations released from the sources glide along the slip planes, cutting through and destroying or assimilating any barriers in their paths. This clearing action creates an easy passageway, or narrow channel a fraction of a micron wide, in which travel of subsequent dislocations from the source is easy, and therefore the strain remains confined to the channels. The large blocks of material between the channels undergo little or no deformation. The levels of strain in the channels can be very high, several hundred percent, whereas the bulk strain may be only a few percent or less $[4,5]$. Consequently, the strains and stresses at the head of a channel can greatly exceed the applied bulk values and they have the potential for creating cracks.

Irradiation with neutrons hardens a metal and makes it more prone to DCD $[1,2]$. Although this has been known since the earliest days of radiation damage studies [6], a full measure of the connection between neutron irradiation hardening, changes in mechanical properties, and strain localization is wanting, particularly in commercial alloys used in the construction of nuclear 
reactors. It seems obvious that strain localization must be intimately involved in radiationinduced degradation of mechanical properties, but the correlation is not clear. One way to establish such correlation is with deformation mode maps.

Deformation mode maps originated from the work of M. F. Ashby [7] and his students who, twenty years ago, gathered information about the deformation behavior of a metal from diverse sources and condensed it into a single diagram depicting regions of specific deformation modes in terms of stress-temperature coordinates. Likewise, fracture mechanism maps were developed. With such maps one can instantly see for a given temperature and stress whether a material will be ductile or brittle and can determine what is controlling the deformation. The maps provide a guide to selection of the best range of processing conditions for working the material to a commercial product. Transparencies of maps of mechanical properties of the product and of its processing costs can be superimposed on the deformation map to choose the optimum production route. Ashby maps have now been extended to other parameters and other fields [8] and have become a valuable tool for matching materials and properties to applications. A comprehensive map not only correlates a materials properties with its deformation behavior, it offers the potential for tracking and predicting the material's service performance. Radiation embrittlement curtails service life and raises safety issues in reactor materials. But there are no published Ashby-type maps for irradiated reactor structural alloys to outline the regions of minimum embrittlement or to indicate avoidance strategies. In the area of radiation effects in metals the nearest thing to a Ashby-type deformation map are the two deformation mode-fluence maps [9] for nickel and gold, shown in Fig. 2. These mode maps outline the boundaries between regimes of uniform deformation occurring by cell formation and regions where deformation occurs locally by DCD. The boundaries are dependent on the degrees of fluence and strain. At lower fluences, cell formation is dominant at all strains, and in nickel the size of the dislocation cells decreases from $2 \mu \mathrm{m}$ to $0.5 \mu \mathrm{m}$ with increasing strain and increasing fluence. DCD is observed at a fluence of $2 \times 10^{21} \mathrm{n} \cdot \mathrm{m}^{-2}$, but only at low strains; at higher strains it switches to cell formation. At the higher fluences, DCD is more persistent and is the dominant mode at all strains at fluences above about $1 \times 10^{22} \mathrm{n} \cdot \mathrm{m}^{-2}$.

The goal of the present project is to systematically map the extent of involvement of strain localization processes in plastic deformation of three reactor alloys that have been neutron irradiated. The three materials are a tempered bainitic steel, A533B, representing reactor pressure vessel steels; annealed 316 stainless steel representing fuel cladding and other reactor internal components; and annealed Zircaloy-4 alloy, also used as fuel cladding and internals. The deformation processes are to be identified and related to changes in the tensile properties of the alloys as functions of neutron fluence (dose) and degree of plastic strain. The intent is to define the role of strain localization in radiation embrittlement phenomena. 

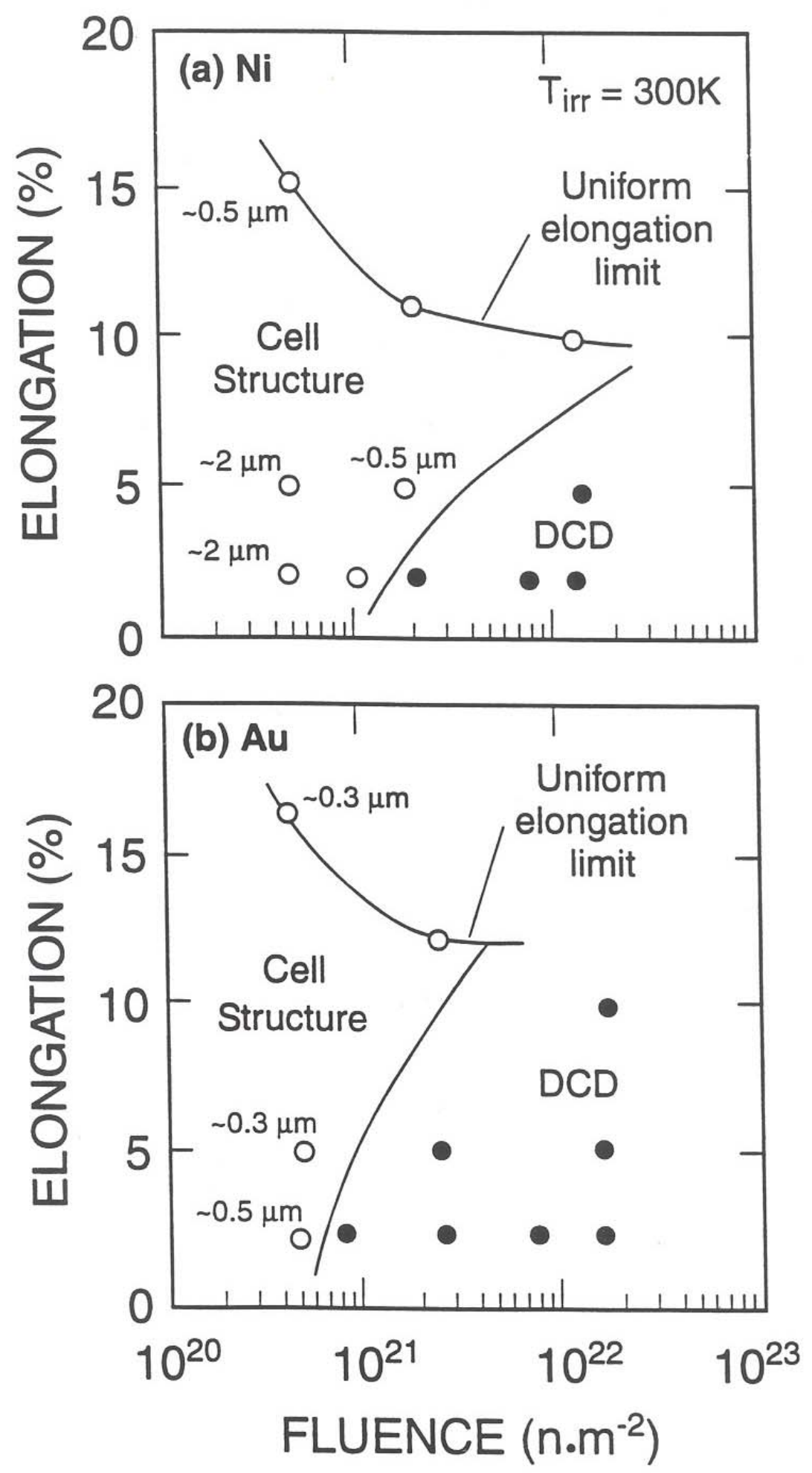

Fig. 2. Deformation mode-fluence maps for nickel and gold irradiated and tensile strained at $300 K$ [9]. 


\subsection{Route}

The occurrence of strain localization can be recognized unambiguously by only one technique visual examination of the strained test piece to determine whether the specimen is deforming in narrow bands instead of stretching uniformly along its gauge length. The examination can be done to a limited extent with the naked eye, to a better degree with the aid of optical instruments, and, with most certainty, by transmission electron microscopy (TEM) examination. Indirect signs of strain localization can be found in tensile stress-strain curves. The most common of these changes are the appearance of a yield point drop, a reduction in the work hardening rate, and a reduction in elongation. Since similar signs can originate from causes other than strain localization, the occurrence of one, or even two, of the signs is no assurance that strain localization is involved. But when all three signs occur together in the test curve there is increased confidence that they are indicating strain localization. One of the goals of this project is to bolster that confidence by correlating changes in the tensile curve with specific deformation modes. Optical examinations and changes in the shapes of tensile curves do not reveal details of the mode(s) of plastic strain localization; they can not tell whether the mechanism is dislocation channeling, mechanical twinning, or some other mode. TEM is the best technique for ascertaining the nature of the deformation mode. Therefore, the experimental route employed in this project is to irradiate tensile specimens of the alloys to a range of fast neutron fluences and obtain their tensile stress-strain curves and tensile properties. Companion specimens are subjected to various predetermined plastic strains in tension and cut into pieces for TEM examination to determine their deformation microstructures. The results are compiled into maps showing how the deformation modes change with neutron fluence and plastic strain. These changes in mode are compared to the corresponding changes measured in the tensile properties to establish and quantify the cause and effect relationship(s) between mechanical properties and deformation mode.

The project is laid out in three consecutive phases each of 12 months duration, as listed in Table 1. The status of Phase 1 was reported on August 25, 2000. At that time, unexpected delays at the reactor had set the program back significantly, and a modification was made to the work plan that allowed tasks 1.2.3 through 1.3 to be carried into Phase 2 (corresponding to Year 2 of the program). Therefore, the present report for Year 2 covers the tasks 1.2.3 through 2.2. Phase 3 has begun and will be the subject of a later report.

\subsection{Experiment Conditions}

The conditions employed in these experiments are summarized below. More details, and some of the reasons behind the choices of paths, are given in Appendix A. The experiments make much use of custom-developed miniature specimens, a report of which was presented orally at the Fourth Symposium on Small Specimen Test Techniques, Reno, Nevada, January 23-25, 2001, and is awaiting publication in the symposium proceedings [10].

Chemical compositions of the three alloys, and the heat treatments given to the tensile specimens, are described in Appendix A1. All machining and sanding operations were completed before the specimens were heat-treated. The dimensions of the specimen are given in Fig. 3. 
Table 1. Project tasks, Phases 1-3.

Phase 1:

\begin{tabular}{|ll|c|c|}
\hline \multicolumn{1}{|c|}{ Task Description } & $\begin{array}{c}\text { Planned Completion } \\
\text { Date }\end{array}$ & Actual Completion Date \\
\hline $1.1 \quad$ Literature search & Sep-99 & Nov-99 \\
1.2 Perform experiments: & & \\
1.2.1 Prepare test specimens & Nov-99 & Jan-00 \\
1.2.2 Conduct irradiations & Jan/Feb-00 & Aug/Sep-00 \\
1.2.3 Do tensile tests & Feb-00 & Merged with Phase 2 \\
1.2.4 Cut TEM pieces from tensiles & Mar-00 & Merged with Phase 2 \\
1.2.5 Do TEM survey & Jul-00 & Merged with Phase 2 \\
1.3 Compile initial maps & Jul-00 & Merged with Phase 2 \\
\hline
\end{tabular}

Phase 2:

\begin{tabular}{|l|c|c|}
\hline 1.2 .3 Do tensile tests & Feb-00 & Apr-01 \\
\hline 1.2 .4 Cut TEM pieces from tensiles & Mar-00 & Apr-01 \\
\hline 1.2 .5 Do TEM survey & Jul-00 & Sep-01 \\
\hline $1.3 \quad$ Compile initial maps & Jul-00 & Sep-01 \\
\hline $2.1 \quad$ Conduct detailed TEM & Jul-01 & Sep-01 \\
$2.2 \quad$ Tabulate TEM data & Jul-01 & Sep-01 \\
\hline
\end{tabular}

Phase 3:

3.1 Do irradiations at $300 \mathrm{C}$

3.2 Perform tensile tests

3.3 Conduct detailed TEM

3.4 Prepare final report

Sep/Oct-01
Oct/Nov-01
Jul-02
Aug/Sept-02

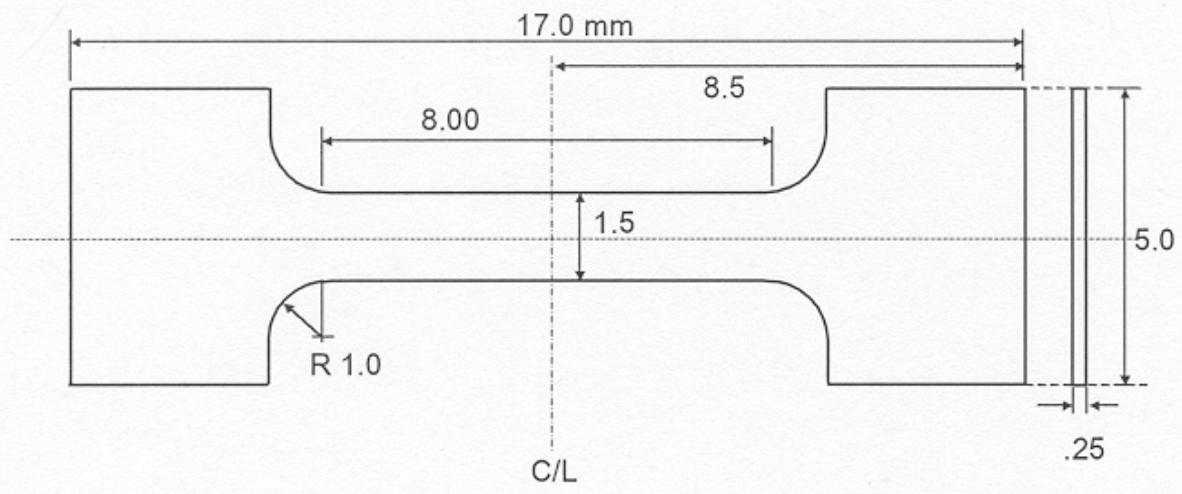

Fig. 3. The tensile specimen. 
All tensile tests were conducted at room temperature in a screw-driven machine at a crosshead speed of $0.008 \mathrm{~mm} . \mathrm{s}^{-1}$, corresponding to a specimen strain rate of $10^{-3} \mathrm{~s}^{-1}$. Engineering strain was calculated from the recorded crosshead separation using a nominal gauge length of $8 \mathrm{~mm}$. Engineering stress was calculated as the load divided by the initial cross section area before irradiation. The load cell was calibrated to NIST-approved standards.

The matrix of tensile tests is displayed in Table 2. For each alloy, at least two specimens representing each dose level were tested to failure to obtain a full tensile curve and complete tensile properties. Tests on other specimens at the same doses were curtailed at prescribed strains and the gauge sections of the specimens were sectioned for TEM study.

Table 2. NERI deformation mode studies, Years 1 and 2. Matrix of tensile tests for each alloy at room temperature and a strain rate of $10^{-3} \mathrm{~s}^{-1}$.

\begin{tabular}{|c|c|c|c|c|c|c|}
\hline $\begin{array}{c}\text { Fluence, } \\
\text { n.m-2 } \\
(\mathrm{E}>1 \mathrm{MeV})\end{array}$ & $\begin{array}{c}\text { Nom. } \\
\text { dpa }\end{array}$ & $\begin{array}{c}\text { Tests to } \\
\text { Failure }\end{array}$ & \multicolumn{5}{|c|}{ Truncated tests } \\
\cline { 4 - 7 } & & & $0.5 \%$, & $5 \%$, & At UTS & In neck \\
\hline$-0-$ & $-0-$ & 4 & 1 & 1 & 1 & 1 \\
\hline $6 \mathrm{E} 20$ & 0.0001 & 2 & 1 & 1 & 1 & 1 \\
\hline $6 \mathrm{E} 21$ & 0.001 & 2 & 1 & 1 & 1 & 1 \\
\hline $6 \mathrm{E} 22$ & 0.01 & 2 & 1 & 1 & 1 & 1 \\
\hline $6 \mathrm{E} 23$ & 0.1 & 2 & 1 & 1 & 1 & 1 \\
\hline $5 \mathrm{E} 24$ & 0.8 & 2 & 1 & 1 & 1 & 1 \\
\hline
\end{tabular}

The irradiations were carried out in flowing coolant water in the hydraulic tube facility of the High Flux Isotope Reactor. The inlet temperature of the water is $49^{\circ} \mathrm{C}$ and the outlet temperature is $69^{\circ} \mathrm{C}$. The temperature of the specimens was estimated to be in the range $65-100^{\circ} \mathrm{C}$. The irradiation exposures ranged from $5.9 \times 10^{20} \mathrm{n} . \mathrm{m}^{2}$ to $5.5 \times 10^{24} \mathrm{n} . \mathrm{m}^{-2}, \mathrm{E}>1 \mathrm{MeV}$.

Correspondingly, nominal atomic displacement levels ranged from 0.0001 dpa to 0.89 dpa for the A533B steel to 0.00009 to $0.8 \mathrm{dpa}$ for the stainless steel and Zircaloy-4. More details are available in Appendix A3 and Table A3.

The TEM pieces cut from the gauge sections of the tensile specimens had dimensions of only 1.5 x $1.5 \times 0.25 \mathrm{~mm}$, which is much smaller than a standard $3 \mathrm{~mm}$ diameter TEM disk. Preparation of electrothinned foils from these small pieces in a Tenupol electropolishing apparatus required substantial development work and modification of Tenupol specimen holders, details of which are available in Ref. 10 and in Appendix A. 


\subsection{Results}

\subsection{Bibliographies}

Before describing the experimental results, attention is directed to the fact that the first task of Year 1 was to compile bibliographies of published information on plastic deformation processes in irradiated ferritic steels, austenitic stainless steels, and Zircaloy. Those lists were not included in the annual report for Year 1. They are presented herein as Appendices B, C, and D, respectively. Data from these Appendices and from a wider survey of literature on strain localization in other materials were used by the Principal Investigator to present an oral review of strain localization in irradiated metals at the first International Workshop on DislocationDefect Interactions in Irradiated Materials, Toledo, Spain, April 3-5, 2000.

\subsection{A533B Steel}

The optical microstructure of the as-heat-treated A533B steel can be seen in Fig. A1.1 in Appendix A. TEM study of the specimens revealed microstructures consisting of packets of lathlike grains divided into equiaxed subgrains about 300-1000 nm size and containing many tangled dislocations, Fig. 4. Numerous carbide particles of sizes $50-500 \mathrm{~nm}$ were distributed randomly through the matrix. The resident tangled dislocations pose a problem for identification of deformation mechanisms after straining because the strain dislocations are indistinguishable from the preexisting dislocation tangles. Fig. 4 was actually taken after $6 \%$ strain, and the structure is essentially the same as for an unstrained specimen.

In the as-irradiated specimens, no radiation-induced defect structure (RDS) was discernable for doses of $0.0001,0.001,0.01$, and $0.1 \mathrm{dpa}$. This apparent absence of RDS does not necessarily mean that none was present; it means that none was seen, either because the defects were too small for detection, $<1 \mathrm{~nm}$ diameter, or the TEM foils were not of sufficiently good quality to allow them to be seen. For the 0.89 dpa dose, RDS was clearly visible as distinct black spot defects, Fig. 5. Note that in all the materials examined in this work, some of these black spots are small dislocation loops, not all of which are visible in a given beam direction. To account for most of the spots, they are measured in dark field weak beam conditions but no attempt is made to determine the invisible fractions. Measurements of the defects in the A533B steel at 0.89 dpa gave a concentration of $6.5 \times 10^{22} \mathrm{~m}^{-3}$ and a mean size of $1.3 \mathrm{~nm}$. Their size distribution is shown in Fig. 6. 


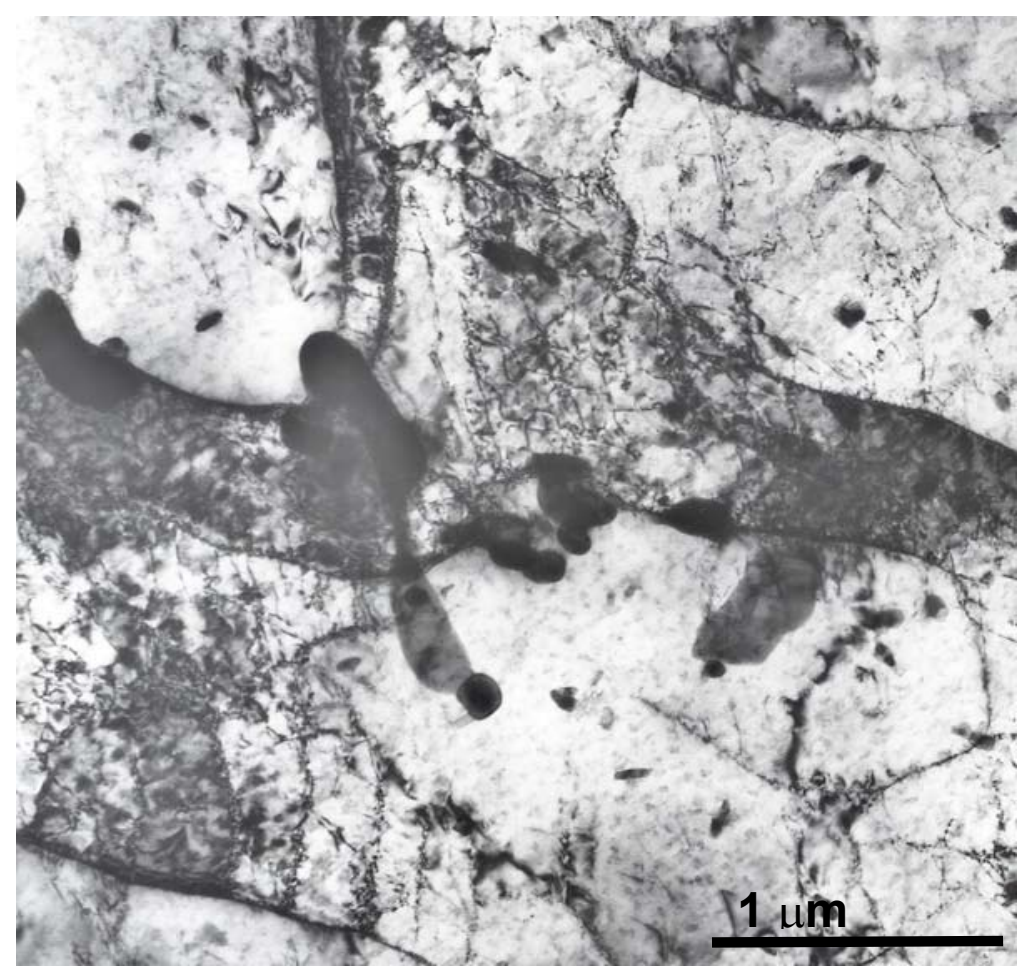

Fig. 4. Microstructure of unirradiated A533B steel at $6 \%$ strain.

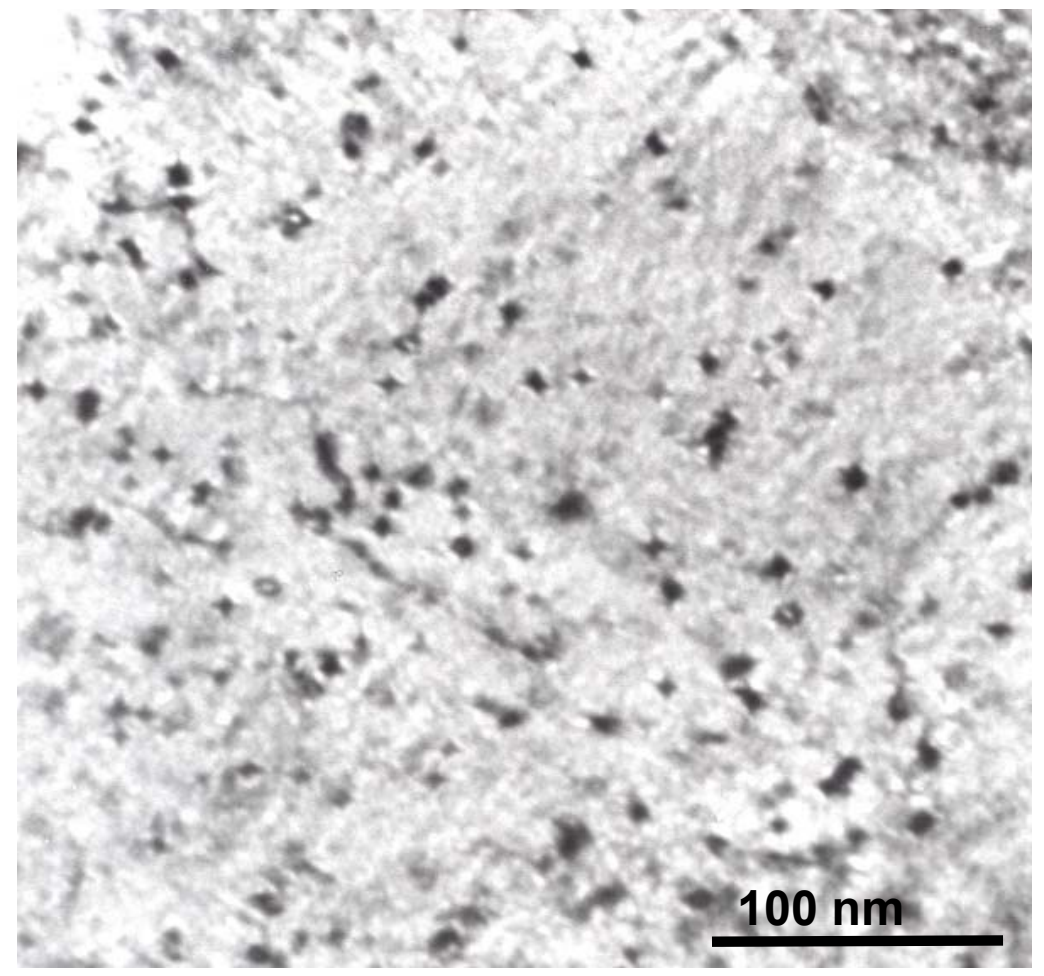

Fig. 5. Black spot irradiation damage structure in A533B steel irradiated to 0.89 dpa. 


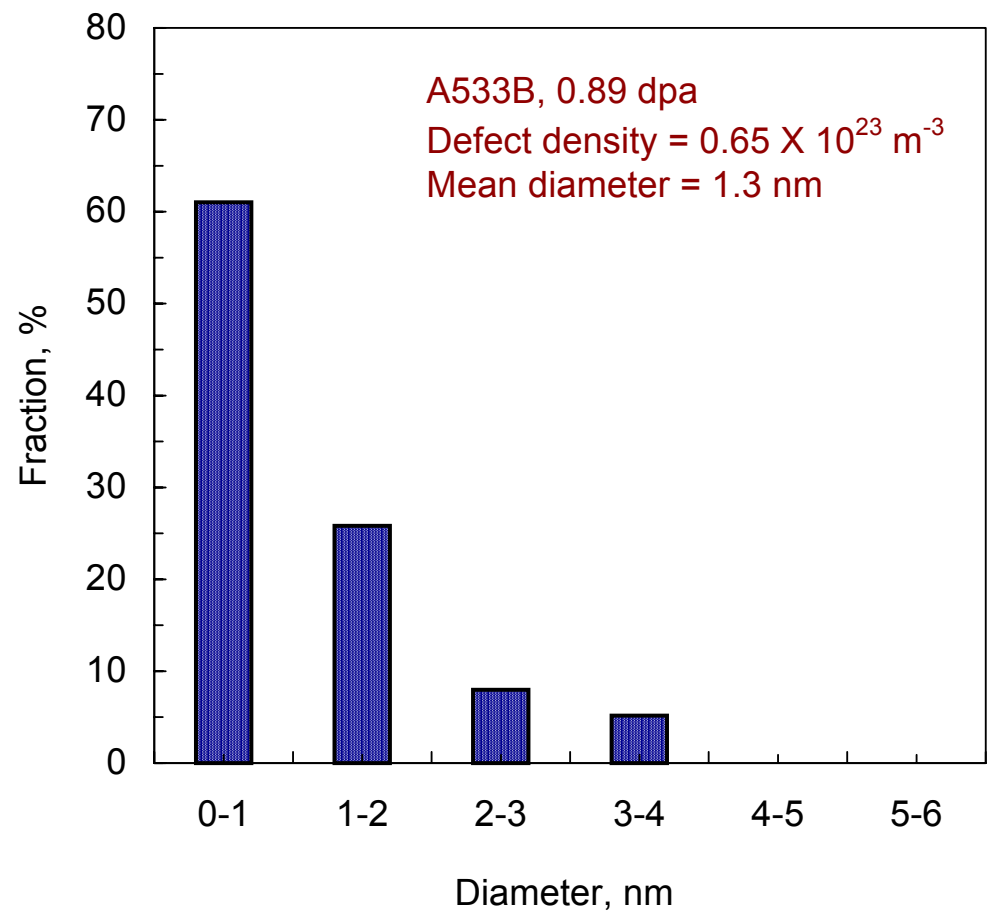

Fig. 6. Size distribution of black spot RDS in A533B steel after irradiation to $0.89 \mathrm{dpa}$.

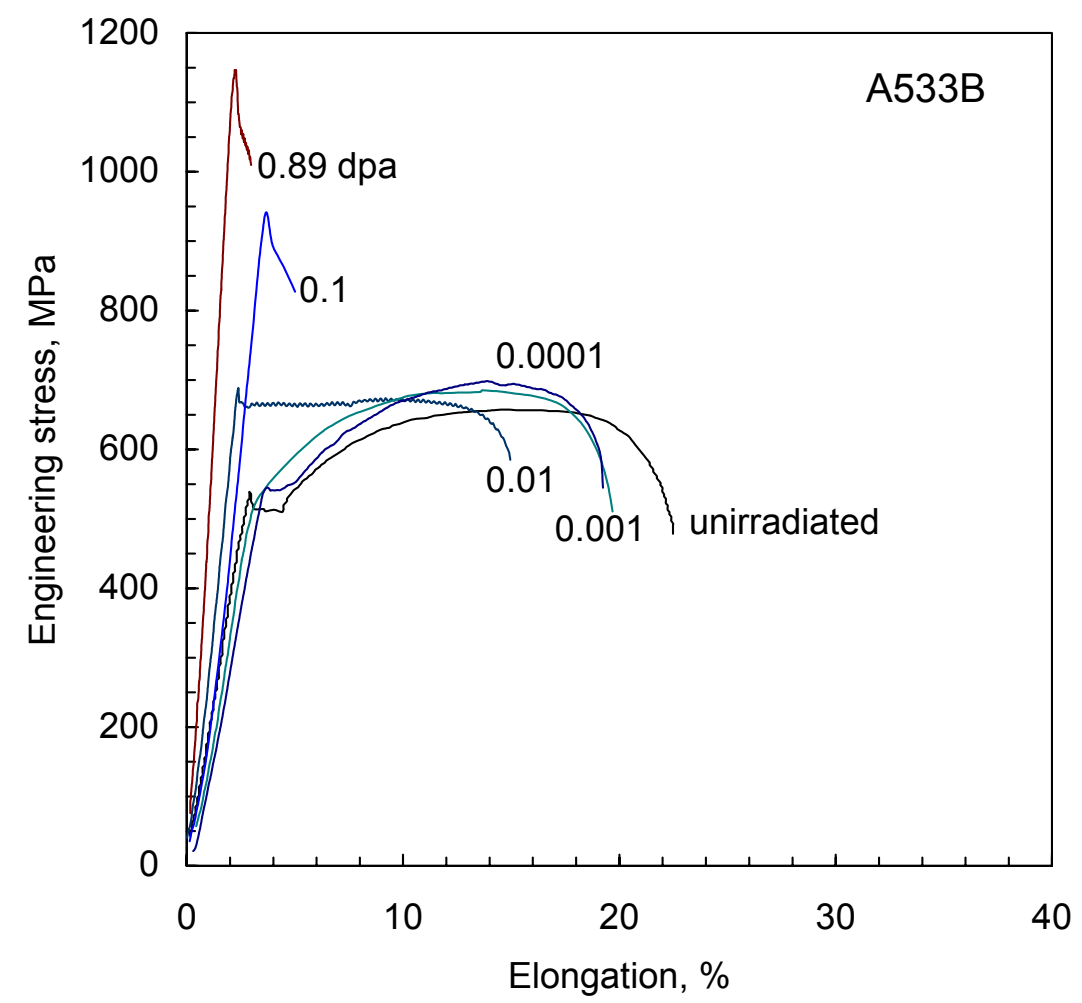

Fig. 7. Representative tensile test curves for A533B steel after different neutron exposures. 
The effects of neutron fluence on the tensile properties of the A533B ferritic pressure vessel steel are presented in Figs. 7 and 8. Fig. 7 contains example tensile test curves. The small wriggles on the curves are electronic noise signals and should be ignored. Also, the seeming increase in elastic modulus with dose is not real. It is a reflection of the 'slackness' of the loading system couplings under the very small loads required for straining the miniature specimens; the system stiffens as the load is increased. The yield point drop and the associated region of elongation at constant stress, known as the Lüders region, for the unirradiated specimen are real and are characteristic of a pressure vessel steel. In Fig. 8, UE is the uniform plastic strain or elongation, and STN is the strain-to-necking, which is a measure of the uniform strain when the work hardening rate in engineering stress units is close to zero. TE is the total elongation.

It can be seen from these figures that for the two lowest doses of 0.0001 and $0.001 \mathrm{dpa}$ there are small increases in yield strength (YS) and ultimate tensile stress (UTS), and small reductions in elongation. The increases in yield strength and UTS are about equal, which means that irradiation to these low doses did not alter the work hardening behavior. At the middle dose of $0.01 \mathrm{dpa}$, the increase in yield strength and decrease in elongation are more pronounced and the work hardening region is almost flat, the UTS being barely larger than the yield stress. Moreover, the UTS is about the same value, if not a little smaller, than the UTS values for the lower doses. For the two higher doses of 0.1 and $0.89 \mathrm{dpa}$, the UTS and yield strength are indistinguishable but are considerably higher than for the lower doses; prompt plastic instability occurs at yield, and elongations are severely curtailed. Concomitant with these pronounced increases in yield strength the work hardening behavior is radically impaired.

Work hardening, or strain hardening as it is alternatively known, is a characteristic of ductile metals in which the stress required to continue plastic deformation is raised asymptotically with increasing strain. It is caused by dislocations interacting with each other and with barriers. Such intermingling of dislocations is essential to maintain bulk plasticity. Without it, plastic deformation becomes localized and shear failure ensues at curtailed elongation. So reduced work hardening is an indicator of strain localization. A rough measure of work hardening rate expressed in engineering stress and strain units can be obtained from the average slope of the tensile curve in the range of the first few percent elongation. More formally, a work hardening exponent, $\mathrm{n}$, can be derived from the tensile flow curve assuming it follows a power law, often, $\sigma=K \varepsilon^{n}$, where $\sigma$ and $\varepsilon$ are true stress and true strain values. It can then be shown that $n$ is numerically equal to, or is proportional to, the strain at which necking occurs. Table 3 is a list of rough work hardening rates and $n$ values measured on all three materials for all doses. Both metrics show the same trend with increasing dose. In the A533B steel, the work hardening rate is around $2500 \mathrm{MPa}$ for the unirradiated material and for the two low dose irradiation levels, indicating that these low levels of irradiation have not altered the deformation behavior, and implying that strain localization is not involved. At the middle dose of $0.01 \mathrm{dpa}$, the work hardening rate is reduced markedly to $70 \mathrm{MPa}$, and at 0.1 and $0.89 \mathrm{dpa}$ it is strongly negative. A decreased value indicates that the deformation mode has changed and there is less resistance to slip, implying intervention of strain localization. A negative value indicates that strain is occurring under a falling stress; it results from the occurrence of gross necking. 

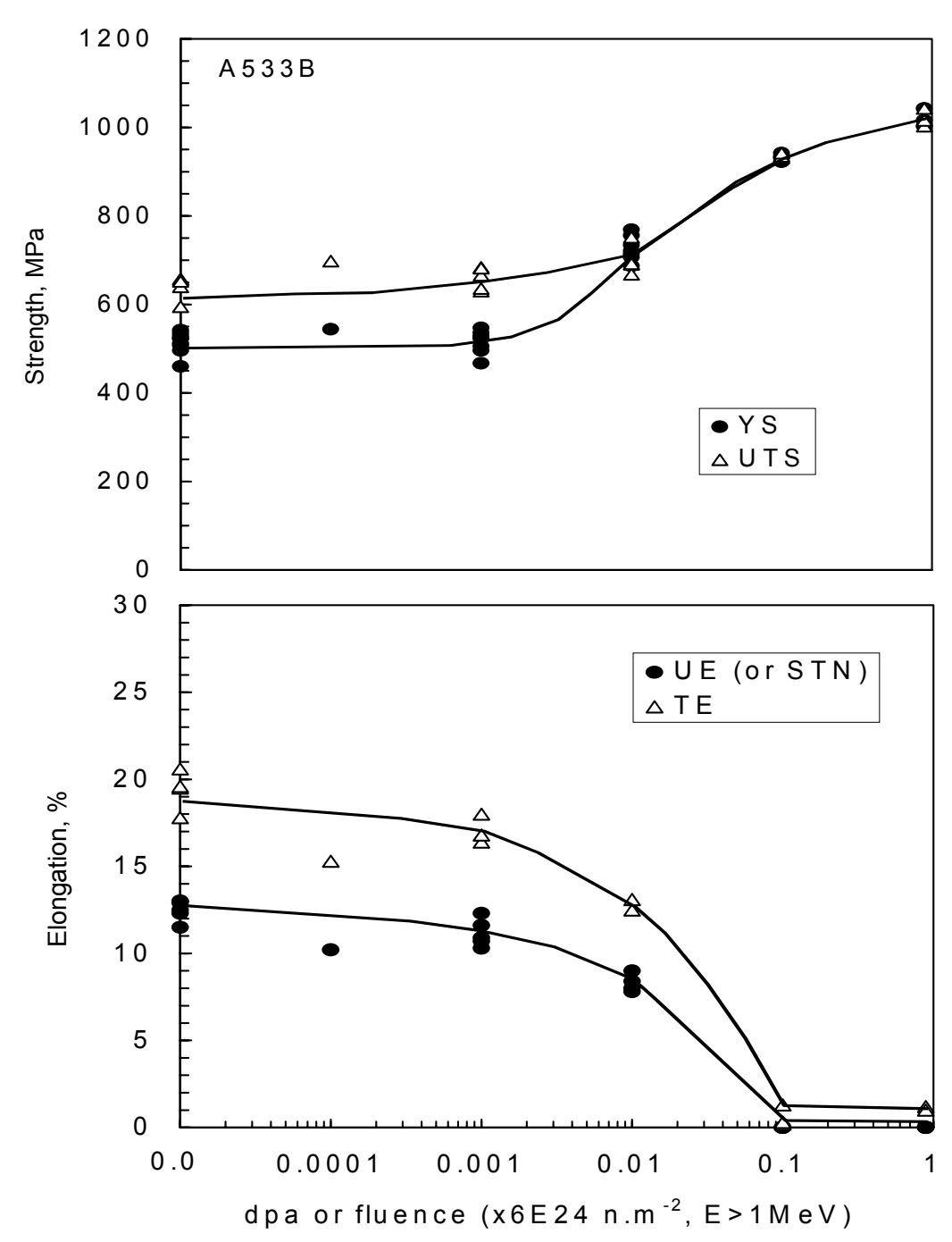

Fig. 8. Dose dependence of tensile properties of A533B steel.

Table 3. Average work hardening rates (MPa, engineering units) in the plastic strain range 0 to $5 \%$ elongation. Values of work hardening exponent, $n$, are shown in square brackets.

\begin{tabular}{|l|ll|ll|ll|}
\hline \multicolumn{1}{|c|}{ Nom.dpa } & \multicolumn{2}{|c|}{ A533B } & \multicolumn{2}{c|}{ Zr-4 } & \multicolumn{2}{c|}{$316 \mathrm{SS}$} \\
\hline \hline 0 & 2220 & {$[.08]$} & 760 & {$[0.06]$} & 1520 & {$[0.25]$} \\
\hline 0.0001 & 2700 & {$[.08]$} & 980 & {$[0.06]$} & 1660 & {$[0.25]$} \\
\hline 0.001 & 2380 & {$[.09]$} & 680 & {$[0.05]$} & 1770 & {$[0.20]$} \\
\hline 0.01 & 70 & {$[0.015]$} & -120 & {$[0.011]$} & 1550 & {$[0.14]$} \\
\hline 0.1 & -6470 & & -440 & & 1160 & {$[0.11]$} \\
\hline 0.8 & -12300 & -1120 & 760 & {$[0.09]$} \\
\hline
\end{tabular}


In the present case, necking occurs prematurely in the form of prompt strain localization and plastic instability failure at the yield stress. If analyzed in terms of true stress-true strain units, a negative engineering work hardening rate corresponds to a small, positive true engineering work hardening rate. The work hardening rate in Zircaloy- 4 is low because of its fewer slip systems; it falls markedly at a dose of $0.01 \mathrm{dpa}$, like in the A533B steel. The 316 steel is different. It shows no abrupt decline at $0.01 \mathrm{dpa}$, and only relatively small reductions at higher doses.

With regard to deformation microstructures in the deformed specimens, the mode of deformation appeared to be multiple slip and dislocation tangling in the unirradiated A533B specimens and in the two lower dose specimens, Figs. 9(a) and 9(b). For 0.01 dpa the deformation mode was still predominantly dislocation tangles. At doses of 0.1 and $0.89 \mathrm{dpa}$, where large increases in yield stresses accompanied by prompt plastic instability failures were found, it was difficult to characterize the deformation mode because the strain was so strongly localized that most of the TEM sections cut from the gauge length contained almost no evidence of deformation, and those pieces taken from the fracture region were of unsuitable shape for electrothinning. Hence, although a few dislocation channels were observed they were insufficient for statistical analysis. Several channels are shown in Figs. 9(c) and 9(d). They are about 40nm wide. The channels pass undeflected through the laths but change direction at the bainite packet boundaries.

The deformation mode map derived for A533B steel from these observations is shown in Fig. 10. 

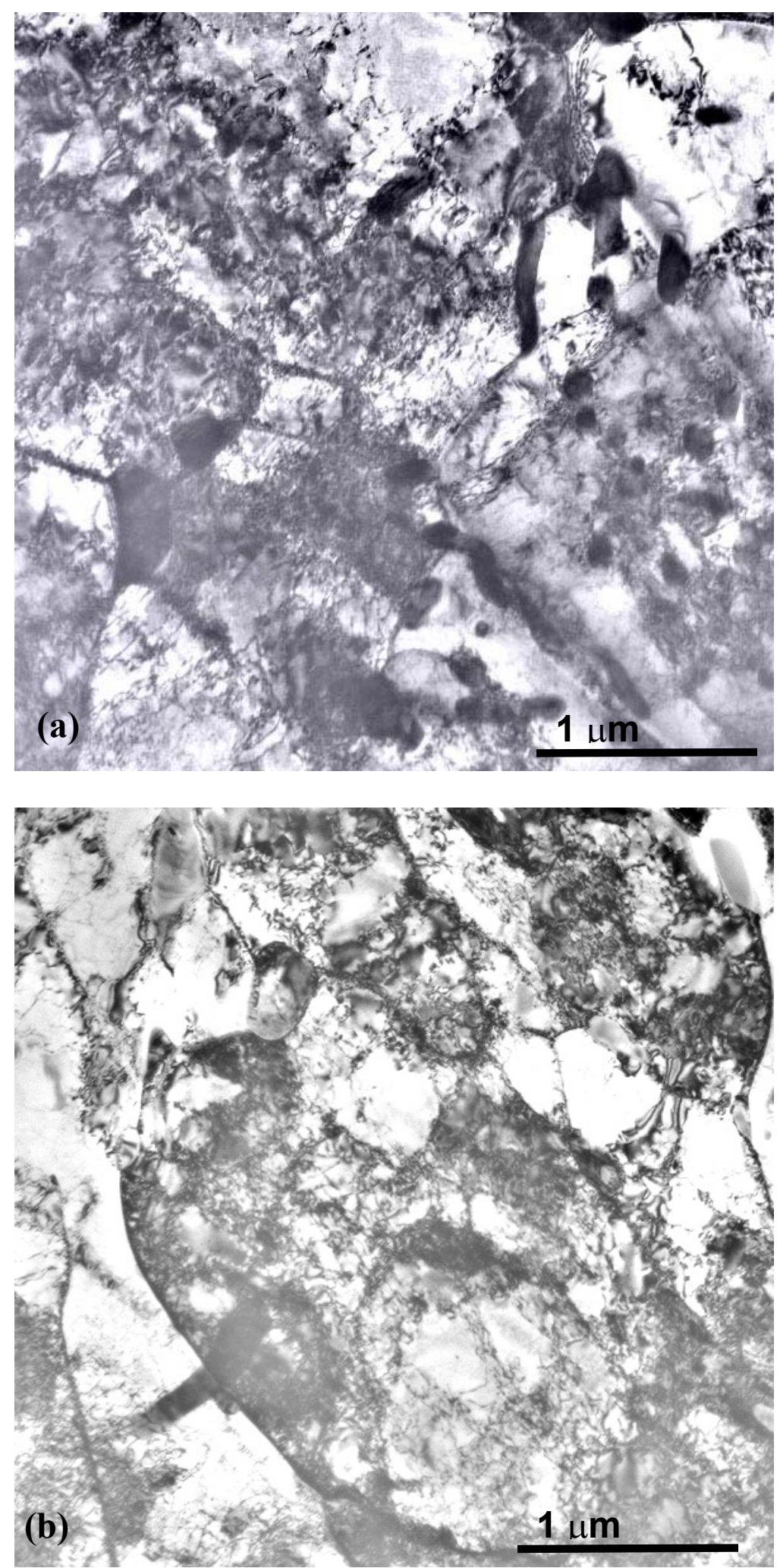

Fig. 9. Deformation structure of unirradiated A533B steel and low dose specimens: (a) at 0.001 dpa after 5\% strain, (b) at 0.01 dpa after 10\% strain. 

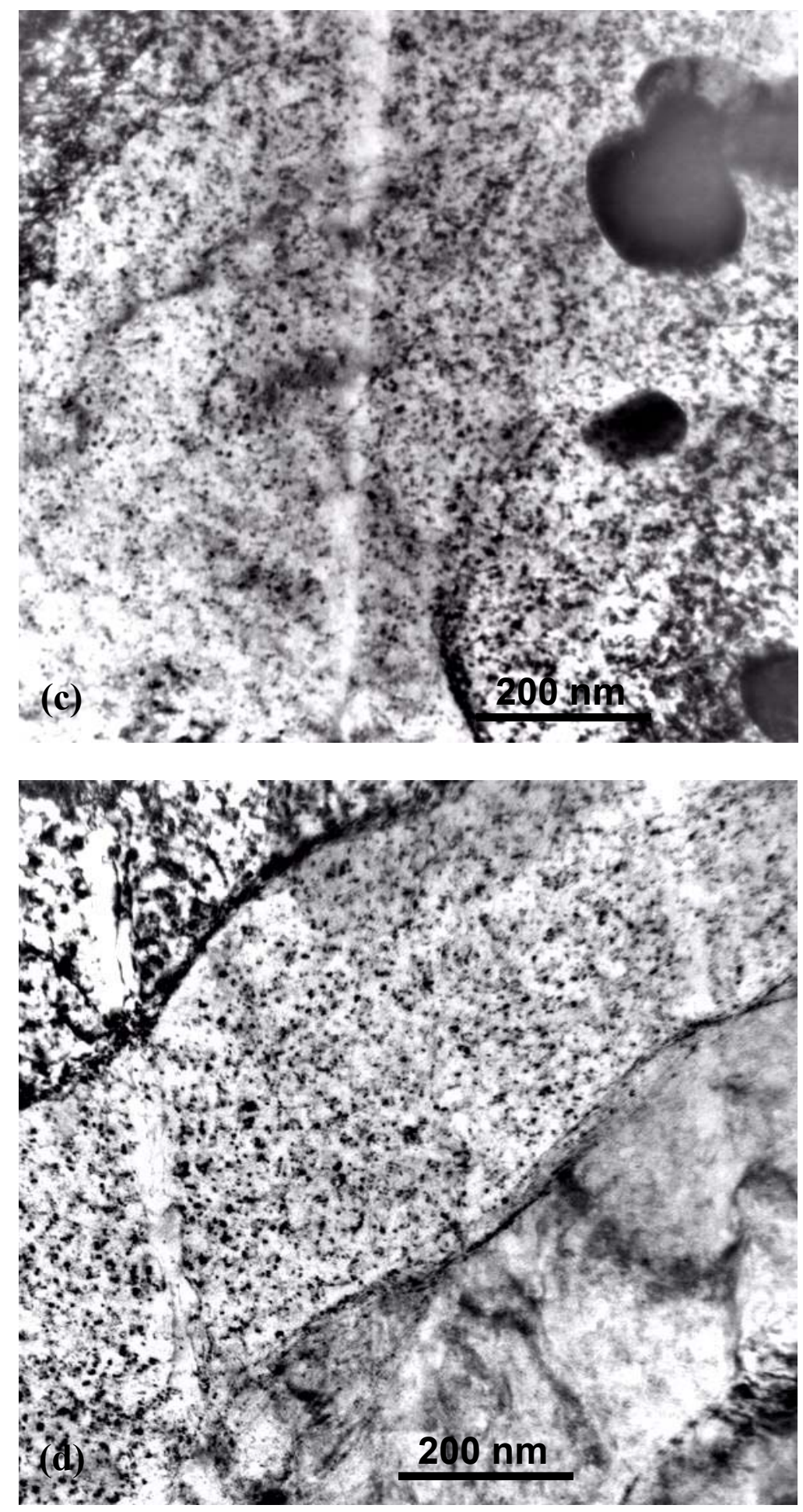

Fig. 9 (continued). Dislocation channels in A533B steel irradiated to 0.89 dpa and strained to $2 \%:$ (c) and (d) from different places. 


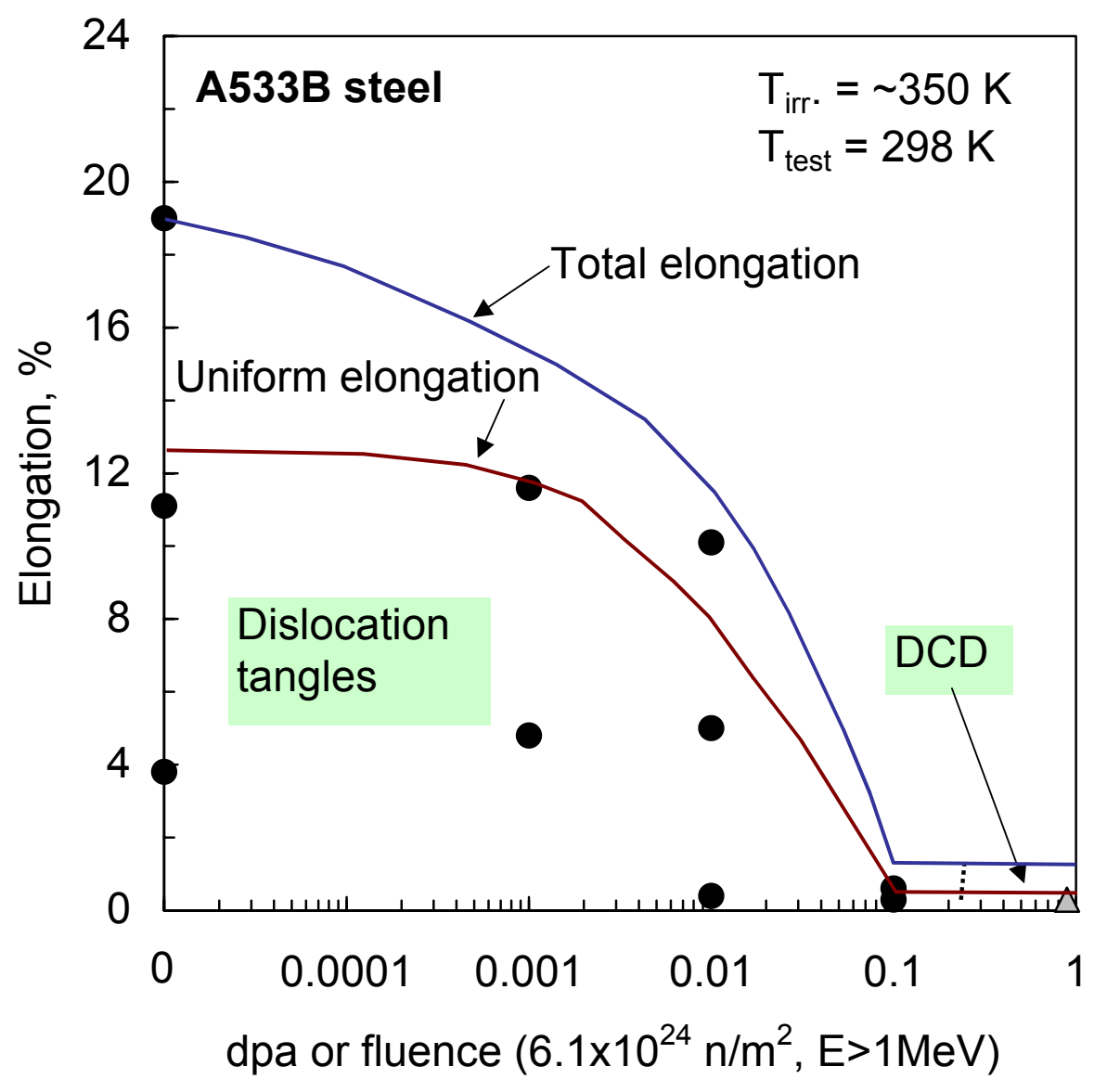

Fig. 10. Deformation mode map for A533B steel neutron-irradiated at $65-100^{\circ} \mathrm{C}$ and tested at room temperature. 


\subsection{Zircaloy-4}

The microstructure of unirradiated Zircaloy-4 consisted of equiaxed grains free of dislocations. In the as-irradiated specimens no RDS was found at a dose of $0.00009 \mathrm{dpa}$. At $0.0009 \mathrm{dpa}$, fine black spots were just discernable at a concentration of about $1.1 \times 10^{22} \mathrm{~m}^{-3}$ and mean size of 1.2 $\mathrm{nm}$. At the highest dose, $0.8 \mathrm{dpa}$, black spot damage was quite evident at a concentration of $6.1 \mathrm{x}$ $10^{22} \mathrm{~m}^{-3}$ and mean size $1.4 \mathrm{~nm}$. A bar graph of the size distribution for $0.8 \mathrm{dpa}$ is given in Fig. 11.

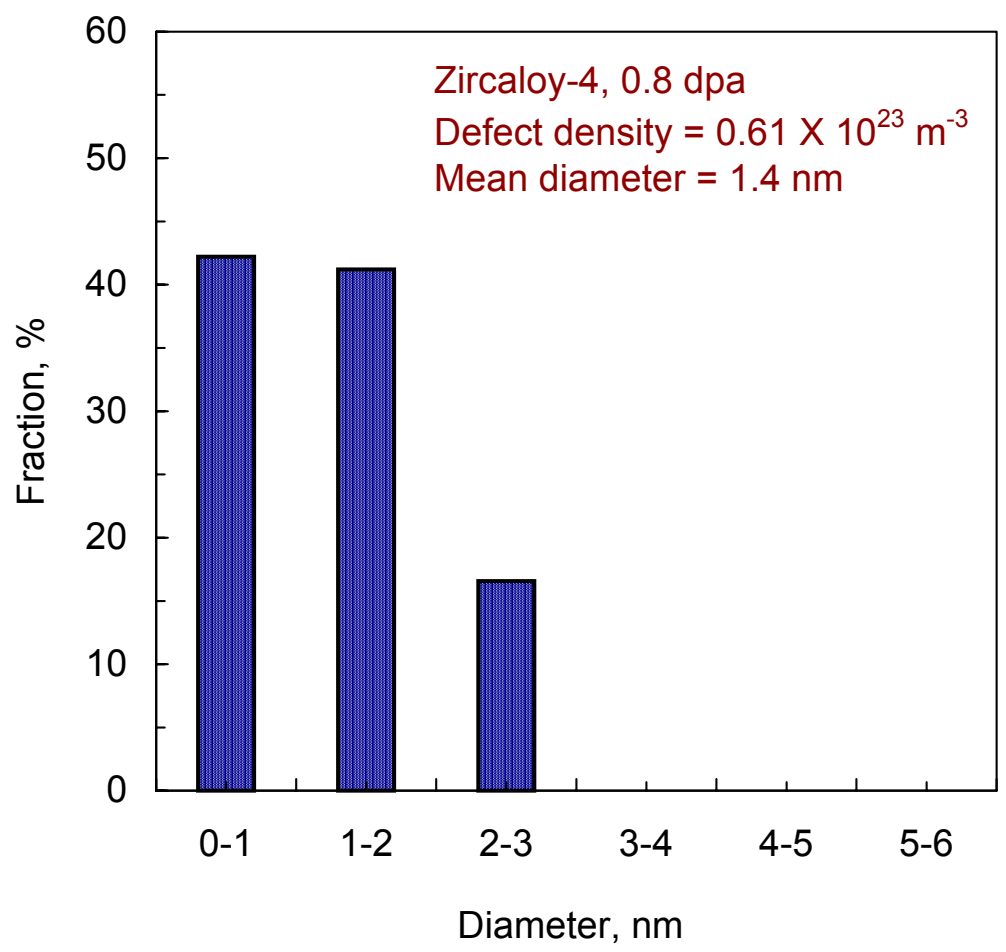

Fig. 11. Size distribution of black spot RDS in Zircaloy-4 irradiated to $0.8 \mathrm{dpa}$.

Fig. 12 displays typical tensile test curves for Zircaloy-4. Characteristically, annealed unirradiated Zircaloy-4 does not display a yield point drop, and none are found in the unirradiated specimens and in those irradiated to low doses of 0.00009 and $0.0009 \mathrm{dpa}$. These low doses raise the yield stress and UTS but do not alter the work hardening rate. The work hardening rate, Table 3, for unirradiated Zircaloy-4 is $760 \mathrm{MPa}$ and is $680-980 \mathrm{MPa}$ for the low dose irradiations. At a dose of $0.009 \mathrm{dpa}$, the increase in yield stress is much larger than at the lower doses and a weak yield point drop is seen; the work hardening rate is negative but necking to failure is not immediate, it is extended over elongations of almost $20 \%$. Several small bumps in the curve suggest that several necks dispersed along the gauge length were involved. The curve for the 0.09 dpa dose is very similar to that for 0.009 dpa except for a higher yield stress and a much stronger yield point drop. Again, necking is drawn out over about $20 \%$ elongation and there are several bumps in the necking part of the curve. For the highest dose of $0.8 \mathrm{dpa}$, a yield point drop is prominent; necking is diffuse but is without bumps. 
The changes in tensile properties of Zircaloy-4 with dose are plotted in Fig. 13. After plastic

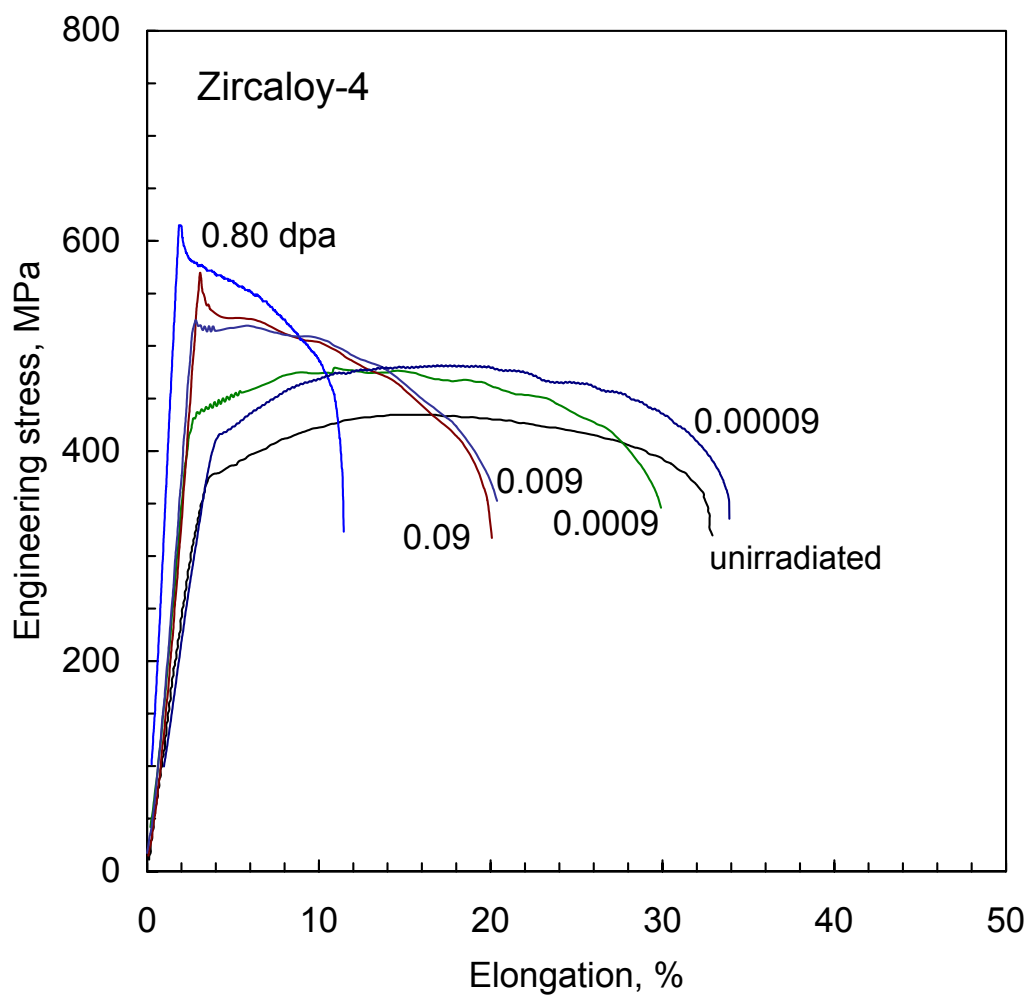

Fig. 12. Tensile test curves for Zircaloy-4.

deformation, the unirradiated specimens and the two lower dose specimens of Zircaloy-4 contain widely-spaced bands of elongated dislocations lying mainly in the $\{0001\}<11 \overline{2} 0>$ slip system, with a small amount in $\{10 \overline{1} 1\}<11 \overline{2} 0>$, Fig. 14 . No DCD is found. In the 0.009 dpa specimens, the strain dislocations are still in widely-separated bands but now the second, $\{10 \overline{1} 1\}<11 \overline{2} 0>$ system, is more strongly involved. The dislocations in the major slip bands are lying in channels, Fig. 15 (a), seen as white bands by slightly tilting the specimen to put the contained dislocations out of contrast, Fig. 15 (b). The channel edges are not sharp, and the channel contrast is not strong, suggesting that there are remnants of RDS in them. Channel widths varied from barely perceptible lines to about $100 \mathrm{~nm}$. The spacing between the wider channels was roughly $500 \mathrm{~nm}$, and the narrower channels were contained between them. Assuming the larger channels to be created first, their presence obviously did not inhibit the formation of new channels.

At 0.09 dpa and $0.8 \mathrm{dpa}$, the dislocation channels were much more obvious, Fig. 16. Within individual grains there tended to be only one slip system, and cross channels were rare. The major channels were uniformly $40-75 \mathrm{~nm}$ wide and were spaced at $400-1100 \mathrm{~nm}$. Between the major channels were relatively few narrow ones, $<30 \mathrm{~nm}$ wide.

The deformation mode map derived for annealed Zircaloy- 4 from these observations is shown in Fig. 17. 

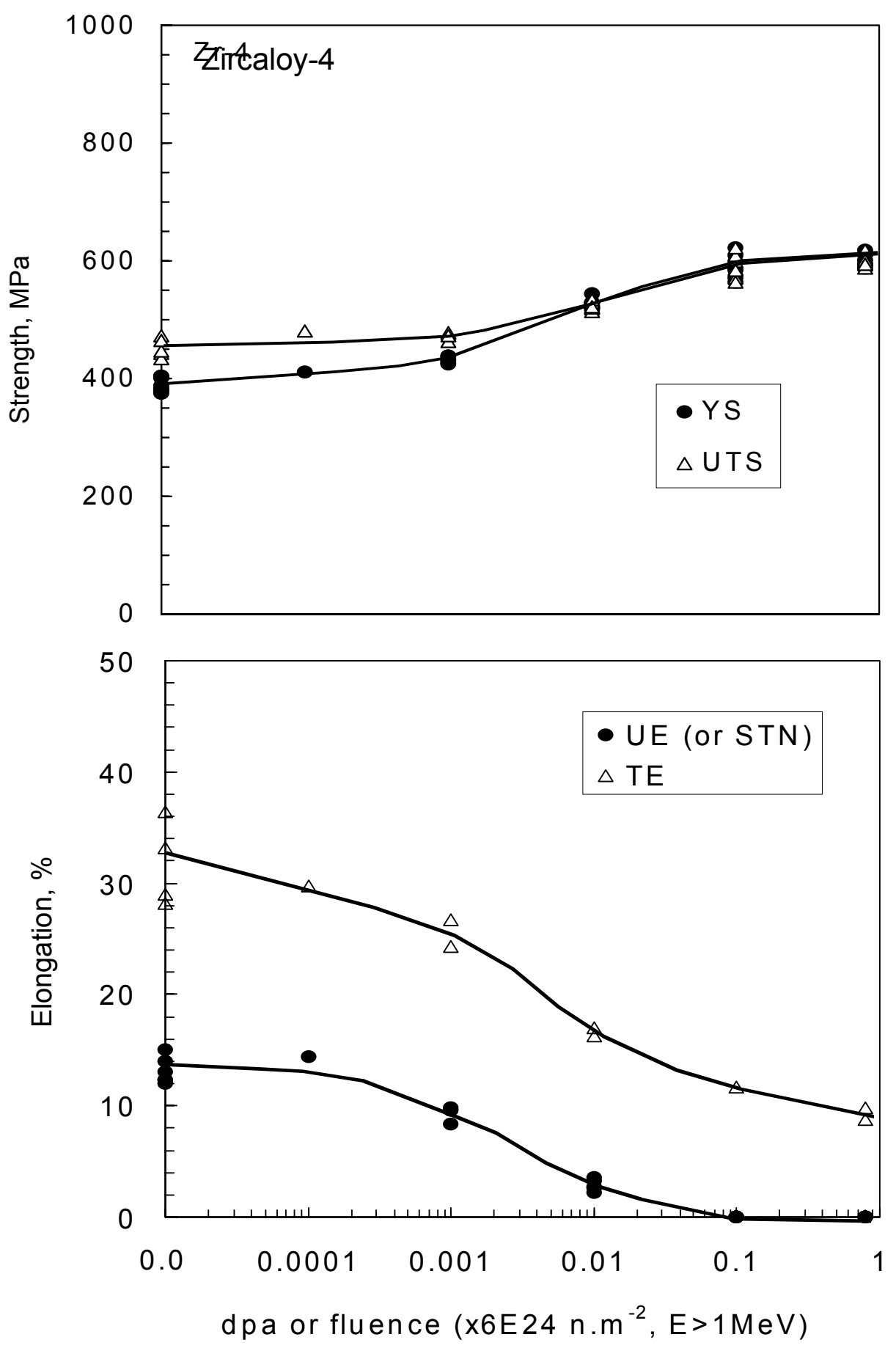

Fig. 13. Dose dependence of tensile properties of neutron irradiated Zircaloy-4. 


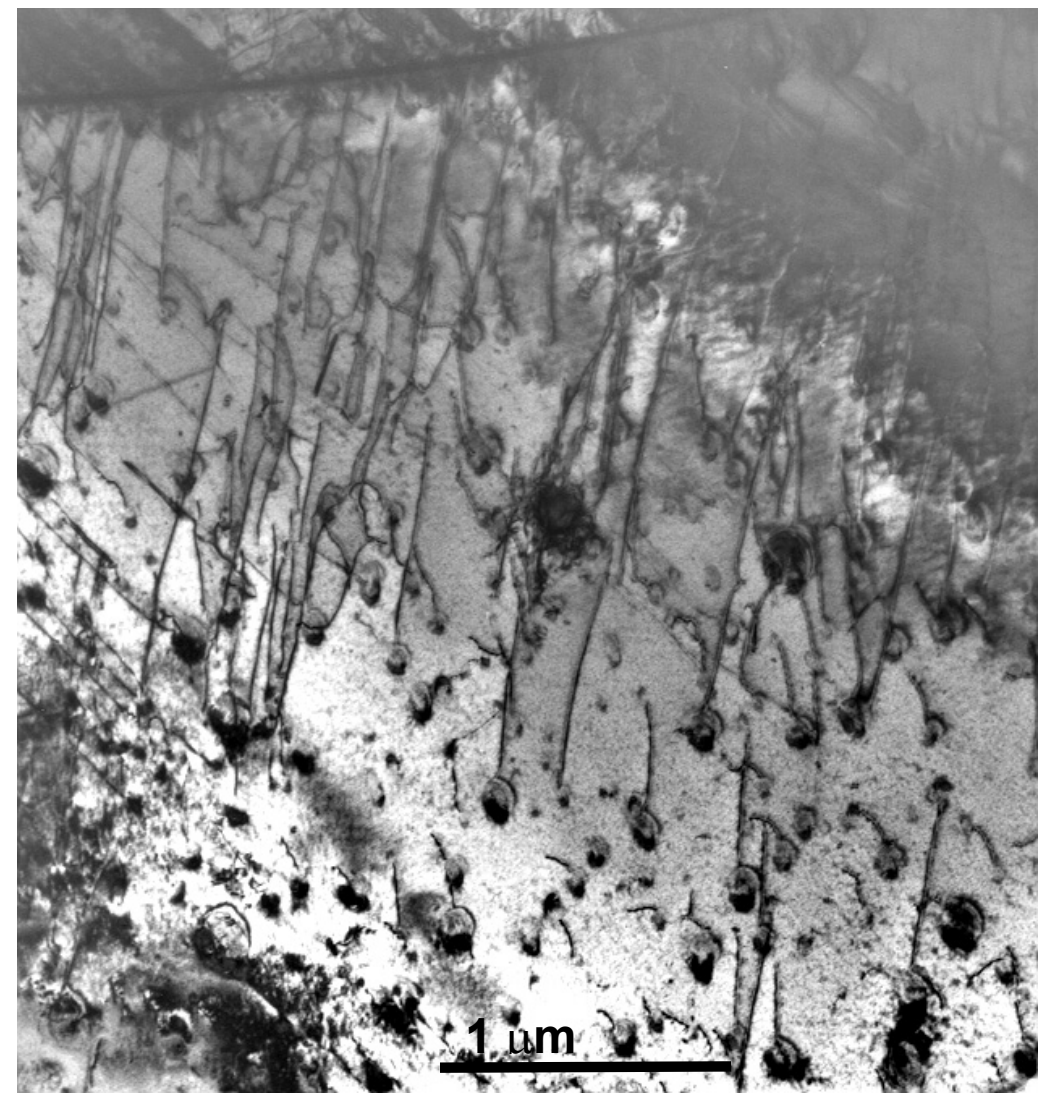

Fig. 14. Typical dislocation structure in unirradiated, deformed Zircaloy-4; at 3\% strain. 

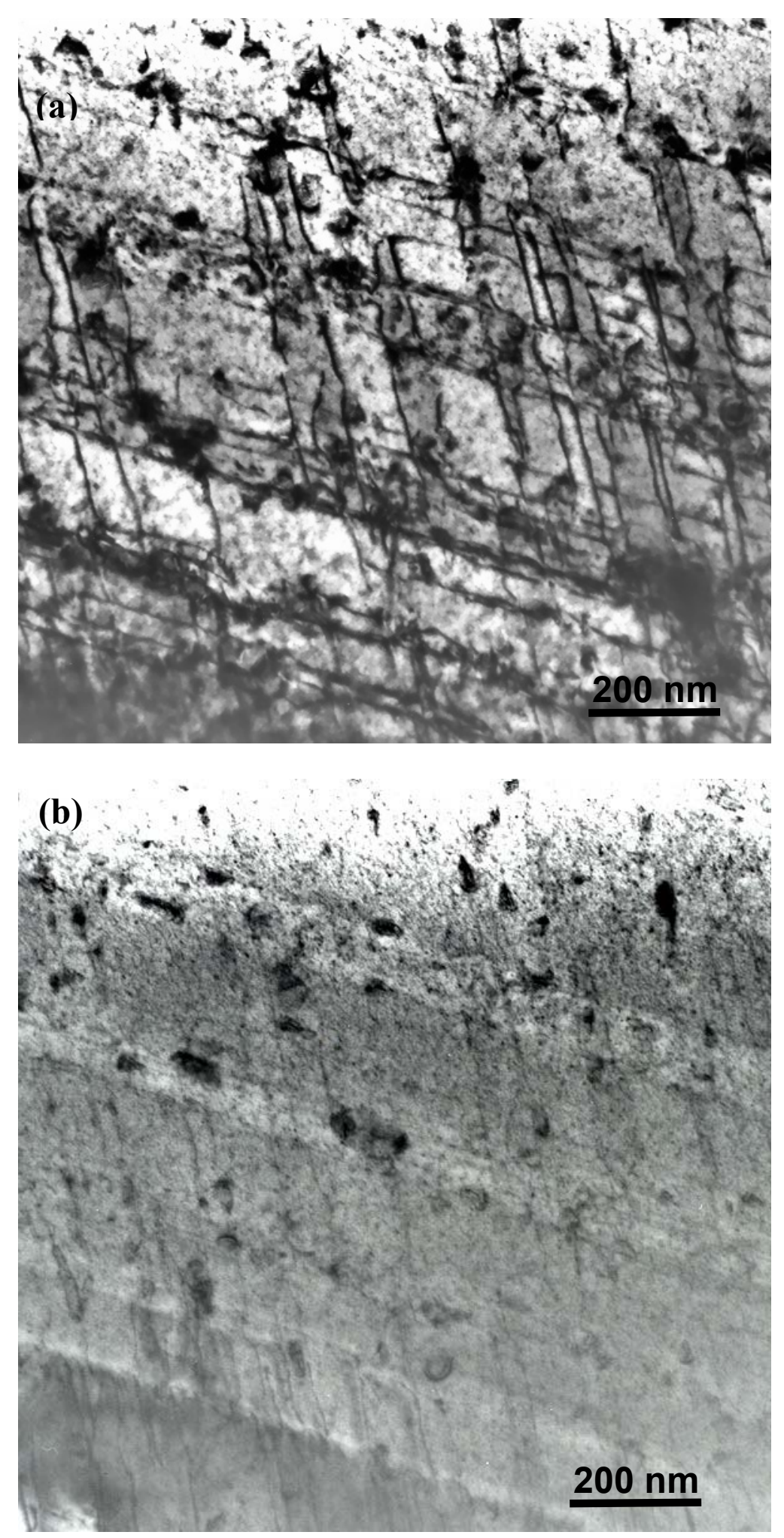

Fig. 15. Dislocation arrays in channels in Zircaloy-4 irradiated to 0.009 dpa and strained 4.8\%; (b) is slightly tilted from (a) to reveal the channels. 


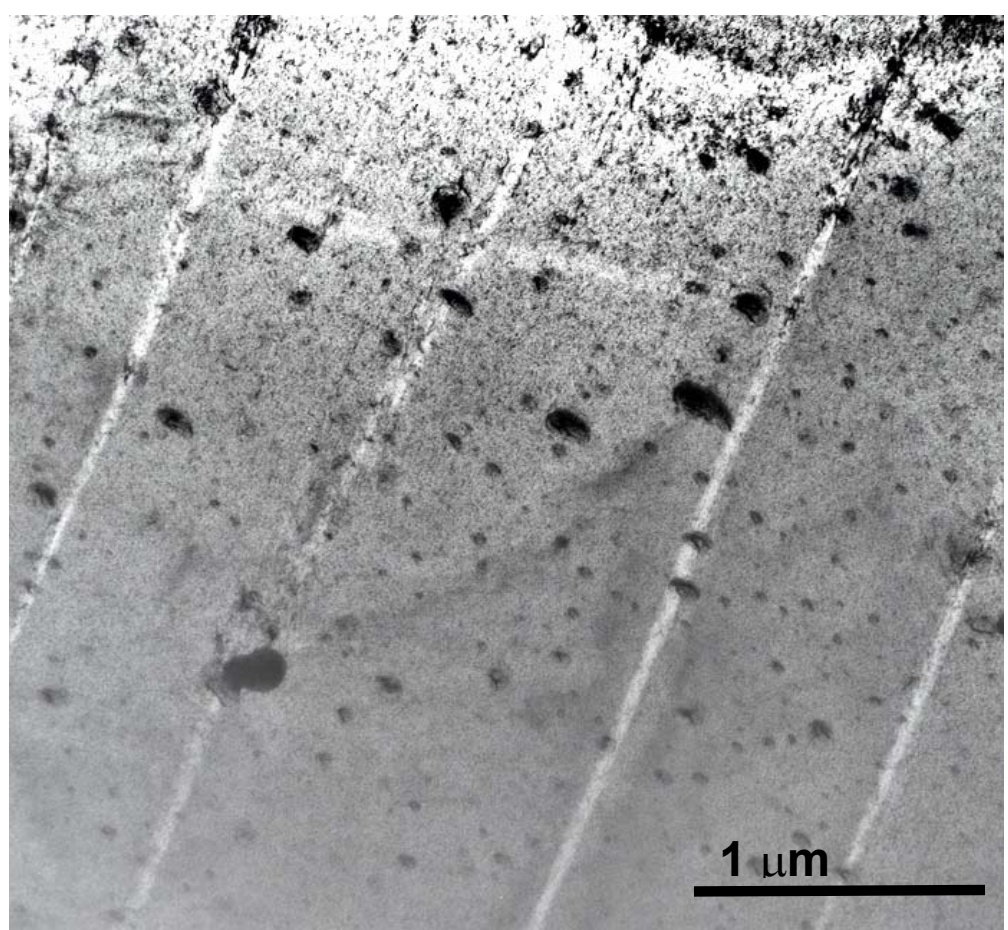

Fig. 16. Dislocation channels in Zircaloy-4 irradiated to 0.8 dpa and strained $6.3 \%$.

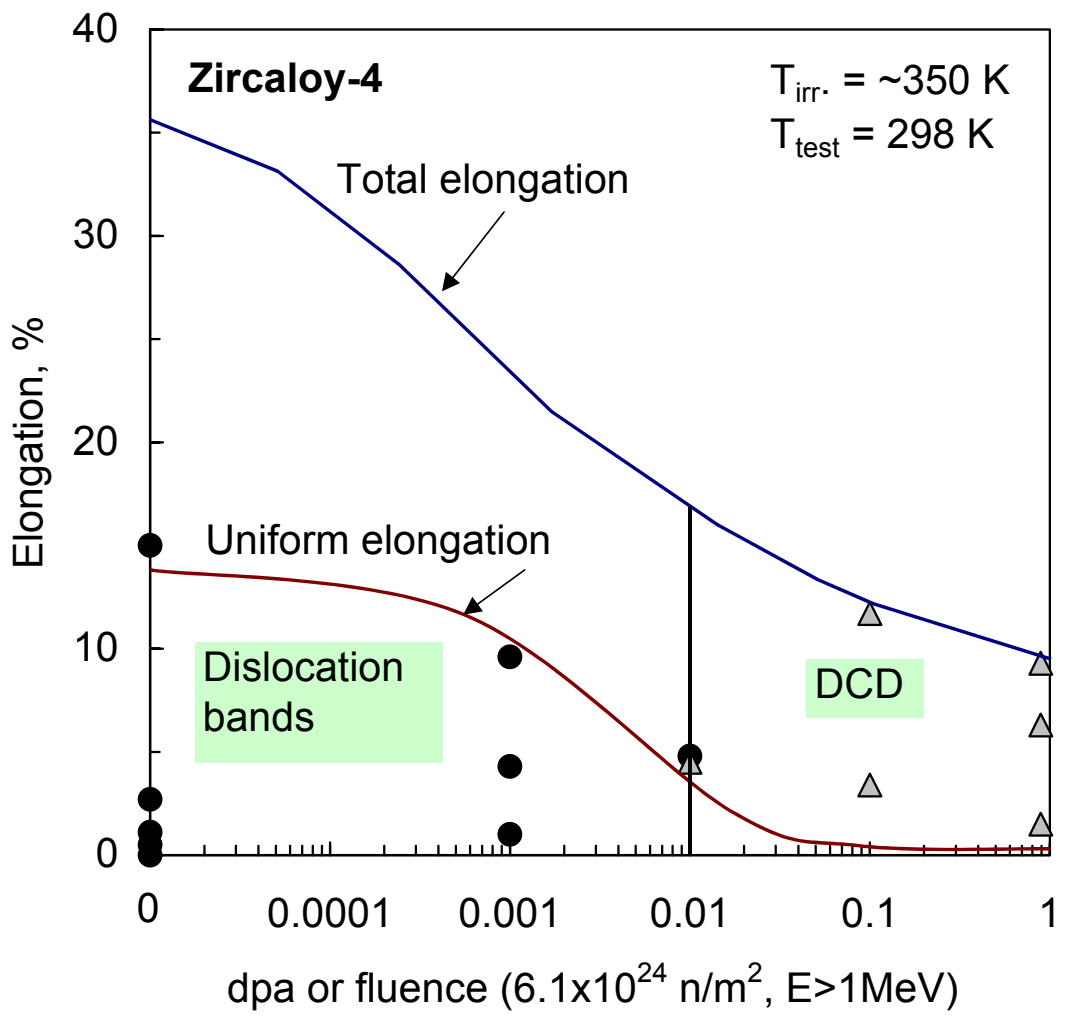

Fig. 17. Deformation mode map for Zircaloy-4 neutron-irradiated at $65-100^{\circ} \mathrm{C}$ and tested at room temperature. 


\subsection{Austenitic stainless steel}

In its unirradiated condition, the microstructure of as-annealed 316 steel consists of equiaxed grains containing some large annealing twins. The annealing twins are a consequence of the low stacking fault energy of austenitic steel. Irradiation to a dose of 0.0001 dpa did not reveal any RDS. For all other doses, black spot RDS was clearly evident. Figs. 18(a) - 18(d) show the defect size distributions. The mean size of the clusters varies little with dose and is about $1.6 \mathrm{~nm}$. Cluster concentrations are of order $1 \times 10^{23} \mathrm{~m}^{-3}$ and they increase by a factor of about 5 over the dose range 0.001 to $0.8 \mathrm{dpa}$.

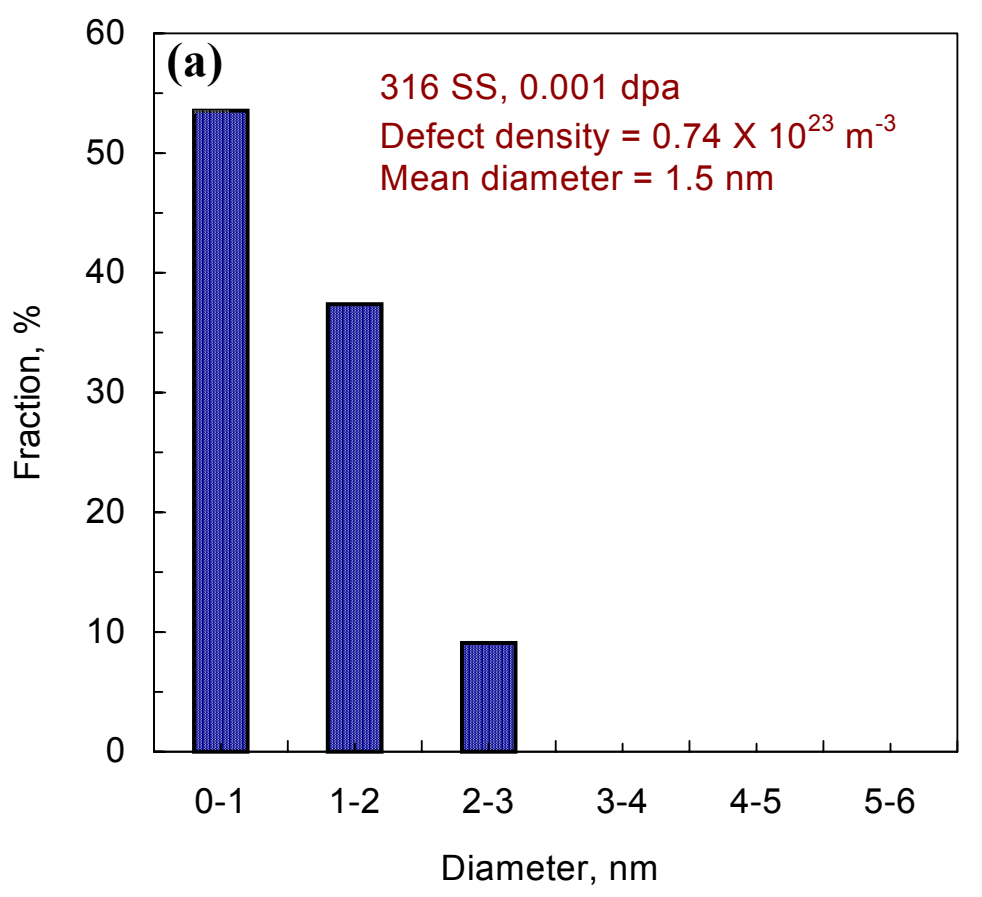

Fig. 18. Size distributions of black spot RDS in 316 stainless steel after irradiation to (a) 0.001, (b) 0.01 , (c) 0.17 , and (d) $0.78 \mathrm{dpa}$. 

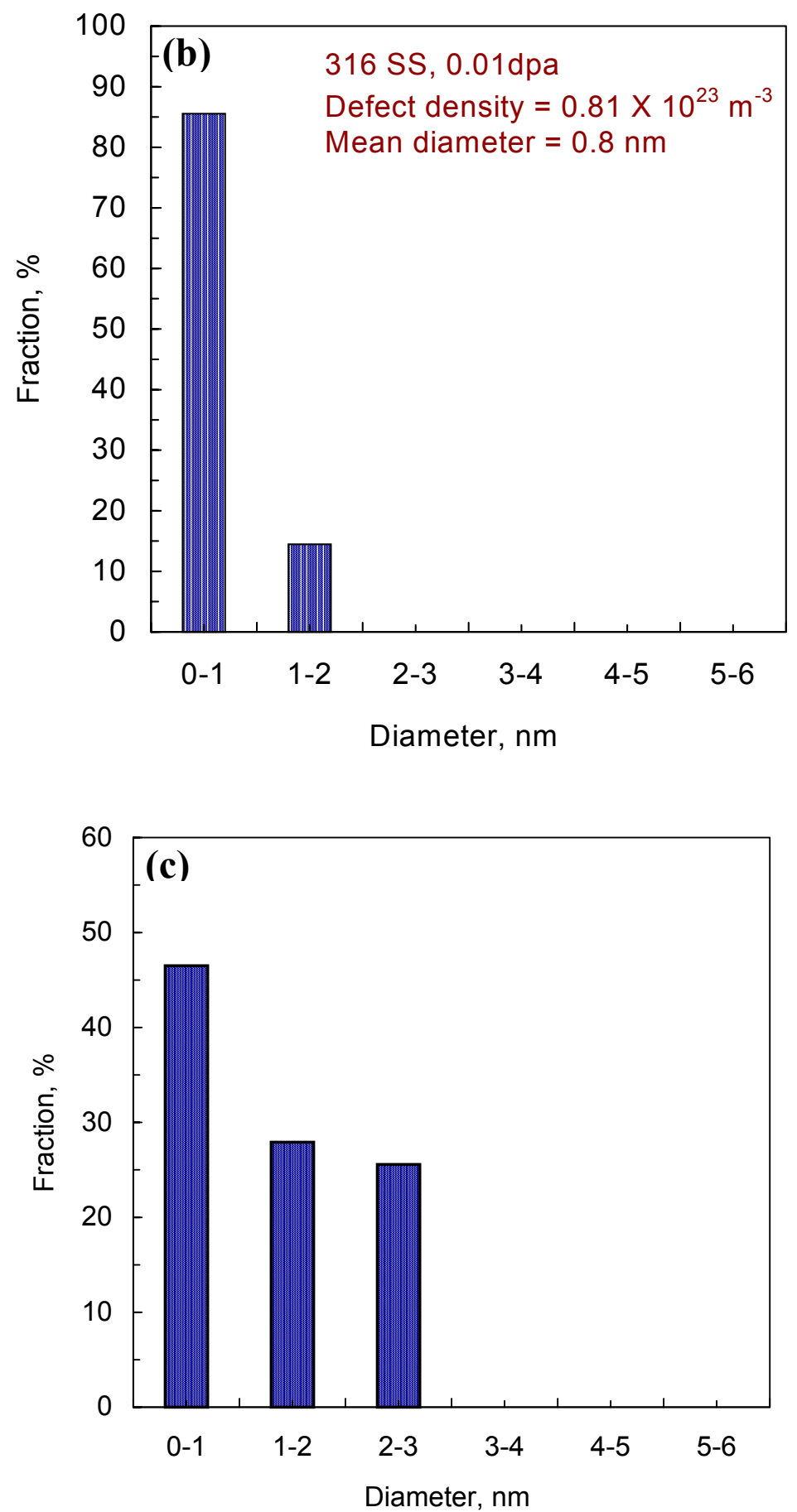

Fig. 18. (continued) 


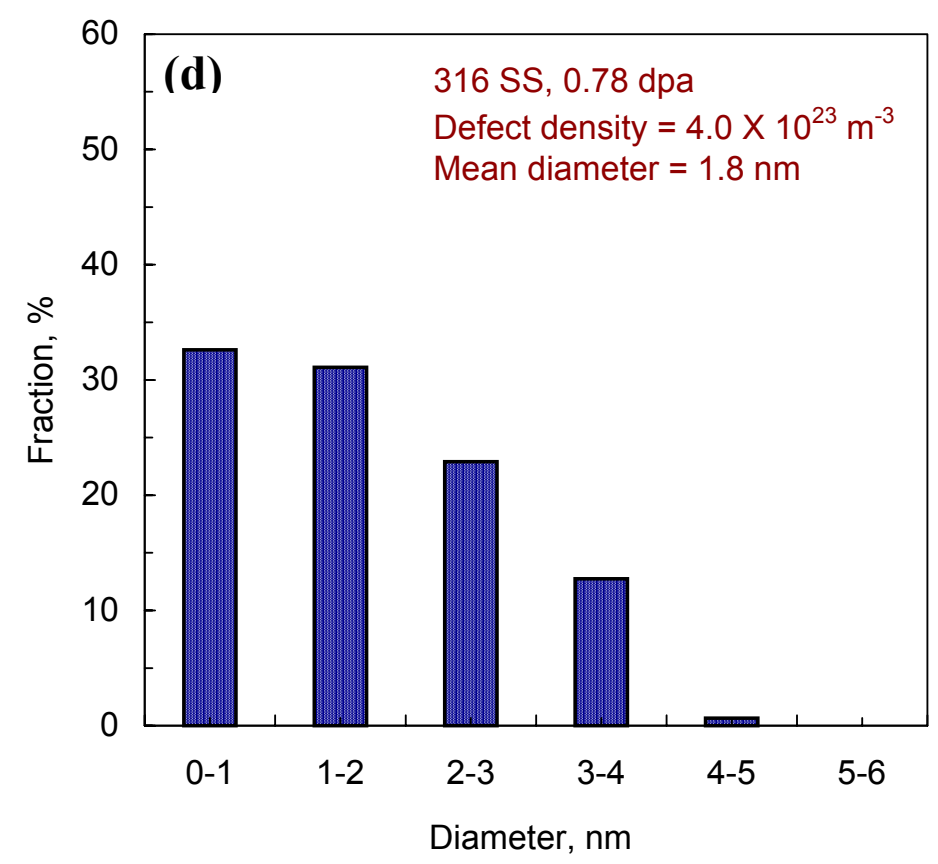

Fig. 18. (continued)

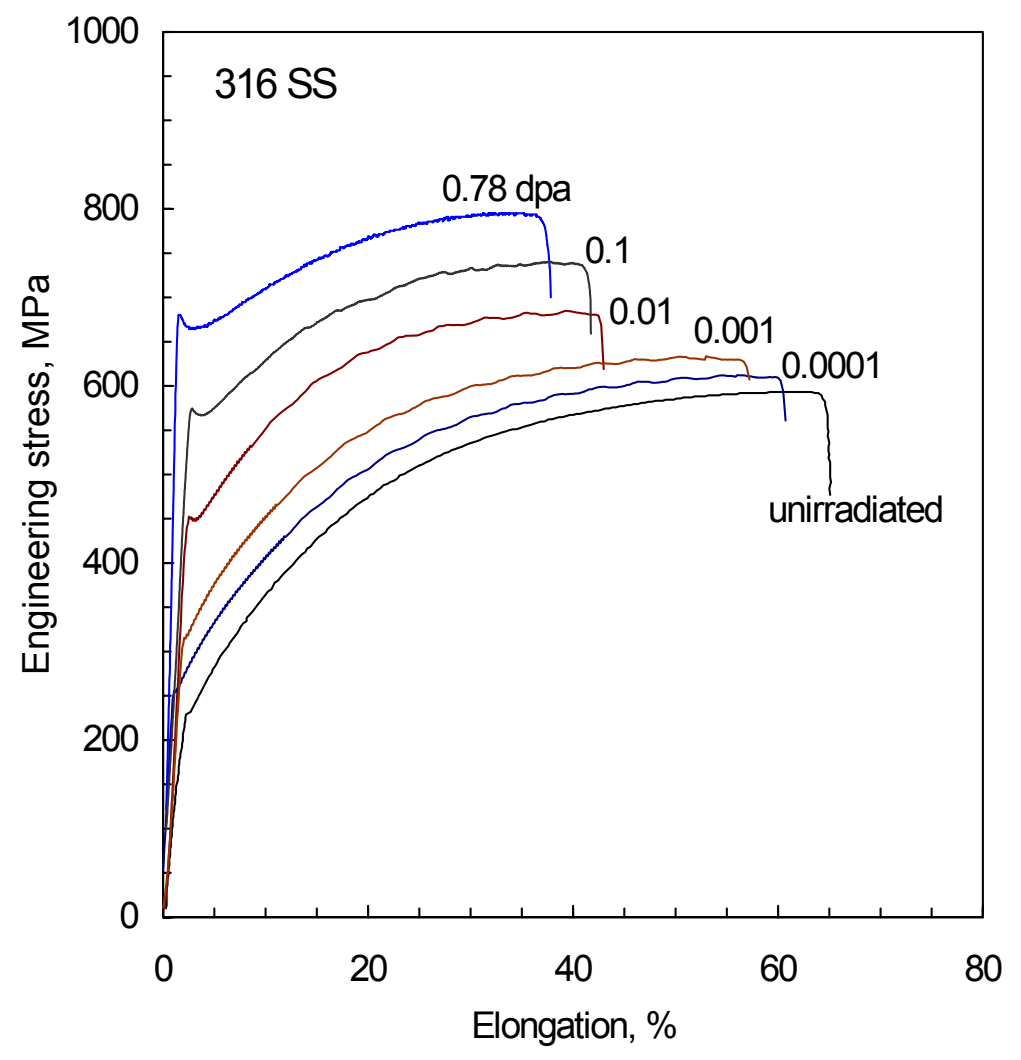

Fig. 19. Representative tensile curves for 316 stainless steel. 
Tensile test curves for the annealed 316 austenitic stainless steel specimens are displayed in Fig. 19. The curves are very similar to those reported for 304, 316, and 347 stainless steel irradiated elsewhere at $\sim 50^{\circ} \mathrm{C}$ to similar doses with larger specimens [14]. In all these stainless steels, there is no yield point drop in the unirradiated materials and in those irradiated to the lower fluences. A yield point drop is introduced at an exposure of about $6 \times 10^{22}$ n.m ${ }^{-2}(\sim 0.01 \mathrm{dpa})$ and it increases in size with increasing dose. The present 316 steel behaves in the same way. There is a small yield inflection but no yield point drop in the unirradiated material and at the two lower fluences. The yield stress is raised a little by the irradiation but there is not much effect on the work hardening rate which remains around $1600 \mathrm{MPa}$, Table 3. This rate is less than for A533B steel and more than for $\mathrm{Zr}-4$. At the middle dose of $0.01 \mathrm{dpa}$, there is little change in work hardening rate in the stainless steel, contrary to the large decreases seen in the A533B steel and the $\mathrm{Zr}-4$, Table 3. At the two highest doses the rate is reduced for the 316 steel, but not to the severe extents observed in the other two materials. There is no negative work hardening and no prompt plastic instability failure in the stainless steel, even at the highest dose.

The dose dependence of the tensile properties is given in Fig. 20. For the low dose irradiations, the yield strength is raised a little and there are small decreases in elongation. At the higher doses, there is substantial increase in yield strength. However, the elongation suffers only relatively mild loss, in sharp contrast to the large ductility losses seen in the A533B steel and the Zircaloy-4.

With regard to deformation mode, the unirradiated 316 steel deforms by slip on $\{111\}<110>$ systems. At low strains of $1 \%$ or so, the dislocations are primarily in planar arrays, Fig. 21 . Short lengths of stacking fault fringes are frequently visible in the dislocations. As the strain level increases the arrays thicken into bands on $\{111\}<110>$, and random, tangled dislocations appear in the matrix between the bands. With increasing strain, the slip bands became more pronounced and at about 5\% elongation, the appearance of streaks in electron diffraction patterns indicated the occurrence of fine twins. Dark field illumination using the twin streaks placed the fine twins in the slip bands. Such fine deformation twins are believed to be created by overlapping of the stacking faults of extended dislocations on consecutive slip planes in the slip bands, as described in Refs. C34-C36. At high strains of 50\% or so, the twins are very evident, Fig. 22.

After irradiation to the two lower doses, no change in deformation mode was observed. At doses up to $0.01 \mathrm{dpa}$, there was still no appreciable distinction between the deformation modes for unirradiated and irradiated specimens. Even at the higher doses there is no radical change in deformation mode; rather, the nature of the deformation remains the same but the degree of damage is altered subtly. Twins show up in the dislocation bands at lower strains than in the unirradiated specimens. At a dose of about $0.1 \mathrm{dpa}$, the dislocation bands are replaced by narrow channels in which the RDS has been largely erased, Fig. 23. Most of the channels contain deformation twins and some glide dislocations, but a small portion of the channels seem to be clear of all structure no matter how much the TEM specimen is tilted in attempts to reveal features in the channels. Offsets are seen at channel intersections, and there is substantial dislocation activity at the junctions. Furthermore, some of the clear channels are curved, departing at an angle of about $7.5^{\circ}$ from the major channels. Numerous short cross channels, like ladder rungs, connect the major channels. There are tangled dislocations in the spaces between 
the channels, and their presence does not seem to have affected the black spot RDS there. Many of the channels are present in the earliest stages of straining, and they proliferate with strain. Large stacking faults and twins are present in the channels even at low strain levels. At the highest dose of $0.79 \mathrm{dpa}$, the channels carve the deformation microstructure into subdivided tetrahedral blocks, Fig. 24.
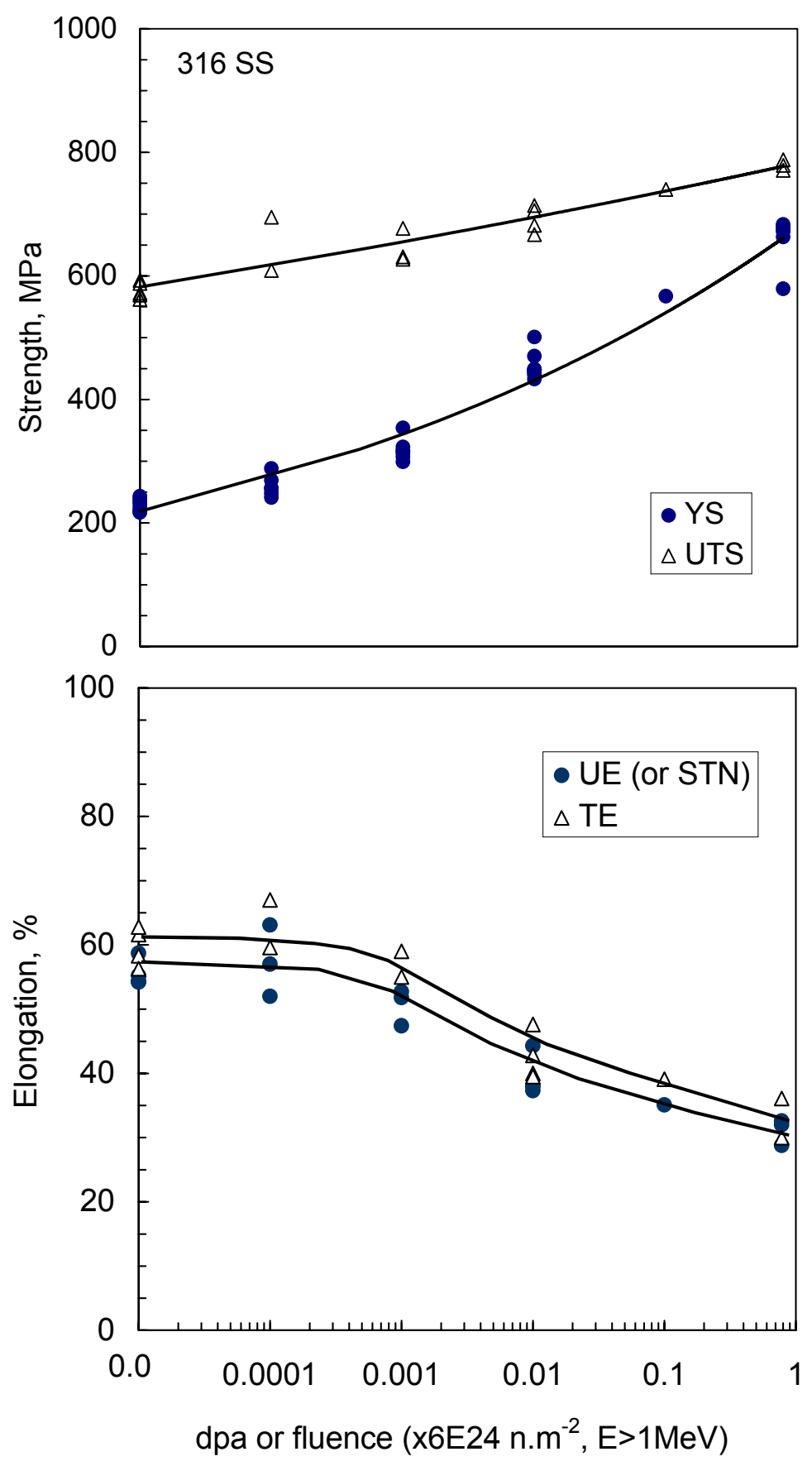

Fig. 20. Fluence dependence of the tensile properties of annealed 316 stainless steel. 


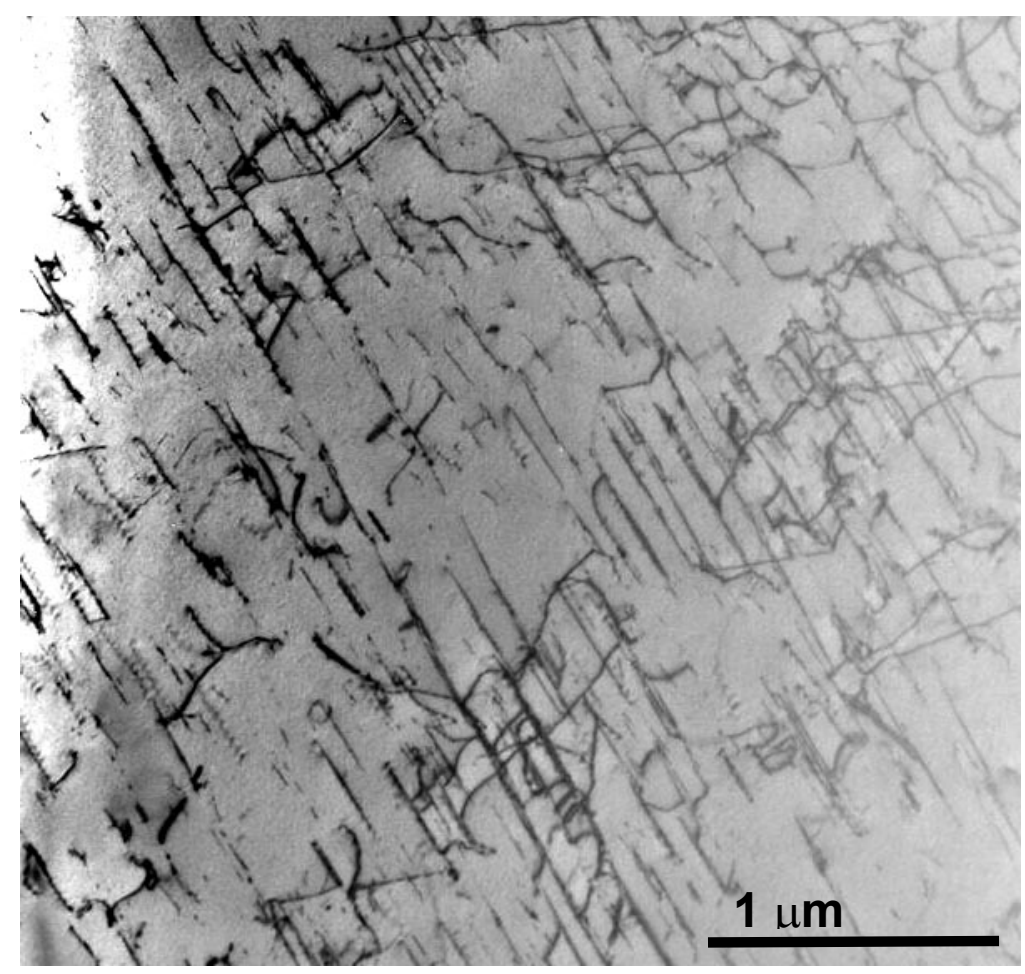

Fig. 21. Planar deformation in unirradiated stainless steel strained 1.5\% at room temperature.

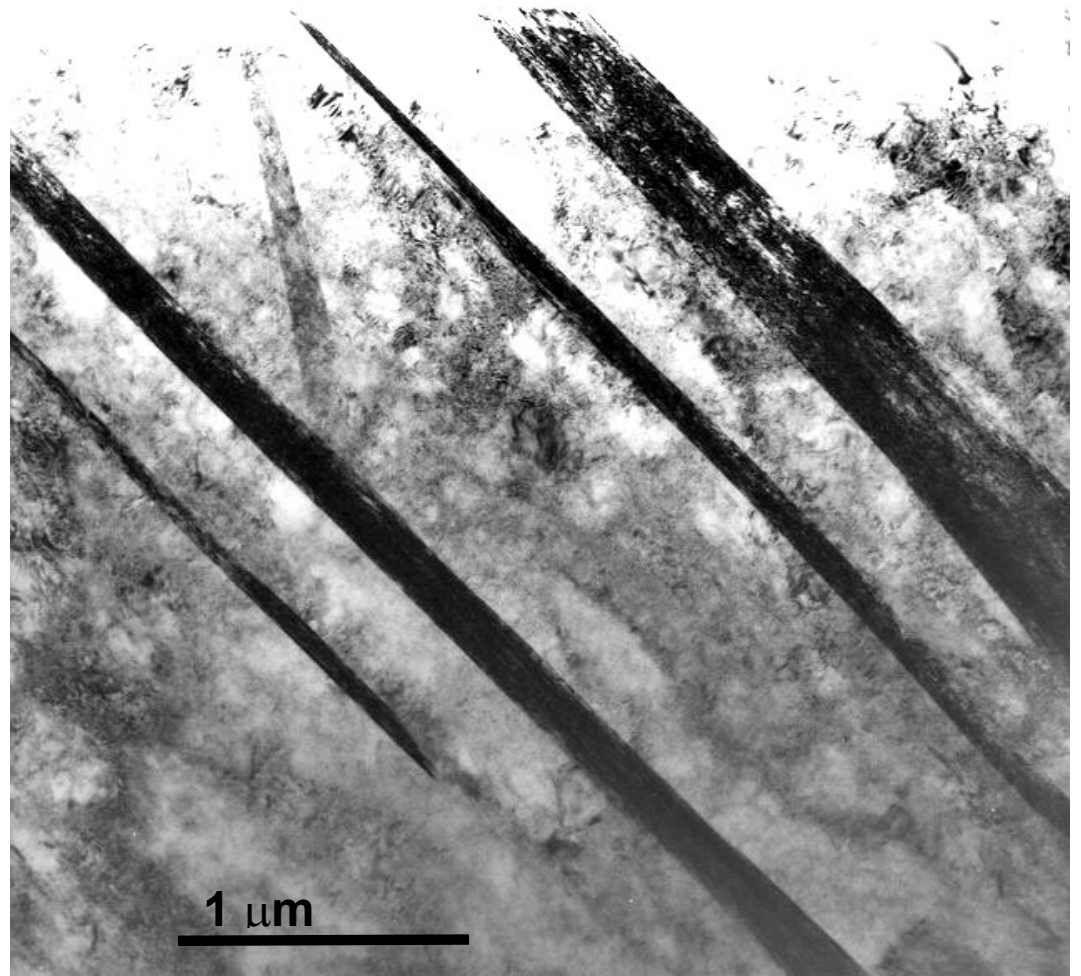

Fig. 22. Deformation twins in unirradiated 316 stainless steel strained $54 \%$ at room temperature. 


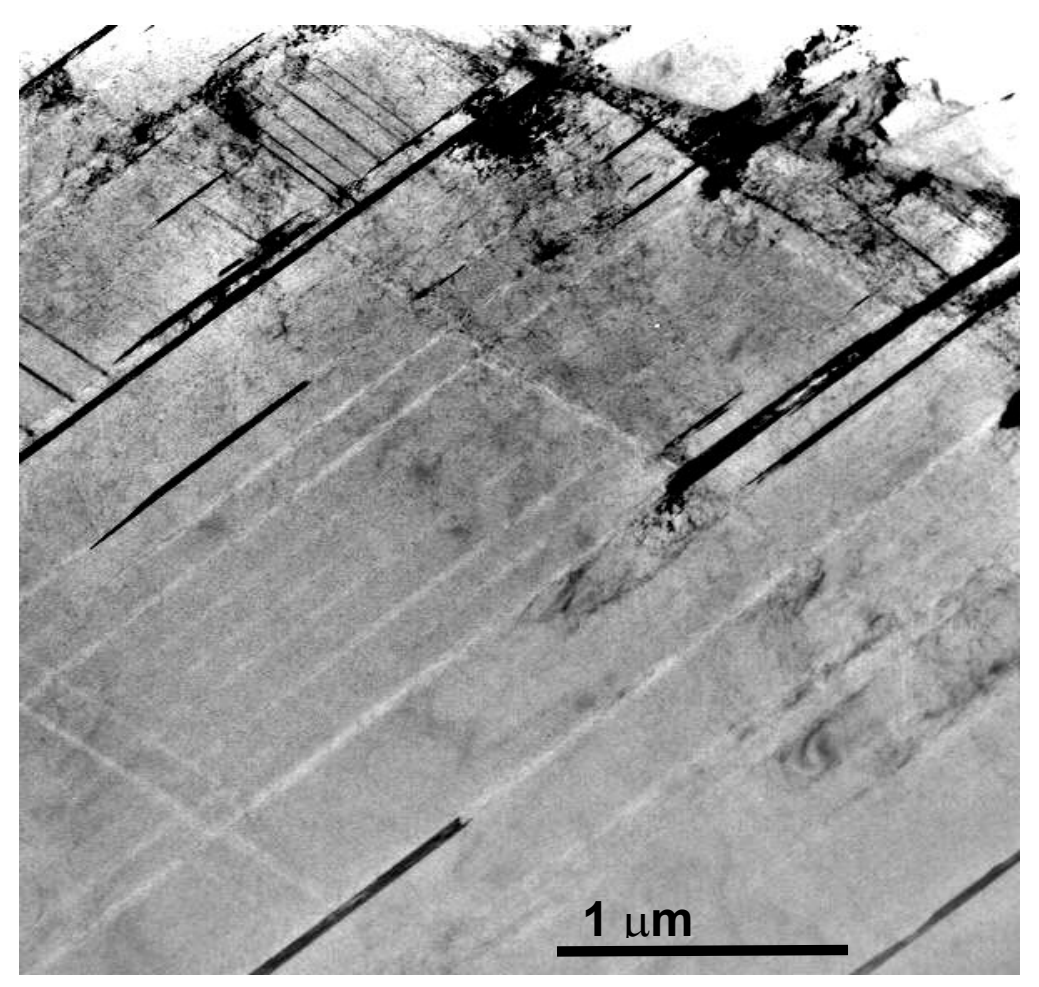

Fig. 23. Dislocation channels in 316 stainless steel irradiated to 0.15 dpa and strained 6\%.

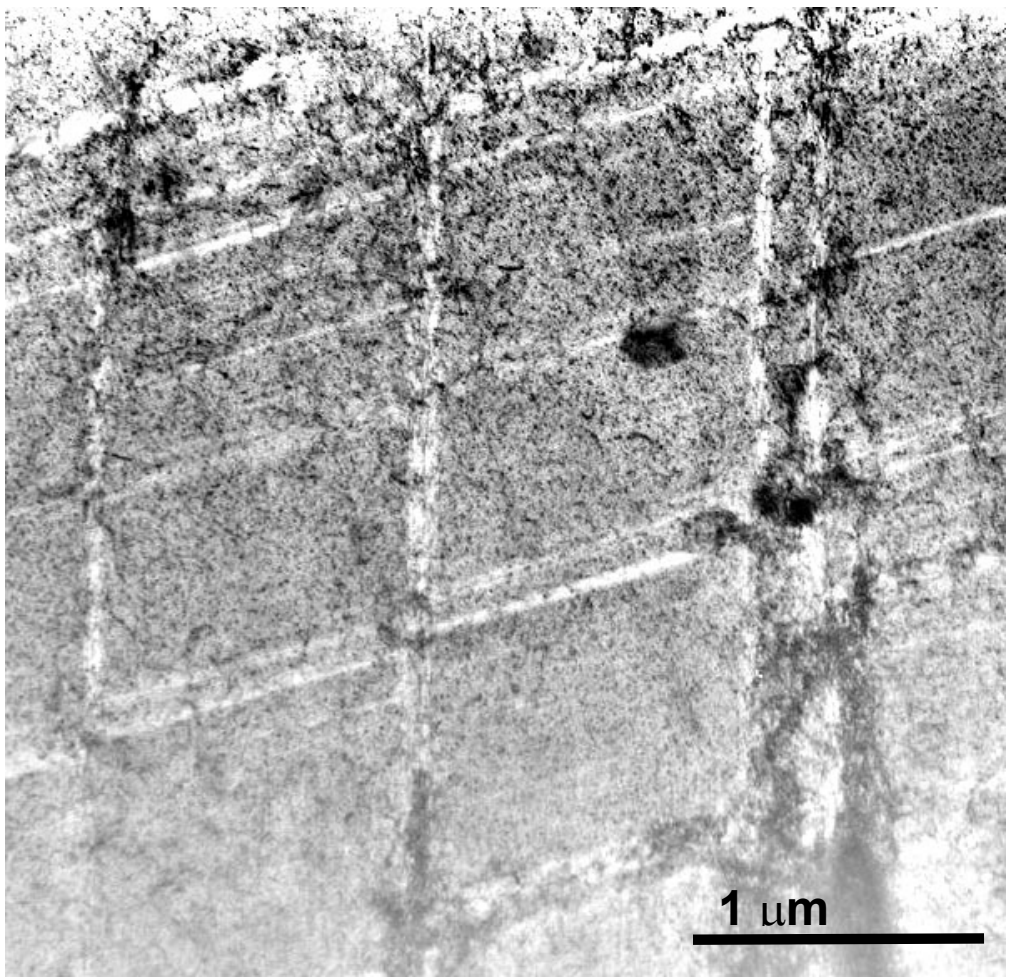

Fig. 24. Blocky arrangement of dislocation channels in 316 stainless steel irradiated to 0.78 dpa and strained $32 \%$. 
Measurements of channel widths and spacings at the two highest doses are presented in Table 4. Considerable grain-to-grain variation was found, and although attempts were made to choose typical grains it is acknowledged that there is significant uncertainty. Even within a single grain there was high deviation. Despite these qualifiers it can be seen that both the channel width and the spacing increase with dose, indicating fewer but wider channels at the higher doses. These results agree with the expectation that at higher doses deformation becomes more localized and confined. With regard to effects of strain, the channel width increases slightly as the strain increases, but no meaningful change is found in the channel spacing.

Table 4. Channel widths and spacings in irradiated stainless steel.

\begin{tabular}{|c|c|c|c|c|c|}
\hline \multirow{2}{*}{$\begin{array}{c}\text { Dose, } \\
\text { dpa }\end{array}$} & \multirow{2}{*}{ Strain, \% } & \multicolumn{2}{|c|}{ Channel width, nm } & \multicolumn{2}{c|}{ Channel spacing, nm } \\
\cline { 2 - 6 } & & Mean & Deviation & Mean & Deviation \\
\hline \hline \multirow{2}{*}{0.17} & 6 & 10 & 5 & 284 & 200 \\
\hline \multirow{2}{*}{0.78} & 2 & 26 & 6 & 622 & 433 \\
\cline { 2 - 6 } & 5 & 24 & 5 & 535 & 246 \\
\cline { 2 - 6 } & 32 & 19 & 11 & 588 & 306 \\
\hline
\end{tabular}

Closer examination of the larger blocks between the major channels reveals that some of them are riddled with vague, fragmented channels lying parallel to the major channels, Fig. 25 . There are also numerous extremely narrow, straight channels that are very difficult to resolve; they correspond to the locations of large stacking faults or microtwins. Dislocation tangling within the blocks is diminished.

The deformation mode map derived for annealed 316 austenitic stainless from these observations is shown in Fig. 26. 


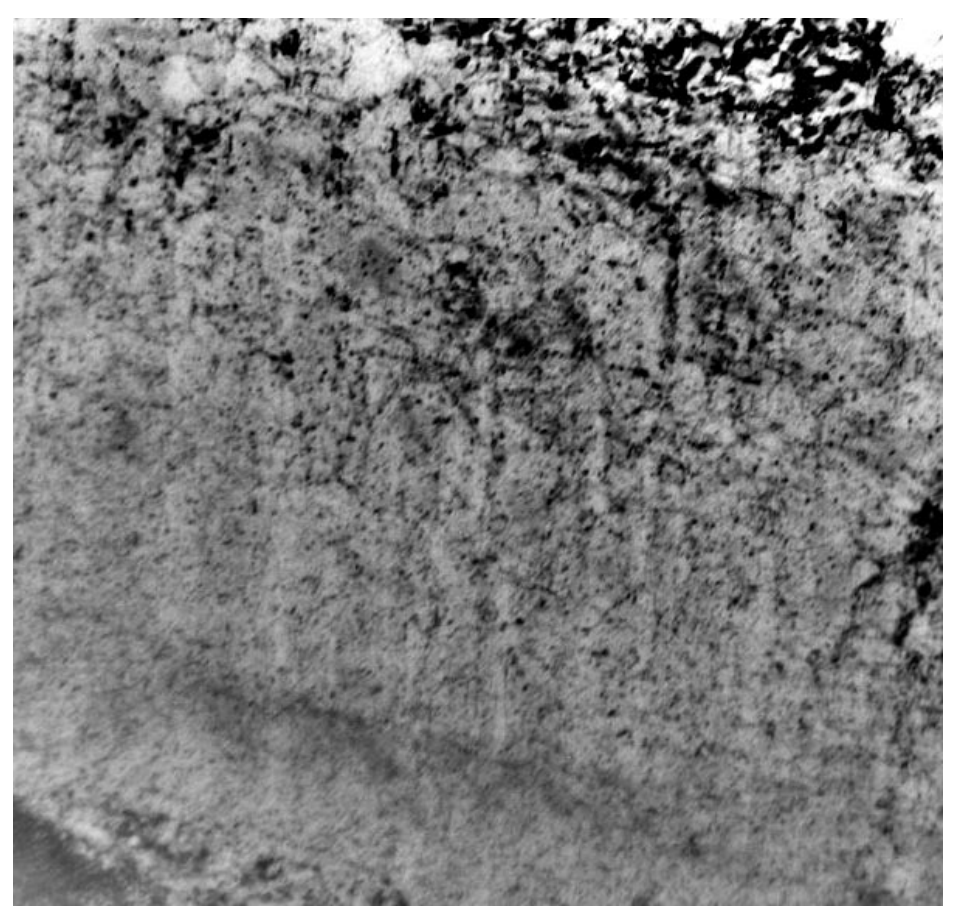

Fig. 25. Fragmented channels within the blocks in 316 stainless steel irradiated to 0.78 dpa and strained $32 \%$.

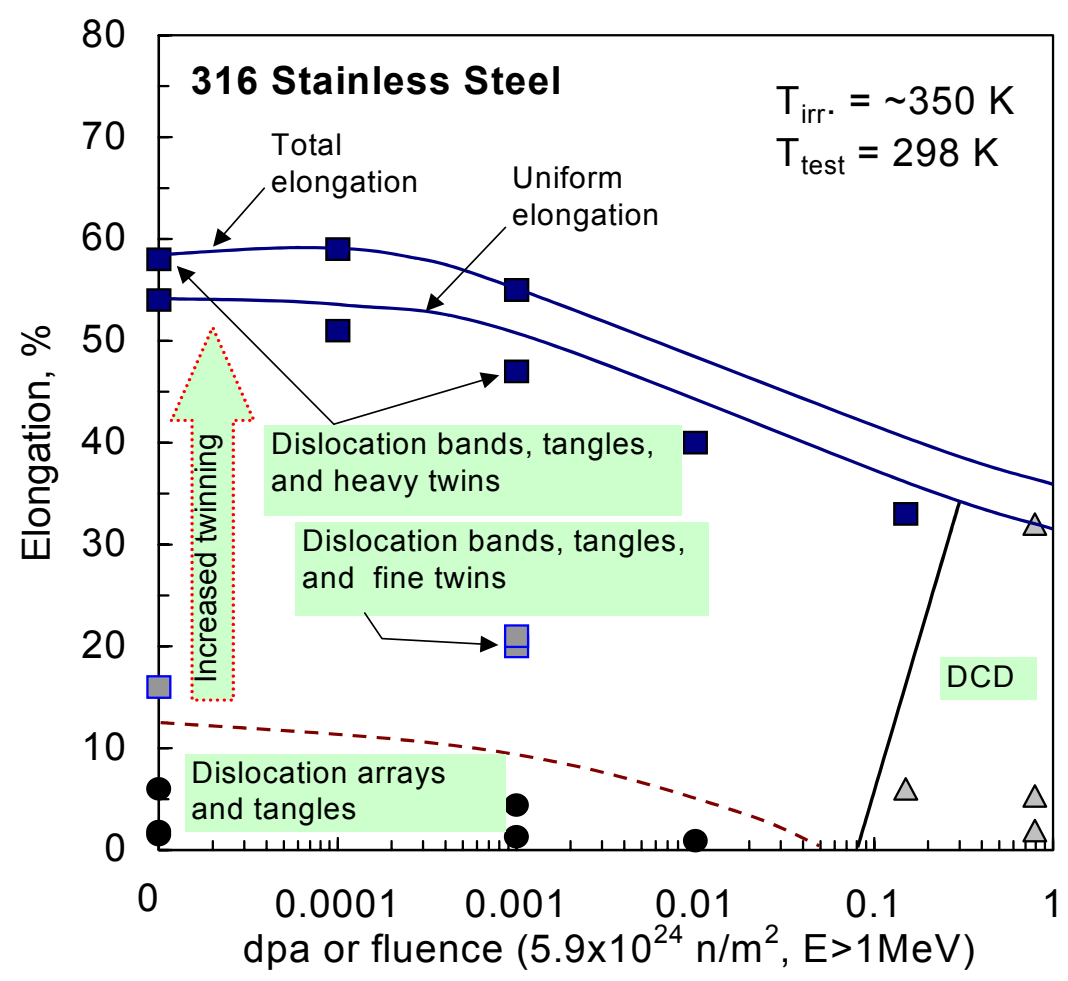

Fig. 26. Deformation mode map for 316 austenitic stainless steel neutron-irradiated at 65$100^{\circ} \mathrm{C}$ and tested at room temperature. 


\subsection{Discussion}

This work has produced the first ever deformation mode maps for neutron irradiated reactor construction alloys, shown in Figs. 10, 17, and 26 for A533B ferritic steel, Zircaloy-4, and 316 austenitic stainless steel, respectively. These maps identify the major modes of plastic deformation operating during tensile tests of irradiated materials at room temperature. The boundaries of the deformation regimes are outlined in terms of neutron fluence and plastic elongation. The data are sparse but the map frameworks are established for subsequent fleshing out as more data becomes available.

Four deformation modes are recognized; namely, dislocation tangling and cell formation; banding or planar deformation; DCD; and deformation microtwinning. Deformation by dislocation tangling and cell formation is the normal mode in most unirradiated metals. It develops from a three-dimensional interaction of dislocations resulting from cross slip and impingement of dislocations on intersecting slip planes. It occurs to some extent in all three materials herein, whether irradiated or not. It is the dominant mode in the A533B steel for doses below $0.1 \mathrm{dpa}$. It competes with DCD and is depressed when DCD is strong. Dislocation banding, or planar deformation, represents confinement of dislocation activity to a limited number of slip planes. It is a normal mode of deformation where a single slip system is dominant, as in Zircaloy-4, or where dislocation cross slip is diminished, as in the 316 steel. Diminished cross slip is a consequence of the low stacking fault energy of austenitic steel, as discussed later. Planar dislocation deformation is encouraged by irradiation. The planar arrays are considered to be precursors of DCD but are not a prerequisite for DCD. DCD, or dislocation channel deformation, is not found in any of the three alloys before irradiation. It is seen in all three alloys after irradiation, but not at the lower neutron fluences. Deformation microtwinning is seen only in the austenitic steel before and after irradiation and is a result of low stacking fault energy; it is encouraged by irradiation.

Regarding the tensile curves and tensile properties, a pattern is noted in which changes in properties induced by irradiation fall into two regimes of fluence dependence. The first regime is at low fluences and is characterized by minor reductions in elongations and by small increases in yield strengths without introduction of yield point drops. In this regime, the deformation modes are the same as those for the unirradiated material; work hardening rates are unchanged, and there are no overt signs of DCD. The second regime is at fluences of $0.01 \mathrm{dpa}$ and higher, and is distinguished by large increases in yield strengths, introduction or enhancement of yield point drops, large decreases in elongations, and significant reductions in macroscopic work hardening rates. In this higher fluence regime, DCD is involved. In the 316 steel, there is increased microtwinning activity in addition to the DCD. For all three alloys the losses in ductility due to irradiation are associated primarily with reductions in uniform elongation. Except for the A533B steel at the two highest doses, the necking strains, i.e. the differences between the total elongation and the uniform elongation, are barely affected by the irradiation. The implication is that the tensile properties are most impacted by the changes in the work hardening regions prior to reaching the UTS.

It is seen, then, that DCD is the only deformation mode induced by irradiation. Furthermore, the incidence of DCD coincides most closely with the larger irradiation-induced changes in the tensile curves. That coincidence is not accidental. It represents an intimate connection between 
channeling and alteration of tensile properties, in conformation with similar relationships established elsewhere in both irradiated and unirradiated materials. Strain localization is not peculiar to irradiated materials. It is quite common in unirradiated materials, where it is referred to as work softening. It is usually preceded by a yield point drop, after which deformation initially proceeds locally at low work hardening rate. Work softening involving swept-out dislocation channels is encountered in materials that have been prehardened by cold straining [3, $15,16]$, by quenching $[17,18]$, or by some precipitates $[19,20]$. Perhaps the best-known example is the strong yield point and related Lüders bands seen in mild steels. The features of non-uniform deformation found in the first tensile tests conducted on a neutron irradiated metal, single crystal copper, reported in 1960 [6], were likened to Lüders bands. The deformation bands in irradiated copper were subsequently shown to be DCD [4, 21,22]. Similarly in irradiated molybdenum [23]. In short, DCD seen in irradiated metals is a facet of the broader phenomenon of work softening.

Explanations of the yield point drop and associated strain localization in work softening are plentiful. They include sudden release of dislocations from locked sources [24], rapid multiplication and movement of dislocations [25], geometrical softening [26], and adiabatic heating [5]. The underlying premises are that the prehardening treatments have locked the dislocation sources which then require higher stresses to activate them, and when the first ones are activated they send avalanches of dislocations sweeping through the barriers ahead of them, clearing softened pathways. A general observation is that the higher the yield stress at which plastic strain begins, the greater is the propensity for channeling. It has been proposed [27] that the character of slip correlates more systematically with stress than with any other parameter, and that focused or localized slip is favored by high stresses. It is also well known that the velocity of glide dislocations increases exponentially with stress [25], which invokes high strain rates in channels. Indeed, high speed photography of the surface slip lines resulting from DCD has shown that they develop very rapidly, in less than a millisecond [28, 29]. Details of the barrier clearing process(es) are specific to particular types of barriers and are still very much debatable. It is generally agreed that once the initial channels are formed, less force is required to maintain the machine crosshead speed, hence the stress drops. Under the reduced stress, activation of additional sources is denied and dislocation activity in the surrounding stronger matrix is suppressed; therefore, deformation is restricted to the cleared channel regions until work hardening at channel/channel and channel/grain boundary intersections raises the stress. The removal of dislocation barriers in the channels reduces the work hardening rate in the channels, which is signaled in the tensile curve as an apparent decrease in bulk work hardening. The degree of reduction in work hardening will depend on the extent to which DCD is involved.

Whatever the basic mechanism(s) of strain localization processes, the symptoms of work softening in the tensile curve and the simultaneous occurrence of local bands of deformation in TEM are similar to those seen in the present work. It is very clear, too, that the propensity for DCD is greater the higher the yield strength, which in turn is a function of neutron dose. These observations leave little doubt that the DCD found herein is associated with, and probably responsible for, the yield point drops and reductions in work hardening rates. The "little doubt" centers on the data for doses of 0.01 and $0.1 \mathrm{dpa}$ in the A533B steel. Strong yield point drops and severely reduced work hardening were seen for these cases but no DCD was found. It is our opinion that DCD did occur in these two instances but its detection in TEM was thwarted by an 
invisibility curtain. The problem is that at these doses and the low irradiation temperature the size of the RDS is submicroscopic in TEM. It is known these doses are sufficient to create small clusters in iron and steels because other techniques of atom probe microscopy, small angle neutron scattering, and positron annihilation have detected them. Also, coarsened clusters can be seen in TEM if the material is post-irradiation annealed to a temperature of $300-400^{\circ} \mathrm{C}$ [30-32] or if the material is irradiated at $290^{\circ} \mathrm{C}[33,34]$. At such higher temperatures thermal diffusion processes are enhanced and are sufficient to enable the clusters to grow to visible sizes. For the present study the size of the RDS at a dose of $0.1 \mathrm{dpa}$ and less is below the TEM resolution limit of about $1 \mathrm{~nm}$. Consequently, since the RDS can not be seen in TEM neither can dislocation channels, even if they are there en masse. The reason for this is that the visibility of a channel is determined by the difference in degree of scattering of the electron beam by the RDS in the channel and by the RDS in the adjacent matrix. In a channel, the RDS is erased or broken up by the passage of glide dislocations, and the resulting reduced electron scattering reveals the channel as a lighter-colored band in a TEM photographic print. However, if the matrix RDS is too small to be seen there will not be a detectable scatter contrast between the matrix and a channel. Then the only hope of detecting such channels in TEM is to search for other evidence of channels such as straight surface slip steps and trails of dislocation debris left at the channel paths, particularly piled-up dislocations at the intersections of crossing channels. Unfortunately, the A533B specimens contained too many residual dislocations to permit reliable use of that technique. The technique has proved useful for exposing channel paths in annealed pure iron irradiated to neutron fluences as low as $1.5 \times 10^{22} \mathrm{n} . \mathrm{m}^{2}, \mathrm{E}>0.1 \mathrm{MeV}$, which is about $0.001 \mathrm{dpa}$, where no RDS was visible [B12]. So the seeming absence of channel contrast in the A533B specimens is not sufficient evidence that no channels are present. Another difficulty with the A533B steel, particularly at the higher doses, is the previously mentioned severity of the strain localization. The deformation occurred only in a very narrow necked region, not uniformly along the gauge length, and it was not possible to get satisfactory TEM pieces from the neck.

By and large, then, the major changes in tensile properties can be connected with the incidence of DCD, which is not unexpected in view of the aforementioned correlations for work softening. It seems, too, that changes in the tensile curve, principally the introduction of yield point drops and reductions in work hardening rate, may be more sensitive indicators of strain localization than TEM examinations, at least for the A533B steel. It might follow that the occurrence of a yield point drop coupled with reduced work hardening is a sure sign of strain localization. However, the opposite is not true. That is, the absence of a yield point drop and no significant reduction in work hardening rate does not necessarily signify an absence of strain localization. This was demonstrated clearly in the investigations [9] that produced the deformation maps for nickel and gold in Fig. 2. The corresponding tensile curves are shown in Fig. 27. Study of these curves shows that in the nickel none of the specimens that exhibited DCD displayed a yield point drop or significant reduction in work hardening rate. In the gold, all the irradiated specimens showed large reductions in work hardening whether they were channeled or not, and only the highest fluence specimen had a yield point drop. The deformation mode in the nickel is notable in that it underwent a transition from dislocation cell type to a lamellar or planar band structure before cleared channels emerged. Such banding is, of course, a form of strain localization and can thus be expected to contribute to channel-like changes in the tensile curve. Judging from the lack of symptoms in the tensile curves for the nickel, that contribution must be very subtle. 
From the above discussion, the minimum dose at which DCD begins in the three alloys is about $0.01 \mathrm{dpa}$ for Zircaloy-4 and A533B steel, and between 0.01 and $0.1 \mathrm{dpa}$ for the stainless steel. These are significantly higher doses than for the onset of DCD in pure nickel and gold. In Fig. 2 the occurrence of DCD in the nickel and gold begins at a fluence of about $1 \times 10^{21} \mathrm{n} \cdot \mathrm{m}^{-2}$. The irradiations were conducted in the Rotating Target Neutron Source II at Lawrence Livermore National Laboratory where the D-T neutron energy is $14 \mathrm{MeV}$. For such high-energy neutrons, the atomic displacement cross sections are more than ten times larger than for fission neutrons with energies $>1 \mathrm{MeV}$. A D-T neutron fluence of $1 \times 10^{21} \mathrm{n} \cdot \mathrm{m}^{-2}$ corresponds to about $0.004 \mathrm{dpa}$ for medium atomic mass number metals like nickel [35]. Hence, the threshold displacement doses for DCD in the present alloys are 2.5 to 25 times higher than the thresholds for nickel and gold. Some of this difference may be due to differences in irradiation parameters such as neutron spectrum and damage rate. But most of the difference is probably attributable to differences in chemical compositions. The alloying additions and impurity elements in the alloys will reduce emission of point defects from displacement cascades and will promote greater recombination of freely migration point defects, thereby reducing the development of RDS. Attainment of a critical yield stress for initiation of DCD will be delayed to higher doses. Actually, it is not known what triggers DCD, whether it is achievement of a critical stress greater than the unirradiated yield strength, or a critical dislocation velocity, or a critical softening stress due to defect clearing. It is not even clear whether there is a true threshold of any kind for DCD.

Although no symptoms of DCD were seen at the lower fluences, it is quite conceivable that DCD is always awaiting its chances and is spurred by the mildest hardening treatment but needs to achieve a critical presence to become noticed. After all, the basic dislocation slip process itself is a heterogeneous deformation mode. It is not obvious whether there is a real threshold for DCD or whether the seeming absence of DCD at low fluences is because of inadequate sensitivity in our detection techniques.

In the present work, the stainless steel displays some of the dislocation banding, or cursory channeling behavior seen in the microstructural development of the channels in nickel. After a dose of $0.01 \mathrm{dpa}$ a yield point drop is produced in the stainless steel but there is no associated decrease in work hardening rate. No channels are discerned but dislocation banding is more pronounced. At higher doses, dislocation channels are observed and they are narrower than those in the other two alloys at a given dose. Moreover, of the three alloys investigated here, the stainless steel is the only alloy that retains much of the channeling dislocations within the channels. The channels in stainless steel also contain fine microtwins, not seen in the other two alloys. 

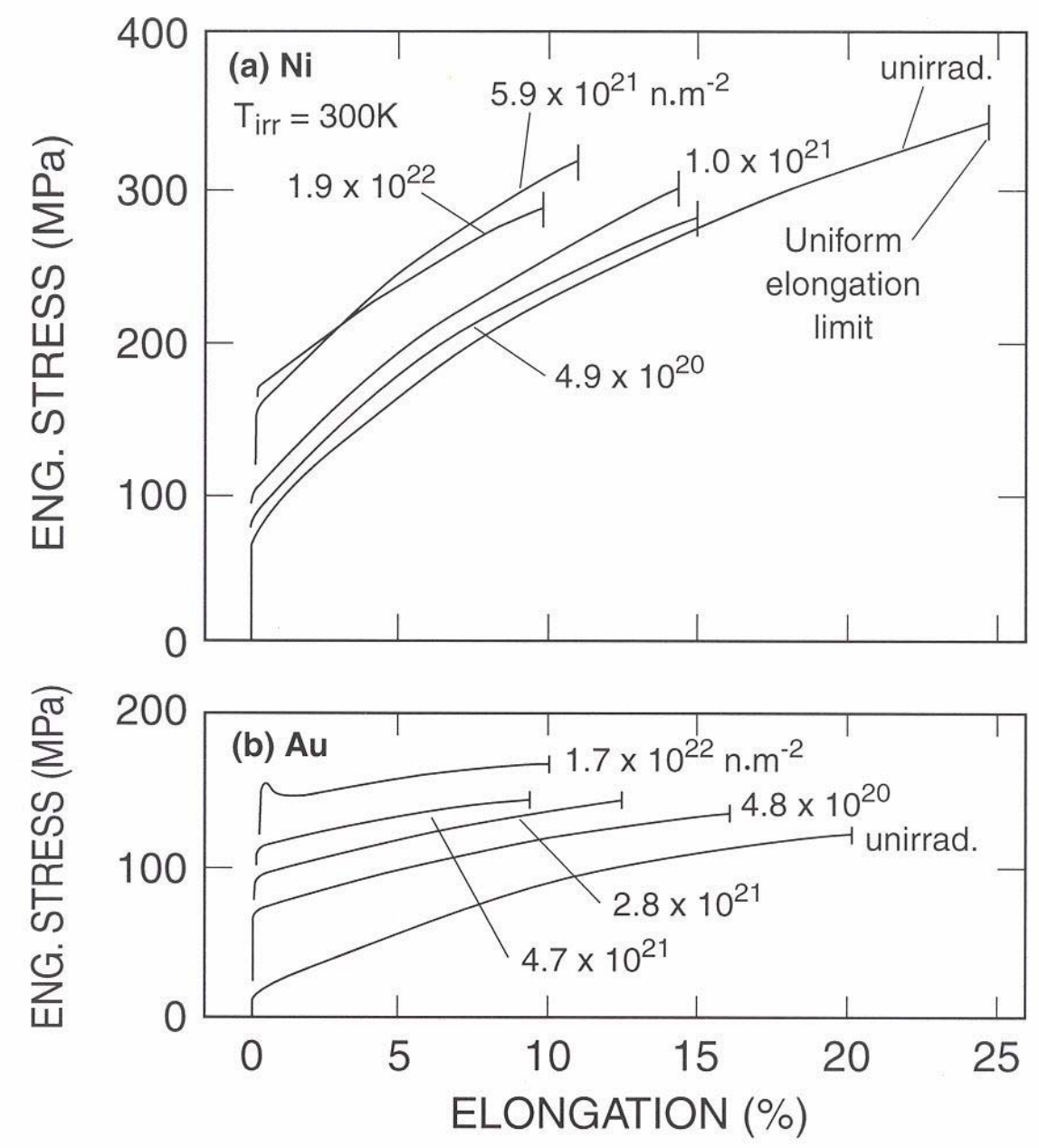

Fig. 27. Engineering tensile curves for the deformation mode maps in Fig. 2 [9].

Because of the low stacking fault energy of austenitic stainless steel, the partial dislocations that constitute a glide dislocation are more widely separated, or extended, than in higher stacking fault materials such as the A533B steel and Zircaloy-4. The separation of the partials is just visible as a short ribbon of stacking fault fringes. For plastic deformation to occur the two partial dislocations must either glide as a pair or the leading partial must increase its separation from the trailing partial, creating a larger stacking fault. Before a dislocation can move off its primary slip plane onto a cross slip plane the stacking fault between the partials must first be compressed, which requires extra energy. Therefore, cross slip is suppressed and the deformation tends to be much more planar in stainless steel than in higher stacking fault materials.

The location of deformation twins within the slip bands in the stainless steel demonstrates that slip and deformation twinning in this material are not two separate processes; the twinning is a direct and coupled consequence of the planar slip. The twins are not the sudden, blocky type, and the tensile curves do not show sharp drops in stress usually associated with rapid, bulk twinning. 
The twins occur gradually by dislocation slip and, as shown elsewhere [C34-C36], they are formed by successive glides on adjacent slip planes. It is speculated here that retention of glide dislocations and twins in the channel / deformation bands moderates the activity of glide dislocations in the channels and dampens the build-up of excessive stresses and strains in the channel bands. This restricts the width of the channels and provides some work hardening capacity in them, which is probably one reason why the stainless steel has much more resistance to radiation-induced ductility loss than the other two alloys. Another reason could be that it is a legacy effect from the unirradiated conditions. The total elongation of the unirradiated stainless steel $(63 \%)$ is much larger than those of the other two alloys, $20 \%$ for A533B and $33 \%$ for Zircaloy-4. This superior elongation in the stainless steel stems largely from protracted uniform elongation, whereas in the other alloys the uniform elongations represent less than half of the total elongations. The feature that prolongs the uniform elongation of the stainless steel might be the microtwins, which develop within the deformation bands. Both the stainless steel and the Zircaloy-4 deform by dislocation banding, which being a strain localization process should limit their elongations. But only the stainless steel develops microtwins in the bands. And the stainless steel is much more ductile than the Zircaloy. Because of its lower stacking fault energy the separation of partial dislocations in the 316 stainless steel is much higher than in the other two alloys, and they contain significant stacking fault ribbons even though they may not always be easily noticeable in the unirradiated material at low strains. Their presence makes cross-slip more difficult, and is the reason that dislocation glide motions are confined to narrower bands in the stainless steel. In these narrow bands dislocation pileups occur more readily, which generates more back stress hardening and activates more slip sources. Additionally, the higher stresses cause greater separation of the partials, producing wider stacking faults. These faults are precursors of the deformation twins found in the bands. Since the faults and twins are formed progressively with strain, they can continue to prolong work hardening. On these grounds it is concluded here that the stacking faults and twins are responsible for the superior elongation of the stainless steel in both its irradiated and unirradiated conditions.

Zircaloy can deform by deformation twinning but no twins were seen in the Zircaloy- 4 in the present work, presumably because of a lack of suitable texture. Zirconium alloys develop strong textures during forming operations, usually their basal planes becoming aligned towards the forming direction. In tension tests the dominant deformation mode is dependent on the texture. If the tensile specimen is machined in the thickness or transverse (T) direction, such that its basal planes lie perpendicular to the tensile axis, it will deform by a mixture of slip and gross mechanical twinning. Some of the twins will be suitably reoriented for slip to occur in them. If the tensile specimen is taken in the longitudinal forming direction (L), it will deform primarily by slip. In the present work, the tensile specimens were machined in the rolling direction, L type. In literature reports of DCD in zirconium alloys, some of the specimens were of T type and they displayed mechanical twinning during tensile testing [D5]. The twins were of the massive, lenticular type. Formation of these broad deformation twins did not remove RDS and cause DCD, but slip bands occurring within the twins did. Interestingly, during those tests, which were made after a fluence of $4 \times 10^{23} \mathrm{n} \cdot \mathrm{m}^{-2}, \mathrm{E}>1 \mathrm{MeV}$, the occurrence of DCD did not seem to be sensitive to material composition; it was found in iodide zirconium, Zircaloy-2, and $\mathrm{Zr}-2.3 \mathrm{Nb}$.

A final point of discussion is radiation hardening. The earliest radiation strengthening data were obtained on copper [6] and were found empirically to fit an equation of the form $\Delta Y S=\alpha(\varphi t)^{1 / 3}$, 
where $\Delta Y S$ is the increase in critical shear stress or macro yield strength, and $\varphi t$ is the neutron fluence or flux-time product. It was quickly pointed out that there is no sound theoretical basis for an exponent of $1 / 3$, and that a more fundamental value based on a distribution of point defect clusters hindering the motion of glide dislocations on the slip planes [36] should be $1 / 2$. The latter assumes the volume fraction of clusters varies linearly with fluence. This assumption was later challenged when measurements of clusters [37] indicated they varied with $(\varphi t)^{1 / 2}$, which would then make $\Delta Y S=\alpha(\varphi t)^{1 / 4}$. It is recognized that all of these relationships will fail at higher doses due to saturation in formation of clusters caused by overlapping of displacement cascades and by absorption of freely migrating point defects at existing clusters. The tensile data obtained in the present work afforded an opportunity to test these predictions. In Fig. 28 the increases in yield strengths are plotted against fast neutron fluence in $\log$-log coordinates. There are obvious signs of saturation at the highest fluence, so those data were omitted from the least squares line fitting analyses. The slopes give hardening exponents of 0.36 to 0.38 , essentially the same slope for all three materials irrespective of their large differences in the crystal structures, chemical compositions, and microstructures. These values are very close to the exponent of $1 / 3$ obtained from curve fitting for copper [6]. It was mentioned earlier that an exponent of $1 / 3$ is difficult to justify from barrier hardening theory. Barrier hardening theories do not address dislocation channeling, which participates in all of these irradiated materials. Perhaps, as more information is accumulated about radiation hardening and dislocation channeling, it may be concluded that a hardening exponent of $1 / 3$ has more relevance to dislocation channeling than to barrier hardening.

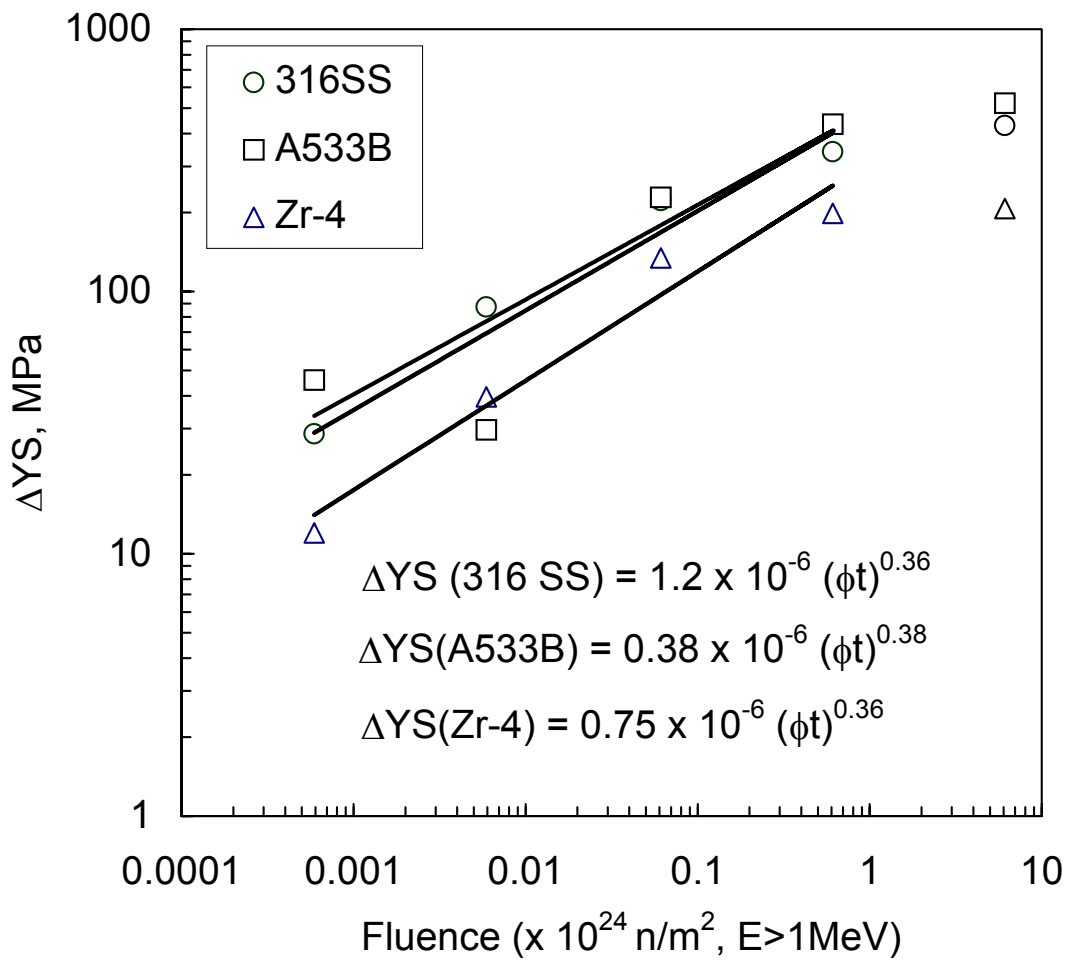

Fig. 28. Determination of radiation hardening exponents for the three alloys. 


\subsection{References}

1) F. A. Smidt, Jr., NRL Report 7078, Naval Research Laboratory, Washington D.C. (1970).

2) M. S. Wechsler, Chapter 2 in The Inhomogeneity of Plastic Deformation, pub. Amer. Soc. for Metals (1971) 19-54.

3) A. Luft, Progr. in Mater. Sci. 35 (1991) 97-204.

4) J. V. Sharp, Phil. Mag. 16 (1967) 77-96.

5) R. P. Tucker, M. S. Wechsler, and S. M. Ohr, J. Appl. Phys. 40-No. 1 (1969) 400-408.

6) T. H. Blewitt, R. R. Coltman, R. E. Jamison and J. K. Redman, J. Nucl. Mater. 2 (1960) 277-298.

7) H. J. Frost and M. F. Ashby, Deformation-Mechanism Maps, Pergamon Press, 1982.

8) M. F. Ashby, Materials Selection in Mechanical Design, Pergamon Press, 1992.

9) A. Okada, K. Kanao, T. Yoshiie, and S. Kojima, Mater. Trans. JIM 30 No. 4 (1989) 265-272.

10) K. Farrell, T. S. Byun, J. W. Jones. L. T. Gibson, R. G. Sitterson, N. Hashimoto, J. L. Bailey, and J. Gardner, " Small Specimen Procedures for Determination of Deformation Maps", in Proceedings of Symposium on Small Specimen Test Techniques: Fourth Volume, ASTM STP 1418, M. A. Sokolov, J. D. Landes, and G. E. Lucas, Eds., Amer. Soc. for Testing and Materials, West Conshohoken, PA, in press.

11) T. S. Byun, E. H. Lee, J. D. Hunn, K, Farrell, and L. K. Mansur, J. Nucl. Mater. 294 (2001) 256-266.

12) S. T. Mahmood, S. Mirzadeh, K. Farrell, J. V. Pace III, and B. M. Oliver, "Neutron Dosimetry of the HFIR Hydraulic Facility", ORNL/TM-12831, Oak Ridge National Laboratory report, February 1995.

13) T. A. Gabriel, B. L. Bishop, and F. W. Wiffen, "Calculated Irradiation Response of Materials Using Fission Reactor (HFIR, ORR, and EBR-II) Neutron Spectra”, ORNL/TM-6361, Oak Ridge National Laboratory report, August 1979.

14) H. R. Higgy and F. H. Hammad, J. Nucl. Mater. 55 (1975) 177-186.

15) A. H. Cottrell and R. J. Stokes, Proc. Roy. Soc. A233 (1955) 17-33.

16) Ch. Ritschel, A. Luft, and D. Schulze, Kristall und Technik 13 (1978) 791-797.

17) S. Yoshida, M. Kiritani, Y. Deguchi, and N. Kamigaki, Suppl. to Trans. JIM 9 (1968) 83-89. 
18) T. Mori and M. Meshii Acta Met. 17 (1969) 167-175.

19) A. Gysler, G. Lütjering, and V. Gerold, Acta Met. 22 (1974) 901-909.

20) T. H. Sanders Jr. and E. A. Starke Jr., Acta Met. 30 (1982) 927-939.

21) I. G. Greenfield and H. G. F. Wilsdorf, J. Appl. Phys. 32 No.5 (1961) 827-839.

22) U. Essmann and A. Seeger, phys. stat. sol. 4 (1964) 177-197.

23) J. L. Brimhall, Trans. Met. Soc. AIME 233 (1965) 1737-1742.

24) A. H. Cottrell, in Bristol Conference on Strength of Solids, Phys. Soc. 30, London (1948).

25) G. T. Hahn, Acta Met. 10 (1962) 727-738.

26) R. J. Price and A. Kelly, Acta Met. 12 (1964) 159-169.

27) P. J. Jackson and P. D. K. Nathanson, South African J. of Phys. 1 (1978) 7-21.

28) M. J. Makin and J. V. Sharp, Phys. Stat. Sol. 9 (1965) 109-118.

29) H. Neuhäuser and R. Rodloff, Acta Met. 22 (1974) 375-384.

30) B. L. Eyre and A. F. Bartlett, Phil. Mag. 12 (1965) 261-272.

31) J. S. Bryner, Acta Met. 14 (1966) 323-336.

32) I. M. Robertson, M. L. Jenkins, and C. A. English, J. Nucl. Mater. 108 \& 109 (1982) 209-221.

33) F. Frisius, R. Kampmann, P. A. Beaven, and R. Wagner, in Proc. BNES Conf. on Dimensional stability and mechanical behaviour of irradiated metals and alloys, Brighton (1983) 171-174.

34) O. Okada, T. Yasujima, T. Yoshiie, I. Ishida, and M. Kiritani, J. Nucl. Mater. 179-181 (1991) 1083-1087.

35) H. L. Heinisch, J. Nucl. Mater. 155-157 (1988) 121-129.

36) A. K. Seeger, Proceedings of the Second International Conference on the Peaceful Uses of Atomic Energy, P/989, 6 (1958) 250-273.

37) S. J. Zinkle, J. Nucl. Mater. 150 (1987) 140-158. 


\section{Appendix A: Details of Experiment conditions.}

\section{A1. Sources and compositions (Wt.\%) of the three alloys, and heat treatments for the tensile specimens.}

All tensile test specimens were electrodischarge-machined from cold rolled, $0.25 \mathrm{~mm}$ thick sheets of the alloys. The edges of the gauge sections were sanded by hand to eliminate machining irregularities. Identity marks were engraved on the heads. After a light surface sanding to remove engraving burrs, the specimens were ultrasonically cleaned in alcohol and acetone, and were then subjected to the appropriate heat treatments.

\section{A533B Ferritic Steel}

Source: R. K. Nanstad, Metals and Ceramics Division, ORNL. This material is from the 02 plate in the HSST program described by C. E. Childress on p. 49 in "Fabrication History of the First Two 12-in.-Thick ASTM A-533 Grade B, Class 1 Steel Plates of the Heavy Section Steel Technology Program, Documentary Report 1", ORNL-4313, UC-80- Reactor Technology, February, 1969. This particular steel is an acknowledged reference material for studies of radiation effects in pressure vessel steels.

Table A1. 1. The chemical composition of A533B steel

\begin{tabular}{|c|c|c|c|c|c|c|c|}
\hline $\mathrm{C}$ & $\mathrm{Si}$ & $\mathrm{Mn}$ & $\mathrm{S}$ & $\mathrm{P}$ & $\mathrm{Ni}$ & $\mathrm{Mo}$ & $\mathrm{Fe}$ \\
\hline \hline .22 & .25 & 1.48 & .018 & .012 & .68 & .52 & Bal. \\
\hline
\end{tabular}

Treatment: Vacuum-seal in a quartz capsule. Anneal 4h @880 ${ }^{\circ} \mathrm{C}$, air-cool to room temperature; reheat for $4 \mathrm{~h} @ 660^{\circ} \mathrm{C}$, air-cool to room temperature; reheat $20 \mathrm{~h} @ 610^{\circ} \mathrm{C}$, furnace-cool to $315^{\circ} \mathrm{C}$, then air-cool to room temperature. This treatment produces a microstructure of lath-like tempered bainite in which the mean pocket size of granular bainite structure was measured at $9 \mu \mathrm{m}$, Fig. A1.1.

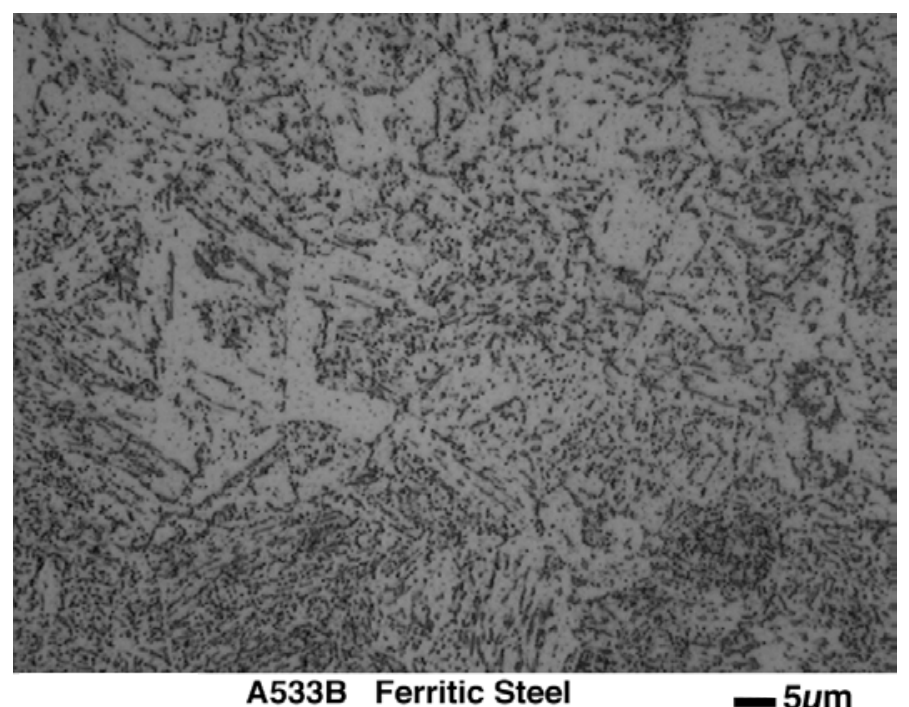

Fig. A1.1. Microstructure of A533B steel. 
Zircaloy-4, Batch 7.

Source: D. Hobson, Metals and Ceramics Division, ORNL. Chemical analysis provided by ABB C-E Services Inc, letter of March 7, 2000 to K. Farrell.

Table A1. 2. The chemical composition of Zircaloy-4

\begin{tabular}{|c|c|c|c|c|c|c|c|}
\hline $\mathrm{C}$ & $\mathrm{Sn}$ & $\mathrm{Fe}$ & $\mathrm{Ni}$ & $\mathrm{S}$ & $\mathrm{N}$ & $\mathrm{O}$ & $\mathrm{Zr}$ \\
\hline \hline .015 & 1.4 & 0.1 & $<0.1$ & 0.001 & $<0.001$ & 0.06 & Bal. \\
\hline
\end{tabular}

Treatment: Anneal 30 min. @ $670^{\circ} \mathrm{C}$ in vacuum. The microstructure was recrystallized equiaxed grains of mean size $13 \mu \mathrm{m}$, Fig. A1.2.

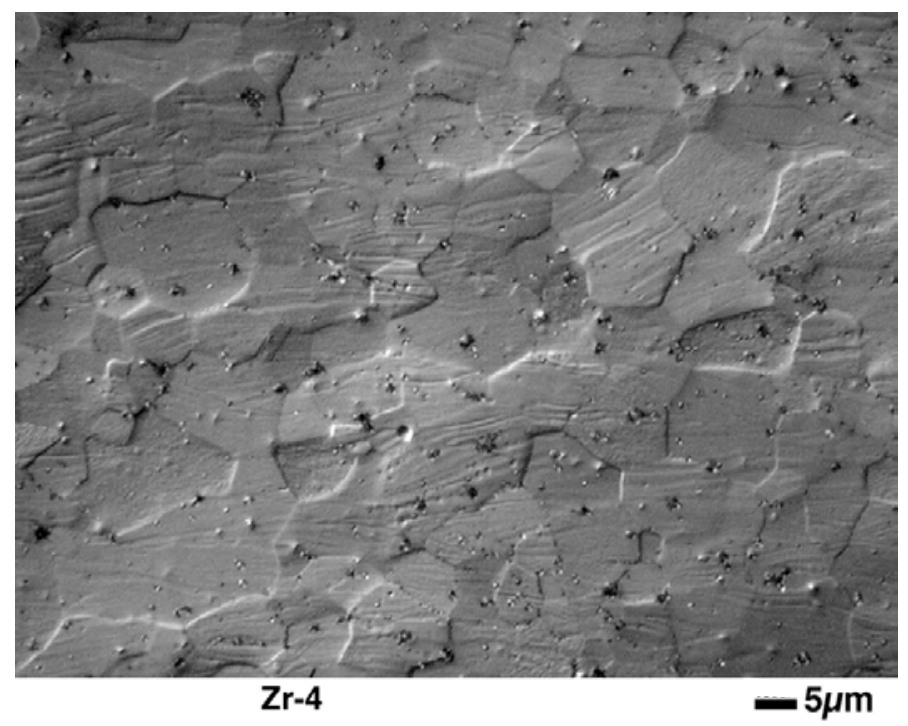

Fig. A1.2. Microstructure of annealed Zircaloy-4. 
Ref 316 Austenitic Steel.

Source: L. T. Gibson, Metals and Ceramics Division, ORNL. This material is the reference heat \# 8092297C described in Table 4.3 in "Mechanical Properties Design Data Program Semiannual Progress Report for Period Ending January 31, 1984”, ORNL/MSP/1.3-84/1, May, 1984.

Table A1. 3. The chemical composition of 316 stainless steel

\begin{tabular}{|c|c|c|c|c|c|c|c|c|c|c|c|c|c|c|}
\hline $\mathrm{C}$ & $\mathrm{Mn}$ & $\mathrm{Si}$ & $\mathrm{S}$ & $\mathrm{P}$ & $\mathrm{Cr}$ & $\mathrm{Ni}$ & $\mathrm{Mo}$ & $\mathrm{Ti}$ & $\mathrm{Nb}+\mathrm{Ta}$ & $\mathrm{Cu}$ & $\mathrm{Co}$ & $\mathrm{N}$ & $\mathrm{B}$ & $\mathrm{Fe}$ \\
\hline \hline .059 & 1.86 & .57 & .018 & .024 & 17.15 & 13.45 & 2.34 & $<.01$ & $<.01$ & .10 & .02 & .031 & 0.0005 & Bal. \\
\hline
\end{tabular}

Treatment: Anneal 30 min. @ 1050 ${ }^{\circ} \mathrm{C}$ in vacuum. The microstructure, Fig. A1.3, was recrystallized equiaxed grains of mean size $67 \mu \mathrm{m}$.

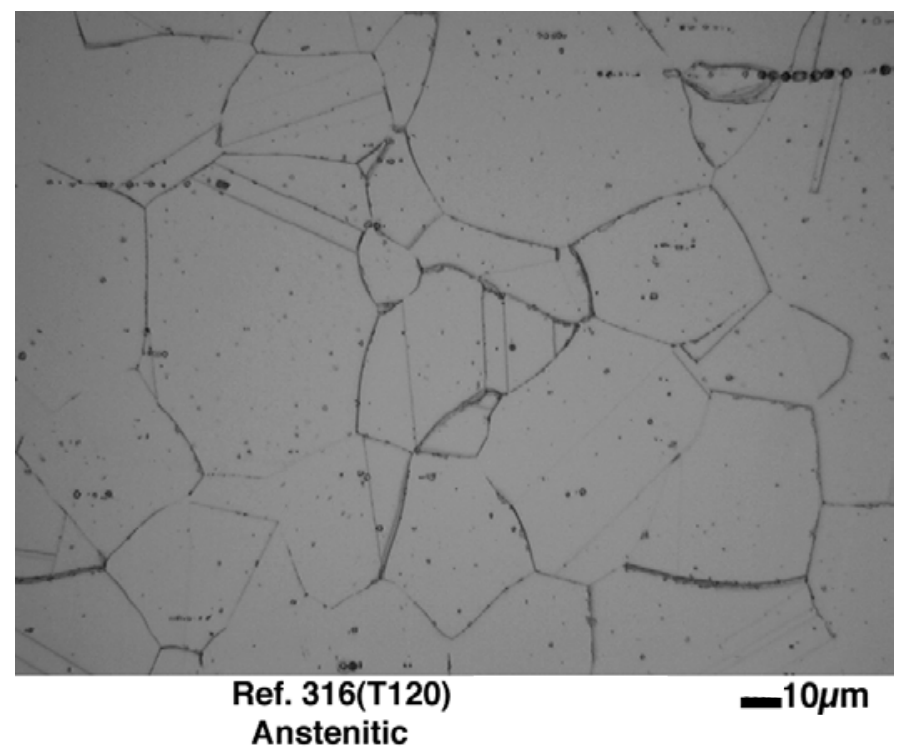

Fig. A1.3. Microstructure of annealed 316 stainless steel. 


\section{A2. Specimen size and handling}

Experiments of the type and scope needed to obtain deformation mode maps for irradiated materials entail testing and handling of many radioactive specimens, sometimes outside the hot cell where radiation exposure to research personnel can be high. To minimize radioactivity levels and to make the maximum use of available space in the irradiation facility, a custom-designed miniature tensile specimen was used. The specimen was made thin enough, $0.25 \mathrm{~mm}$, for excision of TEM pieces that required no further reduction in thickness by grinding, thereby eliminating the grinding operation and the associated radioactive dust. The $0.25 \mathrm{~mm}$ thickness did not compromise the strength properties of the materials. Comparison of the tensile properties of our miniature specimens with those of larger specimens showed very good reproduction of strength properties but reduced elongation values due to the size effect. Duplication of property values in multiple tests was excellent. Yield point drops and Lüders strains were reproduced. However, because it is small and thin, the specimen is sensitive to possible introduction of extraneous plastic strains from inappropriate loading techniques. In particular, loading through pins or by friction gripping was considered likely to be unsuitable. Trials with pin-loaded specimens showed much plastic extension at the holes, despite the pin diameter $(1.8 \mathrm{~mm})$ being larger than the gauge width $(1.5 \mathrm{~mm})$. Therefore, an under-the-shoulder loading system was devised. The heads of the specimens were made broad so that the load-bearing area of the shoulders was at least three times larger than the gauge cross section. A bonus of the large heads is that they allow $3 \mathrm{~mm}$ disks to be punched or otherwise cut from them. Such disks are suitable for deformation studies in a disk bend apparatus [11].

The load is applied to the tensile specimen in the custom-built cradle pictured in Fig. A2.1. The cradle cossets the small specimen against accidental bending or torsion moments that might occur during manual positioning of the specimen in the tensile machine. It aligns the specimen, applies the load under its shoulders during the test, and requires only easy movements to release the tested specimen. No clamping is required. The tensile specimen is placed in the cradle simply by lowering the specimen into the open recesses in the cradle head pieces while the cradle is lying on a workbench. The cradle is constructed from cold worked stainless steel. Its two headpieces move on a track made from two rod rails. The rails pass through clearance holes drilled in the headpieces of the cradle. Extension arms screwed into the head pieces have end knobs with convex shoulders that are radiused to mate with concave seats in thimble pieces attached to the pull rods of the tensile machine. This ball-and-socket type arrangement ensures good axial alignment during loading. The load is transmitted to the specimen via the inner faces of the slotted portions of the recessed cavities in the cradle headpieces. Those faces are shaped to match the shoulder contours of the tensile specimen. Sliding gates are installed in the cradle headpieces at right angles to the tensile axis and they straddle the specimen heads. The gates assure that the specimen remains properly seated during lifting of the cradle and insertion in the tensile machine, and they retain the pieces of a specimen broken in test. They were also intended to deter any tendency for plastic buckling of the heads during the test. However, tests to failure with trial specimens, and subsequently with many irradiated specimens, have shown that the gates may not be needed for that purpose; no distortion of specimen heads has been found, not even in tests made with the gates open. 


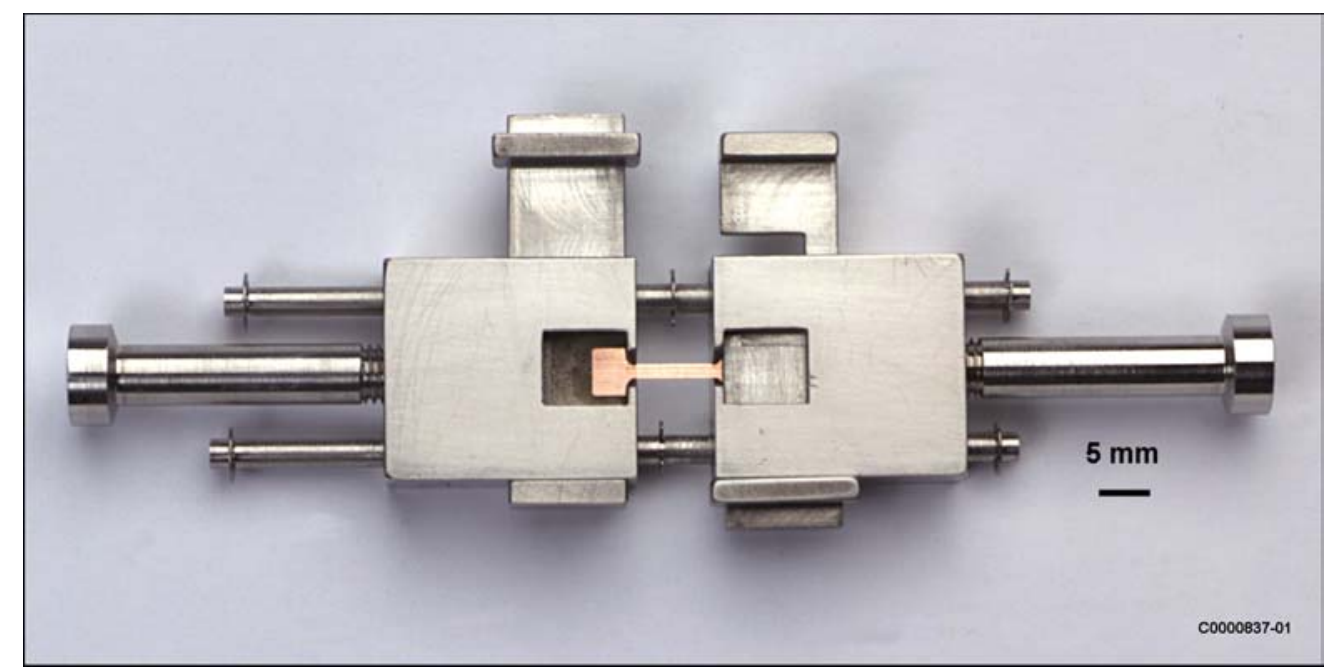

Fig. A2.1. The tensile cradle.

To prepare a specimen for testing, the cradle is laid on its back on a bench with the gates open and the headpieces touching one another. The specimen is picked up with tweezers or vacuum tweezers and is positioned into the channel and the head cavities. Seating of the specimen is checked though a mirror and the heads are separated with tongs until resistance is felt. Using tongs, the gates are closed and the cradle is lifted by one of its extension arms and is placed in the machine pull rod thimbles

All tensile tests were conducted at room temperature in a screw-driven machine at a crosshead speed of $0.008 \mathrm{~mm} . \mathrm{s}^{-1}$, corresponding to a specimen strain rate of $10^{-3} \mathrm{~s}^{-1}$. Engineering strain was calculated from the recorded crosshead separation, using a nominal gauge length of $8 \mathrm{~mm}$. Engineering stress was calculated as the load divided by the initial cross section area before irradiation. The load cell was calibrated to NIST-approved standards.

\section{A3. Neutron irradiation conditions}

Irradiations of the specimens were not described in Ref. 10, so details are given here. The irradiations were carried out in flowing coolant water in the hydraulic tube facility of the High Flux Isotope Reactor. The hydraulic tube passes into the flux trap region at the center of the cylindrical fuel element. The high-pressure water passing through the tube conducts a train of nine, cylindrical, aluminum capsules, called rabbits, in and out of the flux trap without disrupting the operation of the reactor. Neutron fluxes at the rabbits are of order $4 \times 10^{18} \mathrm{n} \cdot \mathrm{m}^{-2} \cdot \mathrm{s}^{-1}, \mathrm{E}>1$ $\mathrm{MeV}$, and $2 \times 10^{19} \mathrm{n} \cdot \mathrm{m}^{-2} \cdot \mathrm{s}^{-1}$, thermal neutrons. The nuclear heating rate in the facility is high, and cooling of the specimens is necessary to maintain a constant, low temperature. There is no instrumentation in the facility to measure the temperature of specimens inside a rabbit so the best way to obtain a low temperature is to ensure that the specimens are in contact with the flowing coolant. In which case, the temperature of the specimens is believed to be in the range $65-100^{\circ} \mathrm{C}$. The rabbit was custom-designed with numerous perforations through the walls and end plugs to permit the water to flow directly over the specimens. The A533B steel and Zr-4 materials are 
prone to oxidation and absorption of hydrogen when exposed to a water environment, and if such events occurred during irradiation they could affect mechanical properties and confound a simple discrimination of the effects of irradiation. Therefore, to screen the specimens from oxidation and at the same time keep them in good thermal contact with the water to allow removal of nuclear heat, the A533B steel and Zr-4 specimens were sealed in soft aluminum envelopes. The envelopes were made from annealed, high purity aluminum foil, $0.125 \mathrm{~mm}$ thick. Each envelope contained two tensile specimens, one laid directly on top of the other. Closure of the envelopes was made by electron beam welding in vacuum. On removal from the vacuum chamber, the atmospheric pressure pressed the soft foil against the specimens. During irradiation, the high water pressure of 3.2 $\mathrm{MPa}$ in the hydraulic tube ensured that good thermal contact was maintained between the envelope and the specimens.

The turnaround time for the rabbit train in the hydraulic tube can be very short, less than a minute. The neutron fluxes in the flux trap are well characterized [12] and are reproduced from one fuel cycle to another. Consequently, a desired neutron exposure can be obtained simply by controlling the time the rabbit spends in the flux trap. The specimens for the current experiments were housed in ten rabbits that were irradiated in positions HT-3 and HT-7 of the hydraulic tube for times between $2.4 \mathrm{~min}$. and about $350 \mathrm{~h}$ to five goal exposures spaced at decade increments. These exposures are listed in Table A3. The corresponding, nominal atomic displacements in the table range from 0.0001 dpa to 0.89 dpa. Rabbits F4 and F9 at the highest exposures were intended to reach 1 dpa but were curtailed due to unprecedented demand for use of the hydraulic facility in view of an impending, maintenance outage of the HFIR. Dpa values were calculated on the basis of a displacement cross section for iron and stainless steel of $1.9 \times 10^{-26}$ dpa per unit total neutron fluence derived for the neutron spectrum in the HFIR flux trap [13]. The corresponding cross section for zirconium is $1.7 \times 10^{-26}$, which makes the dpa values for Zircaloy-4 about 10\% smaller than the listed nominal values.

Table A3. Irradiation exposure conditions. Neutron fluences are in units of $n . m^{-2}$.

\begin{tabular}{|}
\begin{tabular}{|c|c|c|c|c|c|c|c|}
\hline $\begin{array}{c}\text { Rabbit } \\
\text { No. }\end{array}$ & $\begin{array}{c}\text { HFIR } \\
\text { Irrad. No. }\end{array}$ & $\begin{array}{c}\text { Exposure } \\
\text { time }\end{array}$ & $\begin{array}{c}\text { Total } \\
\text { Fluence }\end{array}$ & $\begin{array}{c}\text { Thermal } \\
\text { Fluence }\end{array}$ & $\begin{array}{c}\text { Fluence } \\
>0.1 \mathrm{MeV}\end{array}$ & $\begin{array}{c}\text { Fluence } \\
>1 \mathrm{MeV}\end{array}$ & $\begin{array}{c}\text { Nominal } \\
\text { dpa }\end{array}$ \\
\hline A533B steel and Zircaloy-4. HT-3 position. \\
\hline F1 & $8-00-5$ & $2.4 \mathrm{~min}$ & $5.0 \mathrm{E} 21$ & $3.2 \mathrm{E} 21$ & $1.1 \mathrm{E} 21$ & $5.9 \mathrm{E} 20$ & .0001 \\
\hline F2 & $8-00-3$ & $24 \mathrm{~min}$ & $5.0 \mathrm{E} 22$ & $3.2 \mathrm{E} 22$ & $1.1 \mathrm{E} 22$ & $5.9 \mathrm{E} 21$ & .001 \\
\hline F3 & $8-00-1$ & $4.12 \mathrm{~h}$ & $5.2 \mathrm{E} 23$ & $3.3 \mathrm{E} 23$ & $1.2 \mathrm{E} 23$ & $6.1 \mathrm{E} 22$ & .01 \\
\hline F5 & $7-00-3$ & $41.13 \mathrm{~h}$ & $5.2 \mathrm{E} 24$ & $3.3 \mathrm{E} 24$ & $1.1 \mathrm{E} 24$ & $6.1 \mathrm{E} 23$ & .1 \\
\hline F4 & $8-00-13$ & $369.6 \mathrm{~h}$ & $4.7 \mathrm{E} 25$ & $2.9 \mathrm{E} 25$ & $1.0 \mathrm{E} 25$ & $5.5 \mathrm{E} 24$ & .89 \\
\hline 316 stainless steel. HT-7 position. \\
\hline F6 & $8-00-6$ & $2.4 \mathrm{~min}$ & $4.9 \mathrm{E} 21$ & $3.0 \mathrm{E} 21$ & $1.1 \mathrm{E} 21$ & $5.8 \mathrm{E} 20$ & .0001 \\
\hline F7 & $8-00-4$ & $24 \mathrm{~min}$ & $4.9 \mathrm{E} 22$ & $3.0 \mathrm{E} 22$ & $1.1 \mathrm{E} 21$ & $5.8 \mathrm{E} 21$ & .001 \\
\hline F8 & $8-00-12$ & $4.12 \mathrm{~h}$ & $5.0 \mathrm{E} 23$ & $3.1 \mathrm{E} 23$ & $1.2 \mathrm{E} 23$ & $5.9 \mathrm{E} 22$ & .01 \\
\hline F10 & $7-00-7$ & $41.13 \mathrm{~h}$ & $5.0 \mathrm{E} 24$ & $3.1 \mathrm{E} 24$ & $1.2 \mathrm{E} 24$ & $5.9 \mathrm{E} 23$ & .1 \\
\hline KF5 $*$ & $4-98-2$ & $72 \mathrm{~h}$ & $9.1 \mathrm{E} 24$ & $5.7 \mathrm{E} 24$ & $2.0 \mathrm{E} 24$ & $1.1 \mathrm{E} 24$ & .17 \\
\hline
\end{tabular}
\end{tabular}




\begin{tabular}{|c|c|c|c|c|c|c|c|}
\hline F9 & $8-00-10$ & $333.5 \mathrm{~h}$ & $4.1 \mathrm{E} 25$ & $2.5 \mathrm{E} 25$ & $9.5 \mathrm{E} 24$ & $4.8 \mathrm{E} 24$ & .78 \\
\hline
\end{tabular}

* From an earlier experiment in HT-3 position.

\section{A4. TEM preparations and observation conditions}

The tensile specimen was not the only area of miniaturization in this project. The use of miniature tensile specimens meant that TEM pieces taken from the specimen gauge sections would be significantly smaller than the standard $3 \mathrm{~mm}$ TEM disk. Indeed, the TEM pieces from the gauge sections had dimensions of $1.5 \times 1.5 \times 0.25 \mathrm{~mm}$. Preparation of electrothinned foils from these pieces in a Tenupol electropolishing apparatus required substantial development work and modification of Tenupol specimen holders, as described in Ref. 10. For the electrothinning, a single polishing solution consisting of $600 \mathrm{ml}$ methanol, $360 \mathrm{ml}$ butylcellosolve, $60 \mathrm{ml}$ perchloric acid, and $5 \mathrm{ml}$ glycerin, was used for all three materials. The operating conditions were

\begin{tabular}{lll} 
& $\underline{316 \mathrm{SS}}$ & A533B and Zr-4 \\
\cline { 2 - 2 } Voltage $(\mathrm{V})$ & $10-12$ & $10-12$ \\
Current $(\mathrm{mA})$ & $35-40$ & 30 \\
Temperature $\left({ }^{\circ} \mathrm{C}\right)$ & -12 & -12 \\
Flow rate & Setting \#3 & Setting \#3 \\
Sensitivity & Setting \#7 & Setting \#7
\end{tabular}

For the TEM examinations a strict routine was followed to ensure that different specimens were studied under optimum viewing and diffracting conditions to observe planar deformation. It is well established that plastic deformation by slip bands, channeling, and mechanical twinning occur primarily on certain favored slip systems, notably on the planes with the highest atomic densities, and the direction of the deformation is usually in the direction of closest atomic packing. In order for such planar deformation to be seen most clearly the plane must be examined edge-on, otherwise it is masked by material above and below it and its planar nature is difficult to verify. Therefore, the foils were tilted with respect to the beam direction so as to lay the slip planes for the expected deformation on, or close to, the beam direction, thereby allowing the channels to be viewed edge-on. This permits channel widths and spatial distributions to be measured most easily. The following viewing conditions were used for each alloy:

a. 316 stainless steel has a face-centered cubic crystal structure and the major slip system is $\{111\}<110>$. For this material, the beam direction, $\mathrm{B}$, was set at [011], and the diffracting vector, g, was chosen to be 200 or $11 \overline{1}$.

b. A533B steel is tempered bainite with a ferritic body-centered cubic crystal structure. It has numerous slip systems, the most common of which is $\{110\}<111>$. B was set at [001], and $\mathrm{g}=200$ or 110 .

c. Zircaloy-4 has a close-packed hexagonal crystal structure. Its most likely slip systems are $\{10 \overline{1} 1\},\{0001\}<11 \overline{2} 0>$. B was set at $[2 \overline{1} \overline{1} 0]$, and $\mathrm{g}=0002$ or $01 \overline{1} 1$.

Under these conditions, very thin planar faults will exhibit streaks in the diffraction patterns, which is useful for identifying stacking faults and fine deformation twins. 


\section{Appendix B: Bibliography of localized plastic flow in irradiated iron and ferritic steels}

B1. J. C. Wilson, paper \# P/1978 in Second United Nations International Conference on Peaceful Uses of Atomic Energy, Vol. 5 (1958) 431-445.

B2. R. G. Bergren, in Proc. of USAEC Conf. On Status of Radiation Effects Research on Structural Materials and the Implications to Reactor Design, Chicago, Ill, Oct. 15-16, 1959, USAEC (1959) 91-127.

B3. B. L. Eyre, Phil. Mag. 7 (1962) 1609-1613.

B4. B. L. Eyre, Phil. Mag. 7 (1962) 2107-2113.

B5. B. L. Eyre and A. F. Bartlett, Phil. Mag. 12 (1965) 261-272.

B6. J. S. Bryner, Acta Met. 14 (1966) 323-336.

B7. S. M. Ohr, Scripta Met. 2 (1968) 213-216.

B8. F. A. Smidt, Jr., "Dislocation-Substructure Interactions in Irradiated Iron and Steel”, BNWL-1045, Battelle Pacific Northwest Laboratory, June 1969.

B9. F. A. Smidt and B. Mastel, Phil. Mag. 20 (1969) 651-656.

B10. F. A. Smidt, Scripta Met. 4 (1970) 517-520.

B11. J. S. Bryner and J. G. Y. Chow, Acta Met. 18 (1970) 191-200.

B12. H. Mughrabi, D. Strohle, and M. Wilkens, Zeit. fur Metallkunde 72-5 (1981) 300-309.

B13. B. N. Singh, A. J. E. Foreman, and H. Trinkaus, J. Nucl. Mater. 249 (1997) 103-115.

B14. B. N. Singh, A. Horsewell, and P. Toft, J. Nucl. Mater. 271 \& 272 (1999) 97-101.

B15. Y. Chen, P. Spätig, and M. Victoria, J. Nucl. Mater. 271\&272 (1999) 128-132.

B16. M. Victoria, N. Baluc, C. Bailat, Y. Dai, M. I. Luppo, R. Schaublin, and B. N. Singh, J. Nucl. Mater. 276 (2000) 114-122.

B17. M. I. Luppo, C. Bailat, R. Schaublin, and M. Victoria, J. Nucl. Mater. 283-287 (2000) 483-487. 


\section{Appendix C: Bibliography of localized plastic flow in irradiated austenitic stainless steels}

C1. F. R. Shober and W. E. Murr, Symposium on Radiation Effects on Metals and Neutron Dosimetry, ASTM STP 341, Amer. Soc. for Testing and Mater. (1962) 325-343.

C2. J. O. Stiegler and J. R. Weir, Jr., Chapter 11 in "Ductility", pub. Amer. Soc. for Metals, (1967) 311-342.

C3. R. L. Fish, J. L. Straalsund, C. W. Hunter, and J. J. Holmes, in Effects of Radiation on Substructure and Mechanical Properties of Metals and Alloys, ASTM STP 529, Amer. Soc. for Testing and Mater. (1973) 149-164.

C4. E. E. Bloom, in Radiation Damage in Metals, American Society for Metals, Metals Park, Ohio, (1975) 295-329.

C5. H. Saka, K. Noda, K. Matsumoto, and T. Imura, Phys. Stat. Sol. 31 (1975) 139-149.

C6. G. R. Odette and G. E. Lucas, J. Nucl. Mater. 179-181 (1991) 572.

C7. M. Suzuki, F. Fujimura, A. Sato, J. Nagakawa, N. Yamamoto, and H. Shiraishi, Ultramicroscopy 39 (1991) 92-99.

C8. Fujio Abe, Minoru Narui, and Hideo Kayano, Mater. Trans. Japan Inst Metals 33 (1992) 1123-1129.

C9. Masayoshi Suzuki, A. Sato, T. Mori, J. Nagakawa, N. Yamamoto, and H. Shiraishi, Phil. Mag. A 65 (1992) 1309-1326.

C10. S. J. Bruemmer, J. I. Cole, J. L. Brimhall, R. D. Carter, and G. Was, in Sixth Internat. Symp. on Environmental Degradation of Materials in Nuclear Power Systems-Water Reactors, The Metals and Minerals Society (1993) 537-546.

C11. M. G. Horsten and M. I. de Vries, J. Nucl. Mater. 212-215 (1994) 514-518.

C12. James I. Cole and Stephen M. Bruemmer, J. Nucl. Mater. 225 (1995) 53-58.

C13. Marc G. Horsten and Martin I. de Vries, in Effects of Radiation on Materials: $17^{\text {th }}$ International Symposium, ASTM STP 1270, Amer. Soc. for Testing and Mater. (1995) 919-932.

C14. J. L. Brimhall, J. I. Cole, J. S. Vetrano, and S. M. Bruemmer, Mat. Res. Soc. Symp. Proc. 373, Materials Research Society (1995) 177-182.

C15. J. E. Pawel, A.F. Rowcliffe, D.J. Alexander, M.L. Grossbeck, and K. Shiba, J. Nucl. Mater. 233-237 (1996) 202. 
C16. L. Boulanger, F. Soisson, and Y. Serruys, J. Nucl. Mater. 233-237 (1996) 1004-1008.

C17. J. E, Pawel, A. F. Rowcliffe, G. E. Lucas, and S. J. Zinkle, J. Nucl. Mater. 239 (1996) $126-131$.

C18. S. G. Song, J. I. Cole, and S. M. Bruemmer, Acta Mater. 45 (1997) 501-511.

C19. Peter Mullner, Mater. Sci. Eng. A234-236 (1997) 94-97.

C20. G. E. Lucas, Mat. Res. Soc. Symp. Proc. 439, Materials Research Society (1997) 425-436.

C21. Shiro Jitsukawa, Ikuo Ioka, and Akimichi Hishinuma, J. Nucl. Mater. 271 \& 272 (1999) $167-172$.

C22. S. M. Bruemmer, J. I. Cole, R. D. Carter, and G. S. Was, Mat. Res. Soc. Symp. Proc. 439 (1997) 437-444.

C23. J. Chen, Y. Dai, F. Carsughi, W. F. Sommer, G. S. Bauer, H. Ullmaier, J. Nucl. Mater. 275 (1999) 115-118.

C24. C. Bailat, F. Groschel, and M. Victoria, J. Nucl. Mater. 276 (2000) 283-288.

C25. E. H. Lee, T. S. Byun, J. D. Hunn, N. Hashimoto, and K. Farrell, J. Nucl. Mater. 281 (2000) 65-70.

C26. M. Victoria, N. Baluc, C. Bailat, Y. Dai, M. I. Luppo, R. Schaublin, and B. N. Singh, J. Nucl. Mater. 276 (2000) 114-122.

C27. T. S. Byun and K. Farrell, in Proc. Fourth International Topical Meeting on Nuclear Applications of Accelerator Technology, Washington D.C., November 12-16, 2000, Amer. Nucl. Soc. (2000) 270-277.

C28. C. Baillat, A. Almazouzi, N. Baluc, R. Schaublin, F. Groschel, and M. Victoria, J. Nucl. Mater. 283-287 (2000) 446-450.

C29. K. Farrell and T. S. Byun, "Tensile Properties of Candidate SNS Materials after Irradiation in Two Neutron Areas in the LANSCE Accelerator", SNS report, SNS/TR211, Oak Ridge National Laboratory, Jan. 2001.

C30. N. Hashimoto, S. J. Zinkle, A. F. Rowcliffe, J. P. Robertson, and S. Jitsukawa, J. Nucl. Mater. 283 (2001) 528-534.

C31. T. S. Byun, E. H. Lee, J. D. Hunn, K. Farrell, and L. K. Mansur, 294 (2001) 256-266.

C32. K. Farrell and T. S. Byun, J. Nucl. Mater. 296 (2001) 129-138. 
C33. Y. Dai, X. Jia, J. C. Chen, W. F. Sommer, M. Victoria, and G. S. Bauer, J. Nucl. Mater. 296 (2001) 174-182.

C34. E. H. Lee, T. S. Byun, J. D. Hunn, K. Farrell, and L. K. Mansur, J. Nucl. Mater. 296 (2001) 183-191.

C35. E. H. Lee, T. S. Byun, J. D. Hunn, M. H. Yoo, K. Farrell, and L. K. Mansur, Acta Mater. 49 (2001) 3269-3276.

C36. E. H. Lee, T. S. Byun, J. D. Hunn, M. H. Yoo, K. Farrell, and L. K. Mansur, Acta Mater. 49 (2001) 3277-3287.

C37. K. Farrell, T. S. Byun, J. W. Jones, L. T. Gibson, R. G. Sitterson, N. Hashimoto, J. L. Bailey, and J. Gardner, "Small Specimen Procedures for Determination of Deformation Maps", in Symposium on Small Specimen Test Techniques: Fourth Volume, ASTM STP 1418, Reno, Nevada, January 23-25, 2001, Amer. Soc. for Testing and Materials, in press.

C38. T. S. Byun, K. Farrell, E. H. Lee, J. D. Hunn, and L. K. Mansur, J. Nucl. Mater., 298 (2001) 269-279. 


\section{Appendix D: Bibliography of localized plastic flow in irradiated $\mathrm{Zr}$ alloys}

D1. M. J. Makin and F. J. Minter, J. Inst. Metals 85 (1956-57) 397-402.

D2. J. W. Weber, in Effects of Radiation on Structural Materials, ASTM STP 426, Am. Soc. Testing Mater. (1967) 653-669.

D3. C. E. Ells and C. D. Williams, Suppl. to Trans. Japan Inst. Metals 9 (1968) 214-219.

D4. C. E. Coleman, D. Mills, and J. van der Kuur, Canadian Metallurgical Quarterly 111(1972) 91-100.

D5. B. A. Cheadle, C. E. Ells, and J. van der Kuur, in Zirconium in Nuclear Applications, ASTM STP 551, Am. Soc. Testing Mater., (1974) 370-384.

D6. H. S. Rosenbaum, G. F. Rieger, and D. Lee, Met. Trans. 5 (1974) 1867-1874.

D7. G. F. Rieger and D. Lee, in Zirconium in Nuclear Applications, ASTM STP 551, Am. Soc. Testing Mater. (1974) 335-369.

D8. G. J. C. Carpenter and J. F. Watters, in Zirconium in Nuclear Applications, ASTM STP 551, Am. Soc. Testing Mater. (1974) 400-415.

D9. W. L. Bell, Discussion, ASTM STP 551, Am. Soc. Testing Mater. (1974) 199-200.

D10. R. R. Hosbons, C. E. Coleman, and R. A. Holt, "Numerical Simulation of Tensile Behaviour of Nuclear Fuel Cladding Materials", AECL-5245, Atomic Energy of Canada Limited, October 1975.

D11. J. J. Jonas, R, A. Holt, and C. E. Coleman, Acta Met. 24 (1976) 911-918.

D12. D.O. Northwood, R. W. Gilbert, and C. E. Coleman, in Zirconium in the Nuclear Industry, ASTM STP 633, A. L. Lowe, and G. W. Parry, Eds., Am. Soc. Testing Mater. (1977) 418-436.

D13. D. Lee and R. B. Adamson, in Zirconium in the Nuclear Industry, ASTM STP 633, A. L. Lowe, and G. W. Parry, Eds., Am. Soc. Testing Mater. (1977) 385-401.

D14. T. Onchi, H. Kayano, and Y. Higashiguchi,, J. Nucl. Mater. 88 (1980) 226-235.

D15. W. L. Bell and R. B. Adamson in Advanced Techniques for Characterising Microstructure, The Metallurgical Society of AIME, Warrendale, Pa. (1983) 115-124.

D16. R. B. Adamson, S. B. Wisner, R. P. Tucker, and R. A. Rand, in The Use of Small Scale Specimens for Testing Irradiated Material, ASTM STP 888, W. R. Corwin and G. E. Lucas, Eds., Am. Soc. Testing Mater. (1986) 171-185. 
D17. R. B. Adamson, in Zirconium in the Nuclear Industry: Twelfth International Symposium, ASTM STP 1345, Am. Soc. Testing Mater. (2000) 15-31.

D18. M. Fregonese, C. Regnard, L. Rouillon, T. Magnin, F. Lefebvre, and C. Lemaignan, in Zirconium in the Nuclear Industry: Twelfth International Symposium, ASTM STP 1345, Am. Soc. Testing Mater. (2000) 377-398. 


\section{MAPPING FLOW LOCALIZATION PROCESSES IN DEFORMATION OF IRRADIATED REACTOR STRUCTURAL ALLOYS}

\section{Distribution}

Internal Distribution

1. E. E. Bloom, ORNL

2. T. S. Byun, ORNL/UT

3. K. Farrell, ORNL

4. N. Hashimoto, ORNL/UT

5. L. L. Horton, ORNL

6. C. R. Hudson II, ORNL

7. L. K. Mansur, ORNL

8. S. R. Martin, Jr., ORNL

9. G. E. Michaels, ORNL

10. S. J. Zinkle, ORNL

External Distribution

11. Frank Ross, NE-20, U.S. Department of Energy, Germantown, MD

12. Madeline A. Feltus, U.S. Department of Energy, Washington, DC

13. Salma El-Safwany, NSPD, U.S. Department of Energy, Oakland, CA

14. Phil Wong, NSPD, U.S. Department of Energy, Oakland, CA 